UNIVERSIDADE DE SÃO PAULO

FACULDADE DE ECONOMIA, ADMINISTRAÇÃO E CONTABILIDADE E ATUÁRIA DEPARTAMENTO DE ADMINISTRAÇÃO

PROGRAMA DE PÓS-GRADUAÇÃO EM ADMINISTRAÇÃO

Éder de Carvalho Januário

Mudança Institucional e Estrutura de Governança: como as organizações gerenciam as práticas de incentivo 
Prof. Dr. Vahan Agopyan

Reitor da Universidade de São Paulo

Prof. Dr. Fábio Frezatti

Diretor da Faculdade de Economia, Administração e Contabilidade

Prof. Dr. Moacir de Miranda Oliveira Junior

Chefe do Departamento de Administração

Prof. Dr. Eduardo Kazuo Kayo

Coordenador do Programa de Pós-Graduação em Administração 


\section{ÉDER DE CARVALHO JANUÁRIO}

Mudança Institucional e Estrutura de Governança: como as organizações gerenciam as práticas de incentivo

Versão original

Tese apresentada ao Programa de PósGraduação em Administração do Departamento de Administração da Faculdade de Economia, Administração e Contabilidade da Universidade de São Paulo, como requisito parcial para a obtenção do título de Doutor em Ciências.

Área de Concentração: Economia das Organizações.

Orientador: Leonardo A. de Vasconcelos

São Paulo 
Autorizo reprodução e divulgação total ou parcial deste trabalho, por qualquer meio convencional ou eletrônico, para fins de estudo e pesquisa, desde que citada a fonte.

FICHA CATALOGRÁFICA

Elaborada por Martha Ribeiro Neves de Vasconcellos - CRB-8/5994 Seção de Processamento Técnico do SBD/FEA/USP

de Carvalho Januário, Eder .

Mudança Institucional e Estrutura de Governança: como as organizações gerenciam as práticas de incentivo / Eder de Carvalho Januário. - São Paulo, 2019.

$157 \mathrm{p}$.

Tese (Doutorado) - Universidade de São Paulo, 2020.

Orientador: Leonardo Augusto de Vasconcelos Gomes.

1. Mudança Institucional. 2. Estruturas de Governança. 3. Práticas de Incentivos. I. Universidade de São Paulo. Faculdade de Economia, Administração e Contabilidade. II. Título. 


\title{
MUDANÇA INSTITUCIONAL E ESTRUTURA DE GOVERNANÇA: COMO AS ORGANIZAÇÕES GERENCIAM AS PRÁTICAS DE INCENTIVO
}

\author{
Tese apresentada ao Programa de Pós- \\ Graduação em Administração do Departamento de \\ Administração da Faculdade de Economia, Admi- \\ nistração e Contabilidade da Universidade de São \\ Paulo, como requisito parcial para a obtenção do \\ título de Doutor em Ciências.
}

Aprovado em:

Banca Examinadora

Prof. Dr.

Instituição: Assinatura:

Julgamento:

Prof. Dr.

Instituição: Assinatura:

Julgamento:

Prof. Dr.

Instituição: Assinatura:

Julgamento: 

Dedico este trabalho à minha família, em especial à Lourdes Mercês e Mercedes e, Pedro, Miguel e Murilo. 



\section{AGRADECIMENTOS}

Esta tese é o resultado de uma jornada longa e desafiadora, às vezes altamente turbulenta - não apenas em aspectos intelectuais, mas também em aspectos pessoais e até geográficos. Eu gostaria de agradecer às muitas pessoas e instituições que me apoiaram ao longo do caminho.

Primeiro, agradeço ao Deus, o de Spinoza e aos Deuses da mitologia africana e grega pela oportunidade ímpar de estar vivendo essa experiência na terra e de conviver com a natureza e seus fenômenos e com os seres humanos e animais. O processo evolutivo é denso, tenso e intenso.

Aqui deixo, minha profunda gratidão ao meu orientador, Professor Dr. Leonardo Augusto que depositou grande confiança em mim e sempre acreditou no meu trabalho. Estou tremendamente grato por seus excelentes conselhos pessoal e profissional, e admiro a sua grande generosidade e sua orientação acadêmica dedicada a mim. Sua crítica e feedback construtivo foi de alto valor para o desenvolvimento pessoal e para a conclusão desta tese.

Aprecio muito meus colegas do Departamento de Administração por compartilharem comigo suas valiosas experiências e conhecimento, bem como para tornar a FEA um ambiente amigável e inspirador. Em especial Hélder Marcos, Viviane Franco, Rafaela Maniçoba e Nathalie Perret entre outros.

Agradeço aos Hospitais que permitiram a realização dos estudos de caso, em especial a Diego Rodrigues que foi essencial para conseguir atingir os objetivos traçados no primeiro ano do curso. Também agradeço à Fernanda Castro, outra pessoa fundamental neste processo. E à Mara, do Hospital Ibiapaba pela força no desenho do último estudo de caso da tese.

À minha família, em especial meus irmãos, Andreza, Luís e Vanessa que sempre me apoiam e aceitam a minha alegria e loucura. Gratidão a Tia Mara, especialmente nesse momento, cheio de altos e baixos. Agradeço a acolhida, o carinho e todo o suporte. 
Também agradeço a Tia Marta, por me entender e por me apresentar meus priminhos Pedro e Miguel, duas alegrias. Aos primos Nelson e Gabriela por sempre querem o meu bem. Ao Leandro e Adriana, pela amizade e carinho.

Às primas Angélica e Gorete, pela amizade e carinho comigo. Angélica, que correu atrás dos contatos para que Eu pudesse realizar as entrevistas, sem esse apoio tudo poderia ser mais difícil, mas não foi, a ela a minha sincera gratidão.

Sou imensamente grato a Dra. Rosane Bonato Laguardia, por me redirecionar a novos caminhos e, por insistir na prática da yoga e a meditação. Rosane realmente é muito especial. Ao querido Vovô João (Dr. Rodrigo), pelos cuidados médicos, conseIhos e orientações que facilitam minha permanência na terra.

Agradeço também aos servidores e colaboradores da FEAUSP, em especial a Ana Paula da Secretaria da Pós-Graduação e a Cintia e Dani da secretaria geral, sempre cordiais e gentis.

Agradeço ao Alexandra Elbakyan, do Schi - Hub por facilitar minha vida na busca de artigos científicos.

E por fim a CAPES, pelo apoio financeiro para realização do meu Doutorado.

Eder de Carvalho

Tiradentes-MG, 2019 
“... Isso é um duro trabalho... Eu trabalhei duro por muito tempo, e não é sobre... Não é sobre vencer, é sobre não desistir. Se você tem sonho, lute por ele. Existe uma disciplina para paixão, e não é sobre quantas vezes você é rejeitado, ou quantas vezes você caiu e foi derrotado, é sobre quantas vezes você levantou com coragem e seguiu em frente..."

Stefani Joanne Angelina Germanotta. 



\section{RESUMO}

JANUÁRIO, E. de C. (2019). Mudança Institucional e Estrutura de Governança: Como as Organizações Gerenciam as Práticas de Incentivo. Tese (Doutorado). Faculdade de Economia, Administração e Contabilidade, Universidade de São Paulo, São Paulo.

Mudanças institucionais podem exigir que as organizações alterem as suas estruturas de governança. Apesar de existir um rico portfólio de práticas de incentivo na literatura, surpreendentemente, existe ainda uma escassa literatura sobre como as organizações gerenciais tais práticas em um contexto de mudança institucional. Tal gestão pode ser relevante para as organizações consigam ativar os comportamentos e desencadear as ações necessários para alcançar os seus objetivos organizacionais. Diante desse contexto, a pergunta que orienta este trabalho é: como as organizações gerenciam as práticas de incentivos no processo de mudança institucional? Para responder essa pergunta de pesquisa, esta tese construiu o seu modelo conceitual, a partir da literatura sobre design organizacional, práticas de incentivos e mudança institucional. Esse modelo conceitual serviu de base para a realização da pesquisa empírica: estudos de casos múltiplos em três hospitais. O contexto de mudança institucional analisado foi o processo de adesão ao protocolo de higienização das mãos - regulamentado através da Resolução da Diretoria Colegiada de número $36-\mathrm{RDC} \mathrm{n}^{\circ} 36$. A regulamentação tem objetivo promover segurança dos pacientes em hospitais no Brasil, ampliando a adesão da higienização das mãos nas instituições de saúde. A pesquisa foi dividida em duas fases. Na primeira, foram realizados dois estudos de casos em hospitais localizados na cidade de Ponte Nova-MG; nessa ocasião foram entrevistados gestores relacionados a cada uma das organizações estudadas. Os resultados indicam que existe heterogeneidade na percepção sobre a utilização das práticas de incentivos no contexto da mudança institucional. Com base nos resultados encontrados na primeira fase, propomos novos constructos - sinalização, tradução, realce, direcionalidade, coerência/consistência da governança - que trazem novos entendimentos sobre utilização da estrutura de governança. Com isso, na segunda fase da pesquisa, realizamos um novo estudo de caso para investigar/aprofundar o entendimento sobre os construtos emergidos da primeira. Consolidando as duas fases, propomos um framework emergente e exploratório de como as organizações gerenciam as suas práticas de incentivo em ambiente de mudança institucional. Espera-se que este estudo ajude revigorar o debate sobre gestão das práticas de incentivo e do design organizacional no contexto de mudança institucional.

Palavras-chaves: Mudança Institucional; Estruturas de Governança; Práticas de Incentivos. 


\begin{abstract}
JANUÁRIO, E. de C. (2019). Institutional Change and Governance Structure: How Organizations Manage Incentive Practices. Tese (Doutorado). Faculdade de Economia, Administração e Contabilidade, Universidade de São Paulo, São Paulo.

Institutional changes may require organizations to change their governance structures. Although there is a rich portfolio of incentive practices in the literature, surprisingly, there is still little knowledge on how management organizations manage such practices in the context of institutional change. Such management approach may be relevant in order to activate and deactivate the actions required to achieve their organizational objectives. Given this context, a question that guides this work is: How do organizations manage incentive practices in the process of institutional change? To answer this research question, this study builds its conceptual model on the literature on organizational design, incentive practices, and institutional change. This conceptual model serves as the basis for empirical research: multiple case studies in three hospitals. The context of the institutional change analyzed was the process of adhering to the hand hygiene protocol - regulated by Collegiate Board Resolution number 36 - RDC 36. This regulation aims at promoting patient safety in Brazilian hospitals Our empirical research was organized into two phases. In the first, two case studies were performed in hospitals located at the city of Ponte Nova-MG. The results show that there is heterogeneity in the manager's perception about the use of incentive practices in the context of institutional change. Based on the results found in the first phase, we propose new constructs related to how organizations manage incentive practices - signaling, translation, remarking, directionality, coherence / consistency of governance - which brings new ventures on the use of the governance structure. Thus, in the second phase of the research, we conducted a new case study in order to investigate / deepen our understand about the emerging constructs. We then proposed an emerging exploratory framework for managing incentive practices in context of institutional change environment. This study hopes to reinvigorate the debate on the management of incentive practices and organizational design in the context of institutional change.
\end{abstract}

Keywords: Institutional Change; Governance structures; Incentive Practices. 


\section{LISTA DE FIGURAS}

Figura 1 - Três Níveis da Economia de Custos de Transação. ...............................33

Figura 2 - Modelo Conceitual: Incentivos e Motivação e Desempenho...................52

Figura 3 - Mapa com a localização dos hospitais analisados nos estudos de casos

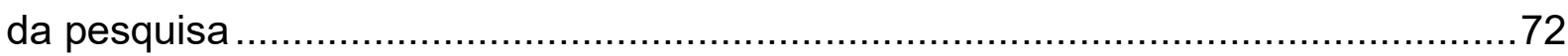

Figura 4 - framework exploratório de como as organizações podem gerenciar suas equipes. 119 


\section{LISTA DE TABELAS}

Tabela 1 - Relação dos respondentes na primeira etapa de entrevistas. 61

Tabela 2 - Relação dos respondentes na segunda etapa de entrevistas. 63

Tabela 3 - Dados demográficos das equipes entrevistados. .74

Tabela 4 - Utilização das práticas de incentivos (antes e depois da mudança institucional). .76

Tabela 5 - Utilização das práticas de incentivos (antes e depois da mudança institucional).

Tabela 6 - Utilização das práticas de incentivos (antes e depois da mudança institucional).

Tabela 7 - Utilização das práticas de incentivos (antes e depois da mudança institucional).

Tabela 8 - Dados demográficos das equipes entrevistadas.

Tabela 9 - Utilização das práticas de incentivos (antes e depois da mudança institucional).

Tabela 10 - Utilização das práticas de incentivos (antes e depois da mudança institucional).

Tabela 11 - Utilização das práticas de incentivos (antes e depois da mudança institucional)

Tabela 12 - Utilização das práticas de incentivos (antes e depois da mudança institucional) 


\section{LISTA DE QUADROS}

Quadro 1 - Mecanismos de Governança, Princípios de Comportamento, Prática de Incentivos

Quadro 2 - Mudança Institucional e Estrutura de Governança: como as

organizações gerenciam as práticas de incentivo .64

Quadro 3 - Evidências iniciais do construto sinalização nos casos. .98

Quadro 4 - Evidências iniciais do construto tradução nos casos. 100

Quadro 5 - Evidências iniciais do construto realce nos casos. 102

Quadro 6 - Evidências iniciais do construto direcionalidade nos casos. 104

Quadro 7 - Práticas de incentivos utilizadas antes da RDC-36 109

Quadro 8 - Práticas de incentivos utilizadas depois da RDC-36. 110

Quadro 9 - Evidências do Hospital Ibiapaba das entrevistas com os gestores....115 


\section{LISTA DE SIGLAS}

Anvisa Agência Nacional de Vigilância Sanitária

$\mathrm{CClH} \quad$ Controle De Infecção Hospitalar

CDC Centers for Disease Control and Prevention

OMS Organização Mundial da Saúde

OPAS Organização Pan-Americana de Saúde

RDC-36 Resolução da Diretoria Colegiada

SEMSA Secretaria Municipal de Saúde de Ponte Nova/Minas Gerais

SUS Sistema Único de Saúde

WHO World Health Organization 


\section{SUMÁRIO}

INTRODUÇÃO

Pergunta de Pesquisa e Objetivos da Pesquisa ............................................25

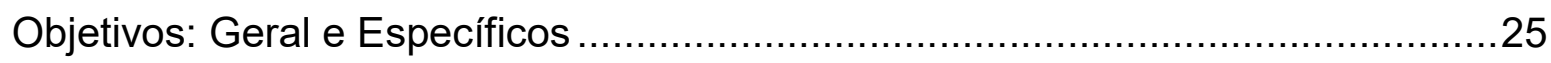

Justificativa e Relevância da Pesquisa .........................................................25

Contribuição do Trabalho Para Teoria e Para a Prática........................................28

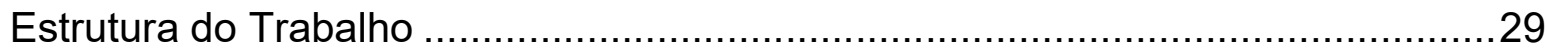

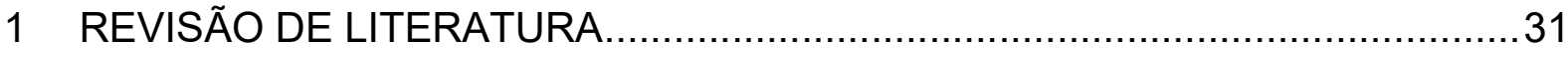

1.1 Ambiente Institucional, Estrutura de Governança e Indivíduos ...................31

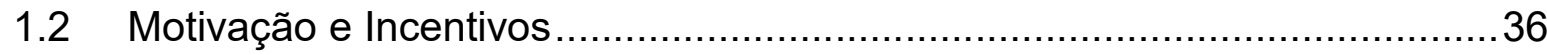

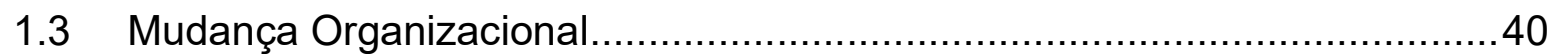

1.4 Caminhos e Desafios da Mudança Organizacional .....................................40

1.5 Abordagem Combinatória do Design: Práticas de incentivos.......................44

1.6 Mecanismos de governança e Princípios Comportamentais.......................44

1.7 Setor de Saúde e o Combate à Infecção Hospitalar ...................................48

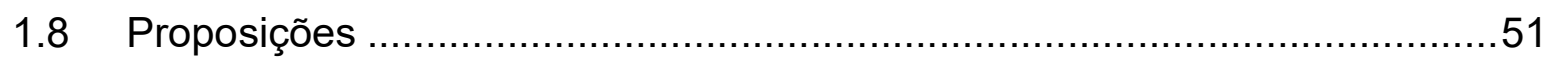

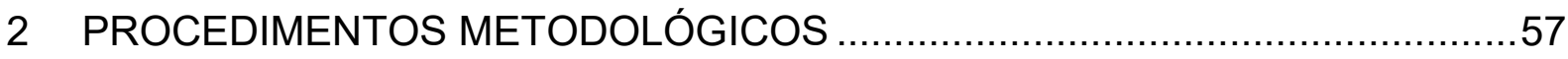

2.1 Definição da abordagem metodológica …………...................................57

2.2 Seleção dos Casos e Características dos Hospitais .....................................58

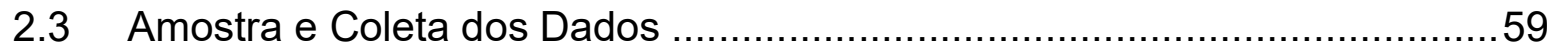

2.4 Coleta Complementar Para llustrar os Novos Constructos ........................61

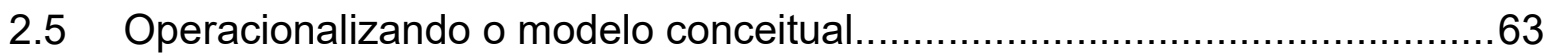

2.5.1 Variável Independente: Mecanismos de Governança ............................63

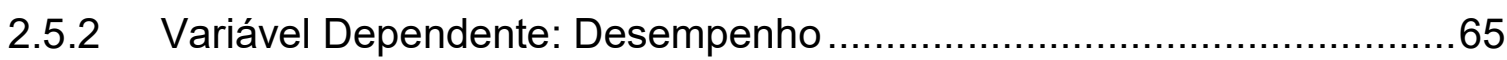

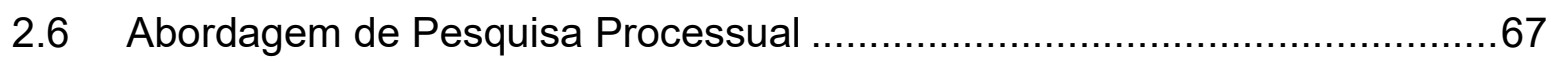

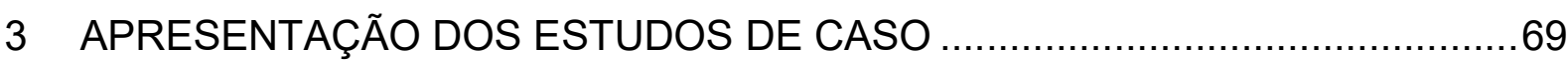


3.1 Principais Práticas de Incentivos Sugeridos por Órgãos Governamentais e Agências Para as Estratégias de Adesão das Unidades de Saúde à Higienização das Mãos

3.2 Descrevendo Como os Gestores Utilizaram Práticas de Incentivos na Transição de uma Regra Institucional

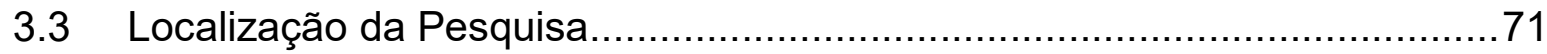

3.4 Hospital Irmandade de Nossa Senhora das Dores ..................................72

3.4.1 Breve Descrição do Hospital ...........................................................

3.4.2 Apresentação da Estrutura Organizacional ........................................72

3.4.3 Perfil Demográfico da Amostra de Entrevistados nos Hospitais .............73

3.4.4 Estruturas de Governança Interna ...................................................75

3.4.5 Estrutura de Governança Mercado....................................................75

3.4.6 Estruturas de Governança Burocrática..............................................76

3.5.1 Estrutura de Governança Comunitária …………………….............78

3.5.2 Estruturas de Governança Democrática.............................................82

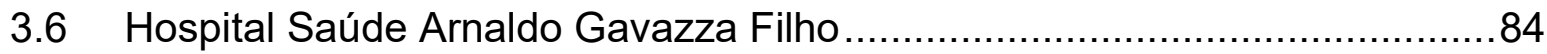

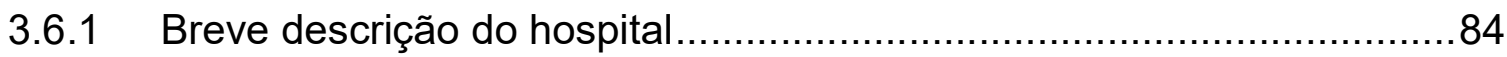

3.7 Breve Apresentação da Estrutura Organizacional ...................................85

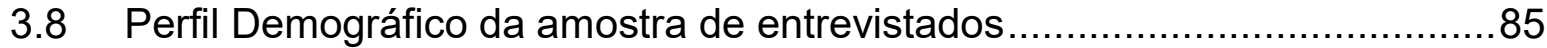

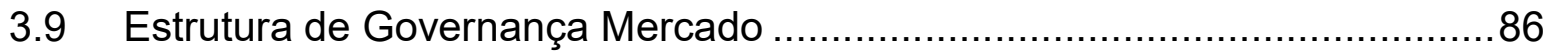

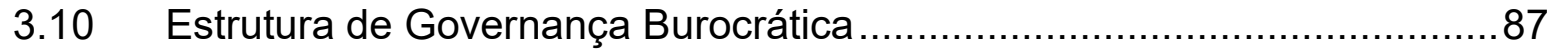

3.11 Estrutura de Governança Comunitária...................................................89

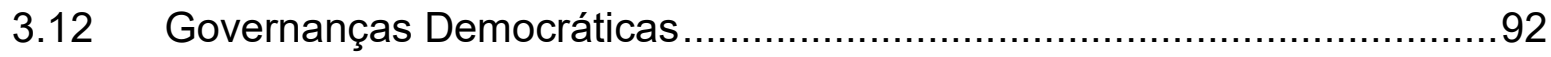

4 PROPOSIÇÃO DE UM FRAMEWORK EXPLORATÓRIO PARA: COMO AS EMPRESAS PODEM GERENCIAR AS ESTRUTURAS DE GOVERNANÇA............95

4.1 Gestão das estruturas de governança: sinalização....................................97

4.2 Gestão das Estruturas de Governança: Tradução ......................................99

4.3 Gestão das Estruturas de Governança: Realce e Direcionalidade ............101 
4.4 Gestão das Estruturas de Governança: Coerência/Consistência da Governança 105

4.5 Caso Complementar: Ilustrando os Constructos ...................................106

4.5.1 Hospital Ibiapaba — Barbacena, Minas Gerais .................................106

4.5.2 Breve Descrição do Hospital ...........................................................107

4.5.3 Apresentação da estrutura organizacional .......................................107

4.5.4 Informações Gerais dos Entrevistados .............................................. 108

4.5.5 Estruturas de governança interna .................................................108

4.5.6 Ilustrando os Constructos de Gestão das Práticas de Incentivo...........111

4.5.7 Propondo um Framework Para a Gestão das Estruturas de Governança 117

4.5.8 Conclusão do Capítulo 120

5 DISCUSSÃO DOS RESULTADOS E IMPLICAÇÕES PARA A TEORIA E PARA A PRÁTICA 121

5.1 Como o Trabalho Contribui Para o Conhecimento e Prática. 121

5.2 Discussão das Proposições 126

5.3 Conclusão do capítulo 128

6 CONSIDERAÇÕES FINAIS, SUGESTÕES PARA PESQUISAS FUTURAS E LIMITAÇÕES DO TRABALHO 129

6.1 Sugestão Para Estudos Futuros 131

6.2 Limitações de Pesquisas 131

REFERÊNCIAS 133

ANEXO I. 137

ANEXO II 142

ANEXO III. 154 



\section{INTRODUÇÃO}

A presente tese analisa a relação entre mudança institucional e estrutura de governança - práticas de incentivo em três hospitais: um filantrópico ${ }^{1}$ e dois beneficentes $^{2}$ em Ponte Nova Minas Gerais. Na visão de (North e Weingast,1990, North 1990, Djabi-Saïdani e Pérugien 2019), as instituições são compreendidas como as regras do jogo, e podem ser formais e informais, atuando de forma a contribuir para a estruturação das interações sociais, econômicas e políticas. Mudanças e variações nas instituições podem implicar alterações de hábitos, incluindo comportamento e pensamentos dos indivíduos (Bruinshoofd, 2016; Hodgson, 2006; Boxenbaun, 2019).

A literatura sugere que a mudança institucional afeta a especialização e os custos de transação, sendo que, um dos efeitos dessa mudança está no aumento da credibilidade dos direitos de propriedade, elevando os investimentos e melhorando a eficiência (North e Weingast, 1989; Hodgson, 2019). Já as estruturas de governança não são definidas somente pelas lentes da Economia dos Custos de Transação (Freeland e Williamson, 1999; Williamson, 1987; Januário, 2014), cujo principal foco está na diminuição dos conflitos potenciais e comportamentos oportunistas. Também envolve mecanismos que proporcionem a coordenação de tarefas complexas e a transferência de conhecimento, aprendizado e mudança padrões comportamentais através de incentivos (Mesquitas e Brush, 2008; Verbeke e Fariborzi, 2019). A nossa motivação neste trabalho é explorar como as organizações planejam e mudam suas práticas dos incentivos no processo de mudança institucional para alcançar objetivos organizacionais.

As estruturas de governança são responsáveis por regras que moldam o processo de tomada de decisão e ação de indivíduos e grupos (Furnari e Grandori, 2013; Grandori, 2016; Grandori, 2017). Gestores são responsáveis pela adoção e

\footnotetext{
${ }^{1}$ É o que integra o patrimônio de pessoa jurídica de direito privado, mantido parcial ou integralmente por meio de doações, cujos membros de seus órgãos de direção e consultivos não sejam remunerados, que se proponha à prestação de serviços gratuitos à população carente em seus ambulatórios, reservando leitos, de acordo com a legislação em vigor, ao internamento gratuito, organizado e mantido pela comunidade e cujos resultados financeiros revertam exclusivamente ao custeio de despesa de administração e manutenção (Brasil, 1985).

2 É o que integra o patrimônio de pessoa jurídica de direito privado, instituído e mantido por contribuições e doações particulares, destinado à prestação de serviços a seus associados e respectivos dependentes, cujos atos de constituição especifiquem sua clientela, que não remunere os membros da sua diretoria, que aplique integralmente os seus recursos na manutenção e desenvolvimento dos seus objetivos sociais e cujos bens, no caso de sua extinção, revertam em proveito de outras instituições do mesmo gênero ou ao Poder Público (Brasil 1985).
} 
desenvolvimento das práticas dos incentivos em resposta às alterações do ambiente externo (como, por exemplo, mudança institucional, tecnológica). Tais práticas podem afetar o comportamento organizacional e, consequentemente, o desempenho da empresa (Klein et al., 2019). Neste contexto, a proposta de pesquisa segue a linha de estudos que relaciona práticas dos incentivos e motivação em equipes de trabalho, tomando como foco os quadros hospitalares no contexto de mudança institucional ocorrida no setor no ano de 2013.

A adaptação as mudanças no ambiente das organizações é grande desafio para os gestores. Diante deste cenário, a motivação é variável importante para o entendimento do comportamento humano. Para vários pesquisadores, utilizando a noção de motivação, é possível analisar a disponibilidade dos funcionários se envolverem em suas atividades profissionais, individualmente ou em equipe (Osterloh e Frey, 2013; Tomo e Todisco, 2018). Tradicionalmente, a motivação das pessoas no interior das organizações tem sido analisada de forma unidimensional pelas lentes da teoria econômica, sobretudo na abordagem neoclássica, que considera os indivíduos como racionais maximizadores de utilidade, que sempre agem autointeressados (Fehr e Fischbacher, 2002; Weibel, Rost e Osterloh, 2010). Recentemente, outra vertente de estudo vem tentando estabelecer visão alternativa, procurando compreender, ou abordar, outros aspectos da motivação das pessoas. Construindo a partir de estudos na psicologia, essa visão alternativa, chamada de Goal Frame, adota compreensão multidimensional das características motivacionais, denominada Teoria do Goal Frame (Lindenberg e Foss, 2011b). Para essa abordagem, a motivação intrínseca é impulsionada pelo "objetivo hedônico" — i.e., de se sentir bem ou buscar a satisfação pessoal - e pelo "objetivo normativo" ou pró-social i.e., o de agir apropriadamente em determinados ambientes ou contextos (Lindenberg e Foss, 2011b). Para Lindenberg e Foss (2011a), a motivação dos indivíduos não está simplesmente relacionada aos padrões presentes nos estudos da Economia Neoclássica (e.g., os indivíduos são auto-interessados e maximizadores de recursos), essa visão negligencia o que se pode ser alcançado por meio da motivação pró-social, que poderá ser atingido utilizando incentivos não monetários, alinhandoos através das metas e objetivos organizacionais. O desafio da liderança está, portanto, em alinhar os incentivos que motivam os indivíduos a desenvolverem resultados desejados (Lindenberg, 2013; Lindenberg e Foss, 2011a). 
Do ponto de vista do design ou do projeto organizacional, uma possível solução apontada para problemas de motivação é moldar a organização para trazer o alinhamento de interesses entre a organização e seus membros e, assim, aumentar a eficiência das decisões (Osterloh e Frey, 2013; Weibel et al., 2010). Em particular, a motivação compreendida pela Teoria do Goal Frame, não é apenas questão de incentivos monetários; as formas de recompensas podem ser monetárias, mas também podem ser não monetárias, como por exemplo: relacionadas à satisfação pessoal ou aprovação social e status (Lindenberg e Foss, 2011b). Para Lindenberg e Foss (2011a), além disso, embora o problema da motivação esteja principalmente relacionado ao indivíduo, pode ser elevado para níveis agregados, como equipes, departamentos ou divisões (Osterloh e Frey, 2013; Weibel et al., 2010).

Os projetos organizacionais podem envolver a definição de diferentes mecanismos ou elementos motivacionais para ativar a motivação. Furnari e Grandori (2013) propuseram abordagem denominada Abordagem Combinatória do Design. Essa abordagem considera que as estruturas de governança interna envolvem a combinação das práticas de incentivos monetários e não monetários para atingir determinado desempenho. Consistente com trabalhos prévios, nós definimos as estruturas de governança interna como coleção de práticas dos incentivos de diferentes naturezas: monetários representados pelos elementos de mercado — pagamento por desempenho e não monetários representados pelos elementos burocráticos (autoridade - regras e planos, divisão de trabalho); elementos comunitários (divisão de conhecimento, valores, cultura); e por fim, os elementos democráticos (difusão de direitos de propriedade e direitos de representação em órgãos dirigentes direitos de autodeterminação de tarefas) (Furnari e Grandori, 2013; Grandori, 2017; Jardim, Saes, e Mesquita, 2013).

Apesar de existir vasta Literatura sobre estruturas de governança (e.g.: OsterIoh e Frey, 2013; Weibel et al., 2010, Furnari e Grandori, 2013; Grandori, 2017; Jardim, Saes, e Mesquita, 2013; Lee, 2017; Lee e Puranam, 2017), existe escassez de estudos sobre como os gestores administram as estruturas de governança durante o processo de mudança institucional. Diminuir esta lacuna de conhecimento é fundamental para a teoria e para a prática. Primeiro, os gestores podem introduzir novos práticas de incentivo sem compreender de fato como tais elementos se associam aos existentes; com isso, a sobreposição de diferentes e, até mesmo contraditórias, práticas de incentivo, podem produzir resultados não desejáveis. Segundo, gestores 
podem tentar implementar novos planos de ação sem implementar mudanças necessárias na estrutura de governança. Terceiro, sem suprir esta lacuna, a Literatura pode oferecer guias limitados sobre como os gestores podem fazer uso mais contingencial das práticas de incentivo da estrutura de governança.

Desta forma, o objetivo é identificar como as organizações (gestores) gerenciam as estruturas de governança e os incentivos para modificar o comportamento das equipes, almejando determinado resultado ou desempenho organizacional. Desta forma, a pergunta de pesquisa que orienta este estudo é: Como as organizações gerenciam as práticas de incentivos no processo de mudança institucional?

Para abordar a presente pergunta de pesquisa, adotamos método de pesquisa exploratório, seguindo as orientações de Eisenhardt (1989). O nosso contexto de pesquisa foram os hospitais e a busca pela redução dos casos de infecção hospita$\operatorname{lar}^{3}$. Para o estudo em particular foi analisada a Resolução Diretoria Colegiada (RDC n. ${ }^{\circ}$ 36/2013), que trata da segurança do paciente no Brasil e está dividida em seis protocolos que fornecem orientações para assistência hospitalar segura (Brasil, 2013). Investigamos o protocolo que trata da higienização das mãos e que se destaca como medida importante para o controle de infecção relacionada à saúde.

Com finalidade de fornecer ilustração empírica e buscar resposta para a questão da pesquisa, foram entrevistados os médicos, os gestores - coordenadores responsáveis pelo controle de infecção e funcionários ligados a assistência à saúde - que adotaram o Protocolo de Higienização das Mãos em suas equipes. O protocolo trata dos processos de higienização das mãos, contido na RDC-36 (Brasil, 2013) que é regulamento compulsório e tem sido tratado de forma prioritária pelas agências de saúde no Brasil, em face aos altos índices de contaminação e morte dos pacientes nos hospitais brasileiros.

Nós argumentamos que as estratégias à melhoria da adesão à higiene das mãos compreendem aspectos que poderão ser potencializados pela motivação e, consequentemente, influenciará em sua prática. Baseado em revisão de literatura e construção de modelo conceitual, nós desenvolvemos um conjunto de proposições teóricas. Tais proposições sugerem que os gestores combinam as práticas dos incentivos das estruturas da governança no processo de motivação das equipes.

\footnotetext{
3 Infecção hospitalar ou nosocomial é a infecção adquirida após 72 horas de hospitalização ou após a realização de procedimento invasivo no âmbito hospitalar. Também é considerada infecção nosocomial, quando, em ambiente hospitalar, houver o isolamento de uma espécie diferente de microrganismo em um sítio de infecção previamente adquirido na comunidade (Brasil, 2013).
} 


\section{Pergunta de Pesquisa e Objetivos da Pesquisa}

A pergunta de pesquisa que orienta este trabalho é: Como as organizações gerenciam as práticas de incentivos no processo de mudança institucional?

A partir desta pergunta, foram desdobrados os objetivos geral e específicos.

\section{Objetivos: Geral e Específicos}

O objetivo geral da presente tese foi explicar como os hospitais em análise gerenciam suas práticas de incentivos organizacionais no processo de transição e adequação de comportamento à melhora dos padrões de higienização das mãos, diante da mudança institucional - RDC n. ${ }^{\circ} 36$.

Tal objetivo geral foi desdobrado nos seguintes objetivos específicos:

- construir modelo conceitual sobre a gestão das estruturas de governança para lidar com mudança institucional;

- investigar de forma exploratória casos de hospitais que passaram por mudança institucional;

- desenvolver framework emergente de como as organizações pode gerenciar a estruturar de governança.

Esse conjunto de objetivos, sempre construídos a partir da pergunta de pesquisa, foram fundamentais para guiar a estruturação e a realização da presente investigação. Na próxima seção, vamos apresentar a relevância da pergunta de pesquisa e a lacuna teórica que nos propomos diminuir mediante a presente produção textual-acadêmica.

\section{Justificativa e Relevância da Pesquisa}

Um dos objetivos da Organização Mundial da Saúde (OMSMHO) é melhorar o padrão dos serviços prestados por unidades hospitalares no mundo. Sendo assim, em 2006, a OMS/WHO realizou o primeiro Desafio Global Para Garantir a Segurança do Paciente, trata- se de estratégia multimodal nomeada como "Cuidado Limpo é Cuidado Mais Seguro" (Clean Care is Safer Care), de forma a promover adesão da 
higienização das mãos nos estabelecimentos de saúde em todo mundo (OMS/WHO, 2006; Squeri et al., 2016).

As principais práticas à prevenção e controle de infecção recomendadas pelo programa da OMS/WHO para os hospitais foram: desenvolvimento de programas de controle utilizando evidências científicas; políticas de gestão de pessoas com treinamento dos profissionais de saúde; estruturação de setor de vigilância epidemiológica das infecções hospitalares e; implantação de estratégias multimodais visando mudança na cultura profissional e institucional. Envolvendo as lideranças e profissionais da área hospitalar, assim como pacientes que devem ser protegidos pelos protocolos de segurança do paciente, essas ações devem agir de forma a promover a mudança na percepção da equipe sobre a higienização das mãos, reconhecendo sua importância na profilaxia das doenças e contaminação hospitalar (Brasil, 2009).

Outras formas de prevenção estão no processo de investimento em componentes básicos, tais como: infraestrutura adequada (investimento em pias, lavabos, dispenseres de álcool e papel toalha); treinamento voltado para controle de infecção; auditorias de boas práticas com feedback (reuniões com os profissionais mostrando a evolução dos indicadores); carga de trabalho e condições adequadas para a atenção à saúde; nível de proteção anti-infecciosa adequado nas áreas e; artigos da assistência à saúde.

Na última década, os órgãos de saúde têm desenvolvido ações para implementação do Protocolo de Higienização das Mãos, tornando-se prioridade de diversos programas de promoção da qualidade e da segurança do paciente, tais como, "Meus 5 Momentos para a Higiene das Mãos", distribuído para as unidades de saúde pela Agência Nacional de Vigilância Sanitária (Anvisa) no Brasil e Diretrizes sobre a Higienização das Mãos em Serviços de Saúde, divulgado pela OMS/WHO na esfera mundial. O objetivo é observar aumento da adesão à higiene das mãos ao longo do tempo até pelo menos 2020, quando se espera que uma cultura de excelência na área de higiene das mãos seja incorporada em todos os serviços de saúde.

Um aspecto importante na prevenção de casos de infecção hospitalar está diretamente ligado aos padrões comportamentais dos profissionais da saúde, que por fatores culturais não têm o hábito higienizarem as mãos antes de prestarem assistência aos pacientes (Romanelli et al., 2013). Para que se tenha adesão do novo Protocolo de Higienização das Mãos envolve ações de mudanças no comportamento dos profissionais de saúde, dada a relevância desse assunto para a sociedade, esse 
tema tem sido objeto de políticas da OMS/WHO, governos e suas agências de saúde, assim como gestores hospitalares preocupados com a diminuição dos casos de infecção nas unidades de saúde, pois esses casos acarretam óbitos e custos (aumenta a permanência de paciente no hospital e processos jurídicos) para os administradores hospitalares (Brasil, 2013).

Nesse sentido, com o objetivo de padronizar o processo com que os profissionais higienizam as mãos, em 2013, o governo brasileiro, através da Anvisa, instituiu a Resolução da Diretoria Colegiada (RDC-36), que está dividida em seis protocolos, que orientam os estabelecimentos de saúde a desenvolverem Plano de Segurança do Paciente, tendo como norte a melhoria contínua dos processos de cuidado com o paciente.

Nesse sentido, dentro do escopo da nova regra, a RDC-36, recomenda um conjunto amplo e integrado de ações que tem como objetivo atuar e direcionar a mudança de comportamento dos profissionais de saúde em relação à higienização das mãos, tais medidas englobam uma série de práticas organizacionais e estruturais que incentivam a higienização das mãos no ambiente hospitalar (Brasil, 2013). Como citado no relatório da OMS/WHO (2016), "uma melhoria da higiene das mãos bem-sucedida e sustentada é alcançada por meio da implementação de várias ações para enfrentar diferentes obstáculos e barreiras comportamentais". Um elemento importante no processo de mudanças, seja comportamental ou institucional, é o hábito, como citado em (Hodgson, 2002, 2007). Para Hodgson (2002, 2007, p. 107), os hábitos são formados por repetições de pensamento e ações e são influenciados por atividades prévias e são definidos como repertórios de um potencial comportamento, podendo ser ativado por estímulos ou dentro de em contexto especifico.

Seguindo essa lógica, Hodgson (2006), estabelece uma relação entre instituições e hábitos, ou seja, regras e organizações. Mudanças e alterações nas instituições podem alterar os hábitos, incluindo comportamento e pensamentos. Sendo que por outro lado, as instituições restringem o comportamento humano e, consequentemente, são responsáveis pelo surgimento de novos hábitos (Hodgson, 2006; North, 1990).

Uma das vantagens da criação de hábitos nas organizações está na economia dos custos de informação, pois o hábito possui o papel de criar referenciais que coordenam as escolhas dentro das organizações, preservando as convenções sociais e institucionais (Hodgson e Knudsen, 2004, p. 36). 
O desafio de transformar uma mudança institucional em hábito é mediado pela estratégia empresarial - isso se refere aos objetivos e intenções da organização - e pela estrutura organizacional (sistemas de recompensas e incentivos) para se alcançar a performance ou resultado planejado (Milagres, 2013).

Medidas individuais não são capazes de modificar e manter o comportamento de higienização das mãos pelos profissionais de saúde por tempo prolongado. Nunes et al., (2019) e Ribeiro (2016) enfatizam que a sustentação dessa mudança consiste em grande desafio para hospitais, ressaltando a importância de novos estudos sobre a temática da higienização de mãos em nos contextos: político, gerencial e assistencial.

Espera-se, com esse estudo, fornecer aos profissionais, administradores e gestores de serviços de saúde, conhecimento gerencial para embasar as ações relacionadas à prevenção e à redução da incidência dos transtornos causados pelas infecções relacionadas à assistência à saúde (Nunes et al., 2019; Andrade et al., 2018).

O nosso argumento teórico é a utilização das práticas de incentivos no alinhamento dos objetivos organizacionais, que podem contribuir positivamente para o desempenho em resposta a mudança institucional. Nessa perspectiva, essa tese explorou as opções e escolhas dos gestores na alocação das práticas de incentivos, frente à exigência da nova regra institucional de higienização das mãos.

\section{Contribuição do Trabalho Para Teoria e Para a Prática}

Esta tese tem duas contribuições principais. A primeira consiste em avançar as discussões teóricas sobre a utilização tipos de práticas de incentivos e mudança institucional. Essa contribuição envolve a proposição de modelo conceitual, que servirá de base para a pesquisa empírica. Nesse trabalho, nós introduzimos a noção que as estruturas de governança podem ser gerenciadas de forma sistemática e intencional para a obtenção de determinado objetivo organizacional. Baseado em dados empíricos, nós propusemos um framework emergente de como os gestores gerenciam as estruturas de governança no processo de mudança institucional. Nós identificamos uma série de novos constructos, que enriquecem e decifram como as 
organizações lidam com a mudança institucional via a gestão das estruturas de governança.

Como contribuição para a prática, esperamos que o nosso framework emergente ofereça um guia de como os gestores podem lidar com a mudança institucional e ativar os comportamentos desejados via gestão da estrutura de governança.

O trabalho tem por objetivo avançar nas discussões teóricas que acercam o papel das práticas de incentivos na percepção dos funcionários no contexto da mudança institucional. $\mathrm{O}$ estudo demonstrou como as diferentes formas de incentivos são utilizados para influenciar o comportamento dos funcionários das organizações hospitalares estudadas.

Acredita-se que o estudo poderá contribuir, não só com o debate da mudança institucional e estruturas de governança, como também, com a discussão de estratégias de recursos humanos na gestão hospitalar no Brasil, cujos resultados são reconhecidamente alarmantes quanto aos eventos adversos que acometem os pacientes, em consequência de falhas das equipes, mas que poderiam ser evitados através da aplicação de procedimentos corretos, com destaque à higienização das mãos.

\section{Estrutura do Trabalho}

Além do capítulo de Introdução, composto por problemas de pesquisa, objetivos, justificativa e contribuições, a tese segue na sua subdivisão. No capítulo 02 , de revisão de literatura, foram discutidas a questão da motivação, utilizando teoria que trata da mudança institucional, estrutura de governança, mudança organizacional e do Goal Frame. No capítulo 03, sobre métodos, foram apresentadas estratégias metodológicas e suas justificativas, tais como, natureza da pesquisa, escolha do método de abordagem processual e critérios de seleção da amostra. Em seguida, no capítulo 04, foi descrito breve informações sobre os hospitais, apresentação da estrutura organizacional, perfil demográfico e os resultados das entrevistas realizadas com os médicos. Em ambos os hospitais, conjuntamente, foram apresentados os principais resultados da pesquisa.

No capitulo 05 , foram analisados e discutidos os resultados da pesquisa e contribuições. 
O capitulo 6, apresentou-se a conclusão sobre os objetivos de pesquisa, limitações e sugestões para estudos futuros. Após, encontram-se as referências e os apêndices. 


\section{REVISÃO DE LITERATURA}

O objetivo deste capítulo é discutir as principais correntes teóricas e Literaturas relacionadas à problemática de pesquisa explorada nesta tese. Começaremos por discutir a relação entre ambiente institucional, estrutura de governança e indivíduos. Depois, discutiremos sobre motivação e desempenho e mudança organizacional e suas definições e desdobramento relacionados à gestão. Posteriormente, abordaremos as diferentes lógicas/tipos de estruturas de governança e práticas de incentivos. Para, ao final do capítulo, construirmos o modelo conceitual, que servirá de base para a pesquisa empírica.

\subsection{Ambiente Institucional, Estrutura de Governança e Indivíduos}

Um constante e fundamental debate na literatura, enfoca a problemática das mudanças no ambiente externo e o impacto nas estratégias, alterando as rotinas e decisões da organização (Klein et al., 2019). Por mudanças, nós nos referimos ao vasto conjunto de aspectos, tais como, inserção de novas tecnologias (Eggers, 2016) e os choques institucionais (e.g., setor alimentício-Instrução Normativa 62 e hospitais em 2013, com a RDC n. ${ }^{\circ} 36$ ). Nessa direção, a Literatura tem procurado investigar como tais mudanças afetam o comportamento de indivíduos e organização, assim como seu desempenho (Eggers e Park, 2018). Dessa forma, para melhor compreender as diferentes respostas das organizações ante as mudanças, um passo anterior consiste em explorar e investigar o ambiente institucional (Klein et al., 2019).

De fato, o ambiente institucional também é variável importante a ser analisada para compreender o comportamento das organizações e indivíduos (Klein et al., 2019). Seguindo a linha de trabalhos previamente analisados, nós definimos o ambiente institucional como as regras do jogo, estruturas e processos legais, políticos e sociais (formais e informais) específicos no ambiente externo, que enquadram estruturas de governança organizacional (Mahoney, 2005; North, 1990; Williamson, 2000). Como exemplos de instituições, podemos citar as regras formais - e.g., políticas e regulamentação - e as regras informais - e.g., valores culturais e códigos de ética (North, 1990). De acordo com North (1990), as instituições podem ser definidas como formais e informais, sendo fundamentais na estruturação da interação 
social, econômica e política (Mahoney, 2005; North, 1990; Williamson, 2000). Ainda de acordo com North (1990), as instituições moldam as interações das pessoas em determinados contextos, gerando incentivos de trocas entre elas.

É amplamente aceito que as instituições contribuem para reduzir a incerteza nas interações entre os indivíduos e organizações (North, 1990). Isso decorre do fato de que as instituições fornecem estrutura que apoia o relacionamento entre as pessoas, além dos mecanismos de controle, enforcement - os custos relacionados ao enforcement são custos relacionados ao monitoramento e ao fazer cumprir um determinado contrato. As origens do enforcement se dão por meio do Estado, através do cumprimento de leis, regras por meio coercitivo, ou enforcement internos, que é realizado através do poder do a gente (North, 1990, 2010).

Mas o papel das instituições vai além disso. Outro papel importante está na inibição, permissão e exigência de determinada ação ou comportamento (North, 1990). Esse papel ajuda a definir melhor fluxo informacional dos direitos de propriedade, definindo padrões relacionais entre os indivíduos (North, 1990). Aqui, por direitos de propriedade, nós definimos como "um feixe que engloba os direitos de uso, usufruto e abuso, e que confere o exercício da exclusão sobre a coisa, que permite afastar terceiros que dela pretendam se apropriar usar ou gozar" (Zylbersztajn e Sztajn, 2002; Hodgson, 2015). Quando tais direitos são bem expressos, dentro ou fora de uma organização, os indivíduos conseguem prever com maior grau de assertividade como serão as transações (trocas). Essa relação entre instituições e comportamento dos indivíduos é aspecto chave para compreender como as organizações agem diante da mudança institucional (Klein et al., 2019).

O ambiente institucional influencia diretamente os custos de transação. Logo, o ambiente institucional afeta a eficiência na transferência do direito de propriedade e os custos de transação. Nós definimos custos de transação como o custo para mensurar o valor dos atributos que estão sendo negociados, ou seja, o custo de proteção dos direitos de propriedade e o custo de fazer cumprir os contratos enforcement e de transformação. Além de influenciar a eficiência na transferência do direito de propriedade e custos de transação, o ambiente institucional tem importante papel na determinação das estruturas de governança presente em transação (Klein et al., 2019; Barzel, 2005). As estruturas de governança são importantes para responder às mudanças institucionais, adaptando-se às regras que definem a maneira que a 
transação ocorre e reagem aos direitos de propriedade e a apropriação dos benefícios (North, 1990; Klein et al., 2019).

O comportamento humano tem relação direta com as instituições pelo fato dos agentes optarem por determinadas opções devido a sua racionalidade limitada, vieses cognitivos, altruísmos e heurísticas - visto aqui como atalhos cognitivos quando atores possuem restrições de tempo e capacidade para processar informações (Simon, 1998).

Daí, a estratégia à solução do desafio gerencial é o de se adaptar à mudança institucional. O que pode envolver o desenho de uma estrutura de incentivos e controle que seja escolhido de forma eficiente e alinhado com os objetivos da organização (Lindenberg, 2013).

A figura 1 ilustra as relações entre ambiente institucional, estrutura de organização e indivíduos. Os incentivos e o ambiente institucional são fatores que determinam a melhor opção de alocação dos recursos a ser feita pela organização. Nesse sentido, o autor propõe esquema de três níveis, explicando a alteração ocasionada pela mudança institucional nos custos de transação que alteram as estruturas de governança.

Figura 1 - Três Níveis da Economia de Custos de Transação.

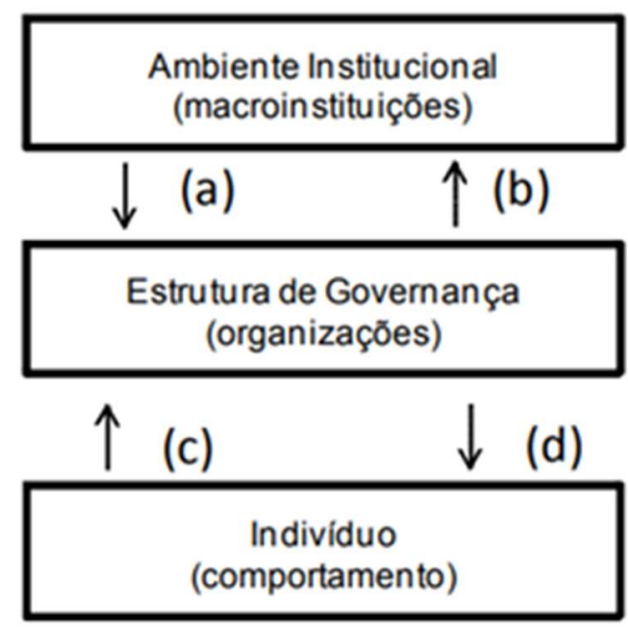

Fonte: Williamson, 1987. 
$\mathrm{Na}$ figura 1, o ambiente institucional, definido anteriormente por nós como um conjunto de regras, influencia as formas organizacionais. Essa relação é representada pela linha (a). Já os indivíduos influenciam as organizações por meio de ações comportamentais (linha c). Esses indivíduos são considerados racionais, porém, de modo limitado e oportunistas, isto é, auto-interessados (Williamson, 1987). Ambos os pressupostos, i.e., racionalidade limitada e auto-interessados constituem condições necessárias para a ocorrência dos custos de transação, como indicado na linha (c).

As decisões estratégicas escolhidas pelas empresas são admitidas como efeito do ambiente institucional e indivíduos, que são representadas pelas linhas (b) e (d). As mudanças que ocorrem no ambiente institucional servem como fator decisivo nas mudanças das estruturas de governança. As garantias dos direitos de propriedade, o que reduz a incerteza nas transações, modificando a eficiência das formas organizacionais.

As diferentes mudanças no ambiente externo demandam também alterações na estrutura de governança. Nessa lógica, Oxley (1999) examinou como a mudança institucional afeta as estruturas de governança, bem como as alianças entre empresas, a escolha de governança entre acordos de equidade e coalizões contratuais, sob diferentes regimes de proteção à propriedade intelectual e outras características institucionais nacionais. Empiricamente, as empresas adotam modos de governança mais hierárquicos quando as proteções aos direitos de propriedade intelectual são mais fracas (Oxley, 1999). Portanto, um entendimento mais completo da escolha da estrutura de governança requer análise da interação entre o ambiente institucional e os mecanismos de governança e suas práticas de incentivos (Klein et al., 2019). Dentro desse espectro, a Teoria dos Incentivos, que compreende a Teoria da Agência (Holmström, 1979; Holmström e Milgrom, 1991) e a Teoria dos Contratos Incompletos (Hart e Moore, 1999), tem sido a base conceitual predominante dos trabalhos que analisam como os agentes econômicos alocam direitos de propriedade no interior da firma, com presença de informação assimétrica.

No entanto, a principal crítica à Teoria dos Incentivos não está na dificuldade em criar incentivos corretos. Isso é assim devido ao fato dessa teoria pressupor que, indivíduos capazes de realizar um exercício de programação dinâmica que envolve saber, pelo menos, probabilisticamente, o excedente produzido (Holmström, 1979, Holmström e Milgrom, 1991). Ou seja, não se coloca a questão da cognição, pois assume-se que os indivíduos possuem o mesmo modelo mental, embora haja evi- 
dência de que a percepção sobre uma dada situação é seletiva e depende do foco da atenção do agente. Em outras palavras, a estratégia à motivação do empregado é determinada pela percepção da intervenção gerencial em administrar o design dos incentivos no ambiente organizacional, direcionando esforços para motivar os funcionários para determinado objetivo (Lindenberg e Foss, 2011).

O desenho do design do ambiente organizacional agrega diferentes práticas de incentivos. É considerado eficiente forma para adequar ao comportamento desejado pela organização. Compreendendo a importância do tema à gestão organizacional, Grandori e Furnari (2008) desenvolveram abordagem preditiva denominada Abordagem Combinatória do Design. Que destaca a importância das diferentes formas de práticas dos incentivos no processo de motivação dos funcionários, sendo divididos em monetários - mercado - e não monetários - comunitários, burocrático e democrático - , combinando-os em diferentes configurações que podem gerar melhor desempenho nas empresas.

A abordagem combinatória está fundamentada na economia dos custos de transação, fundamentada em dois aspectos. O primeiro refere-se à possibilidade de se identificar práticas de incentivos utilizadas pelas organizações. O segundo tem por objetivo separá-los e categorizá-los nos diferentes tipos de mecanismos de governança (mais à frente serão explicadas as estruturas de incentivos e cada elemento de forma separada). Os três principais tipos, apresentados por Williamson (1987) são o mercado, a burocracia e o clã, refinados por Grandori e Furnari (2008) para constituírem os elementos básicos da abordagem desenvolvida por eles.

Para Grandori e Furnari (2008), as empresas podem adotar diferentes estratégias para gerenciar a produção interna, adotando múltiplas práticas de incentivos das estruturas de governança. Podem combinar os tipos de prática de incentivos, como as de mercado, de processo burocrático e comunitário, denominados de forma multimodal. E podem adotar um conjunto de práticas para incentivos de apenas uma dessas categorias, que foi denominado pelos autores de forma unimodal.

As formas unimodais de práticas de incentivos burocráticos são um conjunto de mecanismos compostos somente por uma das estruturas de governança - planejamento, comando e formalização Grandori e Furnari, (2010). Já as formas multimodais compreenderiam combinações de estruturas, como uma combinação de regras (práticas de incentivos burocráticos), com programas de treinamento e equipe 
(práticas de incentivos comunitários) e práticas de incentivos monetários, como pagamento por desempenho práticas de incentivos de mercado).

Desse modo, a corrente teórica supracitada serviu de lente para a análise dos casos da nossa investigação. Entender quais as combinações dos incentivos foram importantes no processo de mudança institucional, pode ser considerado como exemplo futuro à gestão dos recursos humanos às organizações hospitalares.

O que se sabe menos é como se gerencia esses incentivos no processo de mudanças organizacional e institucionais. Seguindo este contexto, neste trabalho, buscamos avançar no entendimento de como os gestores hospitalares administram a utilização das práticas de incentivos para moldar o comportamento dos profissionais. Sabe-se que foram implementados uma série de ações com o objetivo de conscientizar as equipes da importância de higienizar as mãos no ambiente hospitalar.

\subsection{Motivação e Incentivos}

Para ilustrar a questão da motivação e das práticas de incentivos, vamos contextualizar a problemática no âmbito da higienização das mãos. A OMS/WHO e a Anvisa, bem como os profissionais da saúde, identificam a higiene das mãos como procedimento essencial na assistência à saúde e na prevenção e controle de infecção hospitalar (WHO, 2009). A inadequação do atendimento a esse procedimento impacta diretamente na segurança do paciente, portanto, nos resultados do desempenho do setor e na eficiência de suas equipes (Giordani et al., 2014).

A complexidade do ambiente hospitalar demanda, por sua vez, trabalho em equipe, com interação entre especialistas, equipe multiprofissional, áreas ou serviços. São necessárias práticas organizacionais que promovam padrões para a motivação entre os membros da equipe, com redução de comportamentos oportunistas entre os colaboradores (Klajner et al., 2015). No que diz respeito aos métodos de monitoramentos das taxas de adesão à Higienização das Mãos, a OMS/WHO indica como forma eficiente a observação direta. Entretanto, a observação direta, além de ser oneroso, poderia ocasionar vieses devido a presença do observador no ambiente de trabalho profissional.

Do ponto de vista dos incentivos, o desempenho profissional na prática da higiene das mãos é observado em relação direta com a motivação dos empregados 
(WHO, 2009). O desafio está em criar incentivos que influenciam e motivam as equipes a aderirem à higienização das mãos de forma correta e na frequência indicada (Giordani et al., 2014; OMS/WHO, 2009).

A teoria econômica tem servido de base para os estudos que investigam os pressupostos motivacionais dos indivíduos no ambiente de trabalho, (e.g., tipos de práticas de incentivos). Nesta visão, a motivação é tratada de forma unidimensional e supõe que os indivíduos maximizam seus próprios interesses tangíveis, isto é, seu próprio retorno em termos monetários. Os sujeitos são descritos como motivados apenas por recompensas tangíveis, que só podem ser fomentadas pelo pagamento variável por desempenho (Osterloh e Frey, 2013; Weibel et al., 2010).

Fundamentados na teoria da agência, os modelos econômicos estabelecidos consideram os incentivos monetários como a principal fonte da motivação humana. Essa concepção tem servido de base conceitual predominante dos trabalhos que analisam como os agentes econômicos alocam direitos de propriedade no interior da firma, com presença de informação assimétrica (Holmström, 1979; Holmström e Milgrom, 1991).

Para Foss e Stea (2014), a análise tradicional da motivação baseada na relação de incentivos e na assimetria de informação é considerada insuficiente para determinar a motivação dos indivíduos de forma geral. Para incorporar esse aspecto negligenciado, é importante a utilização dos aspectos da cognição para abordar a relações entre o principal (o gestor) e o agente (os seus funcionários). A motivação relacionada aos padrões da Teoria Neoclássica não é excluída da literatura mais recente, apesar de terem sido adotadas contribuições da Psicologia, é mantida a motivação extrínseca, ou seja, impulsionada pelo "objetivo de ganho" focado nos incentivos monetários (Osterloh e Frey, 2013; Weibel, Rost, e Osterloh, 2010). O ponto essencial aqui é que de acordo com Osterloh e Frey (2013) e Weibel et al. (2010) 'o 'objetivo de ganho' não pode ser considerado como a única fonte de motivação". Ampliando essa compreensão, os estudos de Lindenberg e Foss (2011b) propõem outras formas de incentivos para a motivação, que não necessariamente estão relacionados ao ganho monetário. Desta forma apresentam a motivação intrínseca, que é impulsionada pelo "objetivo hedônico", de se sentir bem (Foss e Lindenberg, 2013; Lindenberg e Foss, 2011b).

Outros autores também alertam sobre a existência de outra motivação além da motivação meramente monetária. Essa outra forma de motivação consiste no 
“objetivo normativo" (Foss e Lindenberg, 2013; Lindenberg e Foss, 2011a). O "objetivo normativo" consiste em de agir de forma apropriada ao comportamento desejado, com foco no bem-estar dos outros ou preferências pró-sociais (Foss e Lindenberg, 2013; Lindenberg e Foss, 2011a). É entendida como a motivação que envolve os indivíduos em comportamentos que beneficiam os outros, como por exemplo, altruísmo (Foss e Lindenberg, 2013; Lindenberg e Foss, 2011a). Além disso, tal objetivo pode levar a diminuição do risco moral e o oportunismo, assim como os custos de planejamento e monitoramento (Fehr e Fischbacher, 2002; Penner, Dovidio, Piliavin, e Schroeder, 2005; Foss e Milagres, 2014).

Esta compreensão sobre a motivação abre novas oportunidades para a gestão. Como os indivíduos agem de forma seletiva, certos incentivos do contexto e como são percebidos primeiramente, e outros de forma secundária (Foss e Lindenberg, 2013). Desta forma, o indivíduo se torna mais sensível às mudanças em determinadas "pistas situacionais", e menos sensíveis a outras (Lindenberg, 2013). Daí o papel fundamental não apenas das estruturas de governanças (que será definido posteriormente) e, principalmente, da sua gestão.

Em Osterloh e Frey (2013) e Steg, Lindenberg e Keizer (2016), sugerem que os mecanismos de promoção da motivação intrínseca podem ser alcançados por meio do desenho das tarefas e rotinas da organização. Além de um salário a ser pago de acordo com a atividade desempenhada, existem outras formas de criar um ambiente voltado para a motivação intrínseca, nas quais são destacadas as estratégias descritas a seguir.

O ambiente de trabalho tem um papel importante na percepção dos funcionários na mudança no ambiente interno de uma organização. A percepção pode ser alcançada via algumas escolhas de práticas de incentivos organizacionais fundamentais, tais como o compartilhamento e o envolvimento dos funcionários no processo decisório, recompensas, reconhecimento de resultados (Foss e Lindenberg, 2013).

Assim como o feedback da tarefa realizada, observando que o grau em que o líder fornece informações claras sobre os níveis de desempenho pode aumentar a percepção dos funcionários sobre a sua de competência em executar suas tarefas; enfatizar a percepção dos funcionários sobre estima e relacionamento por processos justos; sinalizar normas sociais e permitir aos funcionários autonomia em suas equi- 
pes para disciplinar os demais funcionários com comportamento free rider $^{4}$ (Kuvaas et al., 2017; Osterloh e Frey, 2013).

Essas noções reforçam um aspecto relevante na literatura: o projeto organizacional que poderá ser uma forma de intervir nos comportamentos desejados (Kuvaas, Buch, Weibel, Dysvik, e Nerstad, 2017; Weibel et al., 2010). Daí, a estrutura de incentivos monetária e não monetária desempenha um papel importante no desencadeamento da motivação necessária para atingir um objetivo organizacional (Foss e Lindenberg, 2013; Lindenberg e Foss, 2011b).

Lindenberg e Foss (2011) apresentam uma série de práticas de incentivos organizacionais, que vão além dos incentivos monetários e que podem ativar e manter a da motivação pró-social ou normativa. O primeiro grupo apresentada pelos autores lida com as pré-condições para ativar um quadro de metas normativas que seja propício à motivação pró-social (por meio de equipe e estrutura de tarefas). As práticas de incentivos incluem a vinculação de estruturas de tarefas e equipes de maneira transparente a objetivos comuns. Já no segundo grupo lida com suportes diretos para o quadro de metas normativas e engloba principalmente a gestão cognitiva / simbólica. O terceiro grupo inclui os suportes mais indiretos para o quadro de metas normativas através da calibragem de estruturas de recompensa, de modo que eles sejam explicitamente orientados para objetivos conjuntos (Foss e Lindenberg, 2013; Lindenberg e Foss, 2011b).

Lindenberg (2013) cita que uma forma de alinhamento estratégico dos objetivos dos indivíduos com o organizacional poderá ocorrer por meio de "integração de metas". Tal integração ocorreria via a combinação das estruturas de práticas de incentivos, que influenciará os indivíduos a agirem de forma apropriada de acordo com as metas organizacionais.

As recompensas, tanto individuais quanto em grupo são importantes neste contexto, mas elas devem ser expressas pelos gestores de como essas recompensas estão sendo administradas para alcançar os objetivos em comum do grupo ou organização Lindenberg (2013).

Apesar da literatura fornecer um rico portfólio de sugestões de como ativar comportamentos, indo além do objetivo ganho, existe pouco conhecimento sobre a gestão integrada destes objetivos mediante uma mudança organizacional. Na próxi-

\footnotetext{
${ }^{4} \mathrm{O}$ comportamento free rider é denominado ao agente que age de forma oportunista, utilizando serviços ou ativos de outra parte sem oferecer a compensação adequada.
} 
ma seção, vamos tratar de forma clara as estruturas de governança. Para melhor compreender, utilizaremos os trabalhos de Grandori e Funari (2008,2010); (Grandori, 2016,2017), que se debruçaram a estudar a relação entre estruturas de governança e comportamentos em empresas italianas. Como base nas abordagens teóricas propostas pelos autores, a utilizaremos com o objetivo de iluminar os estudos de casos realizados nesta pesquisa. Vamos também reforçar que apesar de existirem diferentes estruturas, a literatura não fornece guia suficiente de como os atores (gestores) administram tais estruturas em uma situação de mudança organizacional no contexto de uma mudança institucional.

\subsection{Mudança Organizacional}

Nesta seção, apresentaremos uma breve revisão da literatura sobre a gestão da mudança organizacional. Começaremos apresentando o conceito de mudança organizacional. Posteriormente, trataremos práticas de incentivos para a mudança organizacional, o que é central para a nossa pergunta de pesquisa.

\subsection{Caminhos e Desafios da Mudança Organizacional}

A mudança organizacional é um tema de grande relevo e que vem atraindo a atenção da academia e da prática (Zhang, Wang e O’Kane, 2019). Embora pesquisas anteriores tenham fornecido uma ampla gama de teorias para explicar a mudança organizacional (e.g., Dixon et al., 2010), pesquisadores sugerem que não há uma definição comum para o que venha a ser mudança organizacional (Suddaby e Foster, 2016). Pesquisadores consideram que mudanças organizacionais podem estar ligadas à introdução de uma nova prática ou desenvolvimento de novas capacitações em resposta à mudança tecnológica (disrupção). Tais mudanças podem ser ocasionadas devido ao surgimento de novas leis e ou regulamentos, introdução de novas tecnologias ou até mesmo variações na demanda dos consumidores (Foster, 2010; Will, 2015; Will e Pies, 2018; Santos, 2014). Em muitos casos, tais transformações forçam as organizações a redesenharem suas estratégias e a revisão dos seus processos e rotinas (Glaser, 2017). Assim, em muitos casos, a mudança organizacional pode ser caracterizada pela complexidade e por um alto nível de incerteza (e.g., Corley e Gioia, 2004; Elstak et al., 2015). 
Com o objetivo de compreender os avanços e definições que acercam os conceitos encontrados na literatura sobre mudanças organizacionais existentes (Lamm e Gordon, 2010; Barros, 2019), os autores sugeriram que as mudanças organizacionais podem ter três formas: conteúdo, contexto e processo. O conteúdo tem como proposta atuar no que precisa ser mudado na organização, incluindo os aspectos tangíveis - que podem ser estruturas e processos de trabalho — ou aspectos intangíveis - como as crenças ou as relações interpessoais (Bailey e Raelin, 2015). O processo é definido a forma e modo que a mudança é realizada ou implementada. De acordo com os autores supracitados, o processo pode ser classificado como episódico - quando não há nenhum planejamento para a realização da mudança, ou seja, acontece de forma repentina - ou continuo - quando a mudança ocorre de forma gradual e realizada ao longo do tempo (Bailey e Raelin, 2015; De Massis, Wang, e Chua, 2019),

A terceira vertente, o contexto, relaciona-se com a mudança e com estímulos do ambiente no contexto analisado. Lamm e Gordon (2010) discutem que uma importante corrente de mudança organizacional analisa do ponto de vista do nível macro (e.g., indústria ou fatores ambientais e sociais, externos, que levam à mudança). Essa linha procura analisar como o ambiente institucional ou aspectos ligados à competição ensejam a mudança organizacional. No entanto, Panayiotou, Putnam, e Kassinis (2019) sugerem que o contexto também deve incluir aspectos micro organizacionais (dentro da firma), a saber: fatores relacionados ao ambiente de trabalho, a estrutura da organização, cultura, e os valores ali estabelecidos, tais como o modelo de gestão e liderança, por fim, o comportamento e atitudes dos funcionários (Lamm e Gordon, 2010; Onimole, 2017).

Recentemente, pesquisadores passaram a tentar a construir uma abordagem conciliatória e multilevel, incorporando aspectos macro e micro. Por exemplo, Bailey e Raelin (2015), citam que a mudança organizacional é dinâmica e interdependente, compreendendo em um processo que oscila entre o nível macro para o microorganizacional e vice-versa. Esses autores reforçam que os fatores relacionados ao comportamento do grupo ganham importância para explicar a mudança organizacional e o desempenho, sendo tão mais importantes e profundas quando comparada aos aspectos que provocam a mudança.

Avançando nesse sentido, com foco na relação entre os diferentes níveis da organização e do ambiente, Maheshwari e Veena Vohra (2015) investigaram o papel 
da gestão dos recursos humanos, mais precisamente sobre o papel das práticas de incentivos no processo de gerenciamento de mudanças. Essa linha de investigação procurou mostrar como as práticas de recursos humanos - ou práticas de incentivos - estão relacionadas diretamente - ou indiretamente - com o que se pretende mudar (Bhatnagar et al., 2010; Erwin e Garman, 2010; Silva, Anholon, Ailva, e Quelhas, 2017), seja alterações em processos organizacionais ou até mesmo lançamento de novos produtos e negócios.

A literatura sugere que durante o processo de mudança, a participação dos gestores no gerenciamento da mudança é um ponto importante a ser considerado (Smollan, 2015). Esse autor sugere que gestores podem enfrentar o desafio (e ter autonomia para respostas) de gerir as práticas de incentivos para coordenar e implantar as mudanças necessárias. As práticas de incentivos podem ser usadas para sinalizar o caminho a ser seguido pela mudança e garantir o alinhamento das equipes aos objetivos estratégicos da organização (Smollan, 2015).

Desta forma, os incentivos são recursos fornecidos pela organização com o objetivo de impactar as emoções e comportamento dos trabalhadores quanto à mudança (Onimole, 2017). Os incentivos melhoram os sentimentos de pertencimento à organização, o que contribui com a sensação de valorização (Shin, Taylor e Seo, 2012). Shin, Taylor e Seo (2012) afirmam que o desenvolvimento dos recursos internos dos trabalhadores por meio da utilização de incentivos contribui para: a diminuição da aversão à mudança, redução do desconforto causado pelo processo de mudança, desenvolvimento de atitudes favoráveis em relação à ela. Além disso, autores destacam que a expectativa de receber mais incentivos durante ou após a mudança melhora o envolvimento do indivíduo e a vontade de continuar a manter uma relação simbiótica com a organização (Shin, Taylor e Seo, 2012).

Os incentivos tornam os indivíduos mais confiantes e otimistas. A literatura destaca que há vários tipos de incentivos. Por exemplo, firmas podem em treinamento, gestão de carreira, reconhecimento, possibilidade de promoção entre outros (Shin et al., 2012). Maheshwari e Vohra (2015) e Paren, (2015) citam algumas práticas de incentivos que poderão orientar as organizações a utilizarem no gerenciamento de pessoas no processo de mudança:

a) Práticas voltadas para o processo de formação da cultura, desenvolvimento da liderança, comunicação e tecnologia, caso sejam 
introduzidas e desenvolvidas no processo da mudança organizacional;

b) Categorização e compreensão da cultura existente, alterando o comportamento e criando um ambiente que seja propicio a mudança desejada;

c) Ativar nas lideranças uma visão de mudança, com o objetivo de facilitar e esclarecer a mudança;

d) Ampliar o comportamento de cooperativo e a integração por meio de treinamentos, mensurando o desempenho da equipe;

e) Estabelecer um ambiente de aprendizagem;

f) Criar um ambiente de confiança através de comunicação aberta;

g) Padronizar as novas práticas.

As práticas poderão promover as percepções positivas dos funcionários, orientando-os para o alcance de novas metas. Além das práticas citadas acima, Maheshwari e Veena Vohra (2015) sugerem que a integração da equipe, por meio de processos de comunicação mais objetivos, evitando assim que, mensagens inconsistentes possam ser enviadas aos colaboradores durante a mudança, causando dessa forma, desalinhamento e descrédito.

Em (Canning e Found, 2015, Smollan, 2015 e Xu et al., 2016), enfatizam o papel da comunicação no processo de mudança. Xu et al., (2016), recomenda-se que a comunicação seja frequente e precisa, reduzindo incertezas relacionadas às mudanças, além de diminuir possíveis problemas psicológicos nos funcionário. Ainda sobre a comunicação, Oreg et al. (2018) e Onimole (2017) acrescentam a importância da utilização de técnicas gerenciais de comunicação com os funcionários, como por exemplo: feedback, reuniões, compartilhamento de informação e auxílio na tomada de decisão entre os gestores e responsáveis e treinamento, as práticas quando planejadas atuam diretamente no foco da mudança, aumentando a apropriação das iniciativas e processos de cognição das informações, favorecendo a aceitação da mudança Canning e Found (2015).

A integração organizacional é um importante mecanismo para explicar as alterações nas práticas de incentivo visando um determinado objetivo organizacional. Não apenas mudar os incentivos, mas aumentar o entendimento sobre tais incentivos por meio da integração organizacional (entre indivíduos e equipes, equipes e gestores) pode contribuir para gerar resultados mais positivos no processo de mudança organizacional Shin et al., (2012).

De modo geral, mudança organizacional é um processo delicado, que elenca as alterações fundamentais nos padrões de trabalho de uma organização, incidindo diretamente no comportamento humano, tendo como consequência, as alterações 
estratégicas, que inclui alterações em recursos e tecnologia (Oreg et al., 2018; Onimole, 2017). Uso de tais práticas gerenciais e mecanismos organizacionais podem dirimir os problemas ligados à mudança organizacional, Heckelman (2017) apresenta sumariamente, alguns fatores que podem contribuir para o insucesso de mudança organizacional: falta de visão integrada, para o processo de mudança; a falta de práticas organizacionais que alterem as crenças individuais; falta de planejamento ou execução do processo de mudança; falta de sinergia ou escolha da liderança da mudança; comunicação insuficiente ou confusa e não direcionamento dos esforços de mudança para o prosseguimento da estratégia organizacional.

\subsection{Abordagem Combinatória do Design: Práticas de incentivos}

Nessa seção serão expostos os mecanismos de governança e práticas de incentivos utilizadas nos trabalhos de Grandori e Funari (2008, 2016) e Grandori (2017). Os autores analisam a relação mecanismos de governança e princípios comportamentais ocasionados pelo uso das práticas de incentivos. Os autores denominam as combinações da utilização das práticas incentivos pelos gestores como "Abordagem Combinatória do Design" mais à frente serão expostas.

No contexto desta tese, as práticas de incentivos foram identificadas nos hospitais no processo de mudança institucional, ou seja, para promover a adesão do Protocolo de Higienização das Mãos, contido na RDC-36.

\subsection{Mecanismos de governança e Princípios Comportamentais}

Como mencionado anteriormente, existem diversas práticas de incentivo, que vão além da monetária. Em (Grandori e Funari 2008,2016, Grandori 2017) os autores não só descrevem as estruturas de governança interna que levam a eficiência organizacional. Principalmente, esses autores apresentaram como as combinações das práticas podem predizer a eficiência de uma organização.

Baseada na relação entre inovação e estrutura de governança interna; esses autores propuseram a abordagem teórica denominada "Abordagem Combinatória do Design". Tal abordagem compreende as estruturas de governança, práticas de incentivos adotadas pelas firmas. Essa abordagem destaca as combinações de estru- 
turas de governança e incentivos que geram melhores resultados, tanto para a inovação quanto para a eficiência.

Desta forma, a "Abordagem Combinatória do Design" qualifica as estruturas de coordenação interna que dizem respeito a práticas de incentivos e rotinas adotadas pela firma e gestores, caracterizados como de mercado, burocráticos, comunitários e democráticos. A seguir, apresentaremos em detalhes, cada uma das lógicas de estrutura de governança.

Esses autores, fazendo sentido desses componentes, propuseram quatro mecanismos de governança que atuam através das práticas de incentivo no comportamento dos funcionários dentro das firmas, os primeiros é o mercado incluem incentivos monetários e de controle e pagamento pelo desempenho individual, pagamento pelo desempenho da equipe, pagamento pelo desempenho da firma e outros (Grandori, 2017). Já os mecanismos burocráticos são as regras e planos formais de divisão do trabalho enquanto os mecanismos comunitários incorporam compartilhamento de decisões, de conhecimento, de valores e cultura.

Finalmente, a governança democrática tem como característica a divisão de direitos de propriedade, interesses e tomada de decisões. Essa estrutura possibilita aos membros da equipe o direito de opinar seja nos procedimentos e/ou nos processos para resolução de conflitos. As práticas de incentivos democráticos permitem que o líder realize a integração de diferentes julgamentos e interesses e empodera o empregado em diferentes aspectos, tais como dando-lhe voz nas decisões e até mesmo alocando-o em tarefas superiores ao seu posto de trabalho (Grandori, 2008, 2017; Grandori e Furnari, 2008). As práticas de incentivos e princípios de comportamento organizacional estão apresentados no Quadro 1. 
Quadro 1 - Mecanismos de Governança, Princípios de Comportamento, Prática de Incentivos

\begin{tabular}{|l|l|l|}
\hline $\begin{array}{c}\text { Mecanismos de } \\
\text { Governança }\end{array}$ & \multicolumn{1}{|c|}{$\begin{array}{c}\text { Princípios do } \\
\text { comportamento }\end{array}$} & $\begin{array}{l}\text { Práticas } \\
\text { predominantes em } \\
\text { cada Mecanismo de } \\
\text { Governança }\end{array}$ \\
\hline Bercado & $\begin{array}{l}\text { Cria incentivos com } \\
\text { grande potencial de co- } \\
\text { ordenar a ação com } \\
\text { comunicação mínima. }\end{array}$ & $\begin{array}{l}\text { Pagamento por desem- } \\
\text { penho individual, da } \\
\text { equipe e da firma, ter- } \\
\text { ceirização, mobilidade } \\
\text { de trabalho interno. }\end{array}$ \\
\hline Burocráticos & $\begin{array}{l}\text { Possibilita maior previ- } \\
\text { sibilidade, transparência } \\
\text { e responsabilidade. }\end{array}$ & $\begin{array}{l}\text { Sistema de avaliação } \\
\text { formal, regras formais, } \\
\text { processo e programa, } \\
\text { articulação da estrutura } \\
\text { formal. }\end{array}$ \\
\hline Comunitários & $\begin{array}{l}\text { Permite criação de iden- } \\
\text { tidade e coesão, homo- } \\
\text { geneidade de julgamen- } \\
\text { tos e interesses. }\end{array}$ & $\begin{array}{l}\text { Práticas de divisão do } \\
\text { conhecimento, políticas } \\
\text { comunitárias, trabalham } \\
\text { em equipe, baseados } \\
\text { na auto-organização. }\end{array}$ \\
\hline Democráticos & $\begin{array}{l}\text { Integra de diferentes } \\
\text { julgamentos e interes- } \\
\text { ses. }\end{array}$ & $\begin{array}{l}\text { Práticas que levam à } \\
\text { difusão dos direitos de } \\
\text { decisão e de proprieda- } \\
\text { de, assim como, os di- } \\
\text { reitos de representação. }\end{array}$ \\
\hline
\end{tabular}

Fonte: Grandori e Furnari (2008, 2010, 2016); (Grandori, 2017). (Adaptado).

Os mecanismos de governança podem induzir os funcionários a comportarem de forma socialmente apropriada (Grandori, 2017; Lindenberg, 2003). As firmas podem adotar diferentes formas de organizar a sua produção interna, seja combinando uma ou mais prática de incentivos dos elementos citados anteriormente. No caso da coordenação via mercado, trata-se de uma estrutura que permite criar incentivos focados nos ganhos. Nos elementos burocráticos, atua de forma a inibir que o comportamento hedônico se sobressaia, mediante meios de controle e monitoramento dos indivíduos (Harrison e Freeman 2004). Os mecanismos de governança comunitários permitem a criação de identidade e coesão entre os indivíduos que fortalecem as práticas normativas. O modo comunitário é visto como um recurso eficiente no 
desempenho de tarefas de inovação que dependem da geração e compartilhamento de novos conhecimentos, portanto, de confiança mútua (Grandori, 2016, 2017).

As empresas podem utilizar diferentes estratégias para gerirem a sua organização interna, podendo combinar diferentes práticas de incentivos dos mecanismos de governança - denominadas Grandori e Furnari (2010), de forma multimodal. Quando as empresas optam por adotar somente uma prática de incentivos de um determinado mecanismo de governança, os autores denominam de forma unimodal.

Ainda na visão de Grandori e Furnari $(2008,2010)$, as combinações das práticas de incentivos podem levar a resultados eficientes. Tais combinações podem não representar a falta de coerência das estratégias organizacionais das empresas, mas sim a heterogeneidade das estruturas visando a um resultado desejado pela organização. Neste sentido, observa-se a relevância da liderança na alocação das práticas de incentivos, pois são os líderes que devem motivar o comportamento em suas equipes através das práticas e incentivos (Lindenberg, 2013; Osterloh e Frey, 2013).

O aporte teórico da "Abordagem Combinatória do Design" será utilizado neste estudo dentro do contexto do papel do líder na utilização das práticas de incentivos diante de uma mudança institucional, ou seja, serão analisadas quais práticas foram utilizadas antes da mudança e quais foram utilizadas para promover e direcionar o comportamento dos funcionários depois que a nova regra foi divulgada para o setor de saúde.

Apesar da literatura sugerir que as empresas devam adotar diferentes práticas de incentivo e lógicas de governança, há pouca evidência empírica de como isso de fato ocorre. Menos ainda é sabido como tal gestão ocorre diante de mudança institucional. Nosso principal argumento teórico é que, para lidar com a mudança institucional, os gestores modificam, adaptam ou incrementam as estruturas de governança. Enquanto as estruturas estão bem descritas na literatura, o como estão pouco discutido. Temos os ingredientes, mas não temos nem as técnicas gastronômicas e nem as receitas.

Para abordar a problemática de pesquisa, vamos investigar o contexto da mudança institucional em hospitais. Como discutiremos a seguir, os hospitais oferecem uma a oportunidade para observar e a analisar o fenômeno da gestão das estruturas de governança e suas práticas de incentivo dentro desse contexto. 


\subsection{Setor de Saúde e o Combate à Infecção Hospitalar}

Considerado um relevante problema para saúde pública em todo o mundo, as ocorrências de Infecções Relacionadas à Assistência à Saúde (IRAS) resultam em: elevados índices de complicações à saúde do paciente e mortes; prolongamento do período de internação; aumento direto sobre os custos da assistência; além do risco jurídico de ações contra o hospital e subsequentes indenizações; e, ainda, a disseminação de organismos resistentes à antibióticos (Souza et al., 2015).

Da transformação do hospital, de um local de aglomeração indiscriminada de doentes na Idade Média, para um local de tratamento e cura de doenças, na Idade Moderna, seguiram-se os avanços para a prevenção e controle dos perigos associados à qualidade do atendimento ao paciente Oliveira e Silva,(2016) .Entre as contribuições, destacam-se estudos pioneiros tais como os de Semmelweis, que, por volta de 1847, constataram que a transmissão cruzada de microrganismos pelas mãos e estabeleceram, com seu achado, uma das primeiras medidas de controle e prevenção de IRAS: a necessidade da lavagem das mãos antes e entre contato com pacientes. Em 1865, Florence Nigthingal introduziu a necessidade de padrões de higiene para o ambiente hospitalar e o paciente. Posteriormente, no início dos anos 1960, registram-se as contribuições de Avedis Donabedian, com estudos sobre a avaliação da qualidade e gestão dos sistemas em serviços de saúde, no quais exploraram os conceitos e métodos necessários para examinar/medir a provisão da saúde quanto a estrutura, processos e resultados (Oliveira e Silva, 2016; Brasil, 2014).

A reconhecida trajetória de avanços dos conhecimentos, tecnologias e métodos no campo da saúde, no entanto, não trouxe consigo a efetividade de resultados esperados para a segurança do paciente no atendimento hospitalar. A publicação do relatório de pesquisa do Institute of Medicine (IOM) dos Estados Unidos da América (EUA), nos anos 2000, colocou em foco dados alarmantes sobre a (in)segurança do paciente quanto à exposição a "eventos adversos" nos locais de atendimento à saúde. No estudo, eventos adversos foram considerados como "dano causado pelo cuidado à saúde e não pela doença de base, que prolongou o tempo de permanência do paciente ou resultou em uma incapacidade presente no momento da alta" (Brasil, 2014, p.15). A pesquisa apontou uma taxa de mortalidade maior para os "eventos adversos" do que as atribuídas a pacientes com HIV positivo, câncer de mama ou atropelamentos nos EUA. A partir da mesma metodologia desta pesquisa, diversos 
países europeus e também a Austrália, Nova Zelândia e o Brasil, realizaram estudos e confirmaram a alta incidência de "eventos adversos", demonstrando que, em média, $10 \%$ dos pacientes internados sofrem algum tipo de agravo e dos quais, $50 \%$ seriam evitáveis (Brasil, 2014).

O reconhecimento da questão da segurança do paciente como estratégica no mundo se traduziu na criação da World Alliance for Patient Safety (a Aliança Mundial para a Segurança do Paciente), em 2004, pela OMSMHO. Em 2005, a Aliança Mundial para a Segurança do Paciente identificou seis áreas de atuação, criando metas internacionais para a segurança de pacientes, entre as quais, reduzir o risco de infecções associadas aos cuidados de saúde, tendo como ação principal a higiene das mãos. Essa ação, inclusive, está de acordo com as diretrizes atuais da OMS/WHO (Organização Mundial de Saúde) ou do Centers for Disease Control and Prevention $(C D C)$ e é considerada uma medida preventiva primária (Instituto Onconguia, 2015).

Ao lado dos outros países que aderiram à aliança está o Brasil, que, em $1 .^{\circ}$ de abril de 2013, por meio do Ministério da Saúde (MS), instituiu a Portaria n. 529, de 01/04/2013, criando o Programa Nacional de Segurança do Paciente (PNSP). O objetivo desse programa é de contribuir para a qualificação do cuidado em saúde em todos os estabelecimentos de saúde do território nacional (Brasil, 2013a). Em seguida, com a RDC-36, de 25/07/13, o MS instituiu "as ações" para a segurança do paciente em serviços de saúde no Brasil. Nesse regulamento, entre outras questões, impõe-se a criação de Núcleos de Segurança do Paciente (NSP) em todas as unidades de atendimento hospitalar, e a exigência da implantação de Protocolos de Segurança do Paciente e realização do monitoramento dos seus indicadores (Brasil, 2013b).

De acordo com a OMS/WHO (2016), o êxito e o valor da cobertura em saúde depende de sua capacidade em fornecer serviços seguros, eficientes e de qualidade para todas as pessoas, em todos os lugares. No entanto, a infecção associada à assistência à saúde (IRAS), também designada como infecção "hospitalar" ou "nosocomial", representa o evento adverso mais frequente durante a prestação de cuidados e, de acordo com os dados disponíveis, nenhuma instituição ou país pode alegar ter resolvido o problema. A OMSNWHO (2011) afirma que, embora os índices nos países de renda alta apresentem taxas significativamente mais baixas que os países de rendas média e baixa, estima-se que centenas de milhões de pacientes 
são afetados por IRAS em todo o mundo e, desta forma, impõe-se uma crescente exigência para a construção de padrões de governança que possam intervir na prevenção e controle das infecções relacionadas à assistência à saúde.

Como defende Bellissimo-Rodrigues, (2017), não existe causa definida para as infecções hospitalares, que podem ser multifatoriais. São consideradas como fatores de risco relacionados ao paciente, as pessoas pertencentes a grupos vulneráveis tais como recém nascidos, idosos, ou suscetíveis como os portadores do vírus da imunodeficiência adquirida (HIV), que possuem maior probabilidade que pessoas plenamente saudáveis; e fatores relacionados ao serviço e ao ambiente, que se dão a partir da relação entre o profissional com procedimentos inadequados e o paciente. Destaca-se ainda o tempo de internação e os procedimentos invasivos (como sonda urinária, cateter venoso e ventilação mecânica).

Embora a diversidade de variáveis envolvidas, a higienização das mãos pelos profissionais da saúde é admitida como uma das medidas mais efetivas, simples e seguras de prevenir as infecções relacionadas a assistência à saúde (Pires et al., 2017). Por esse motivo, tem sido considerada como uma das bases em que se assenta a prevenção e controle de infecções dentro dos serviços de saúde (Grepi, 2017). Contudo, os estudos sobre o tema mostram que a adesão à prática da higienização das mãos de forma constante e na rotina diária ainda é baixa, devendo ser estimulada e conscientizada entre os profissionais de saúde (Borges et al., 2010; Giordani et al., 2014; Zottele et al., 2017).

A implantação de novas práticas no ambiente de trabalho depende da atenção de gestores, diretores e administradores dos serviços de saúde, comprometidos com o incentivo e a sensibilização dos profissionais sobre a questão ${ }^{5}$. Considerandose as dificuldades de adesão dos profissionais de saúde à higiene das mãos, a OMS/WHO propôs cinco momentos para a sua execução: antes e após o contato com o paciente, antes da realização de procedimentos assépticos, após contato com as superfícies próximas ao paciente e após o risco de exposição a fluídos corporais (Brasil, 2014).

Para atingir esse objetivo, o gestor tem um papel importante na transformação do ambiente e na motivação dos funcionários por ser tratar de uma prática de difícil

\footnotetext{
${ }^{5}$ No Brasil, agências de pesquisa e empresas do setor de saúde desenvolveram um sistema monitora procedimentos de assistência e de higienização das auxiliando a equipe médica e de enfermagem na implementação de boas práticas assistenciais.
} 
monitoramento, influenciando em seus comportamentos, bem como mobilizando os esforços para ter adesão à higiene das mãos (Singer e Clark, 2011; Singer e Vogus, 2013).

Nesse sentido, a Agência Nacional de Vigilância Sanitária desenvolve estratégias que contribui para o plano de ações de reduções dos casos de infecção hospitalar (WHO, 2008). Essas medidas são fundamentadas nas seguintes práticas: monitoramento da higienização das mãos e o acompanhamento da adesão; a utilização de ferramentas de comunicação; reuniões e treinamentos que disseminem a importância da higienização das mãos no ambiente hospitalar. Dentro dessas ações também inclui a fixação de cartazes instrutivos que reforcem as etapas de higienização das mãos nos diferentes procedimentos hospitalares.

Para que as mudanças sejam sustentáveis, é necessário que os processos organizacionais reforcem os comportamentos desejados. As mudanças nos processos e comportamentos podem depender de como os gestores gerem as práticas de incentivos. Na próxima seção, vamos discutir as proposições, que serviram de base para a pesquisa empírica.

\subsection{Modelo conceitual e proposições}

Nesta seção, vamos apresentar o modelo conceitual da tese e, posteriormente, as proposições. Ambos servirão de guias para estruturar a fase empírica do trabalho. A Figura 1 apresenta o modelo conceitual da tese. Esse modelo relaciona a estrutura de governança e práticas de incentivos (monetários e não monetários). Também são destacados a utilização das estrutura de governança no processo de transição na mudança institucional. Utilizamos tal modelo para estruturar a pesquisa de campo e investigar a como os hospitais gerenciaram as estruturas de governança em resposta à mudança institucional (i.e. Protocolo de Higienização das Mãos), que define novas práticas no ambiente hospitalar, visando à diminuição de infecção nos pacientes. 
Figura 2 - Modelo Conceitual: Incentivos e Motivação e Desempenho

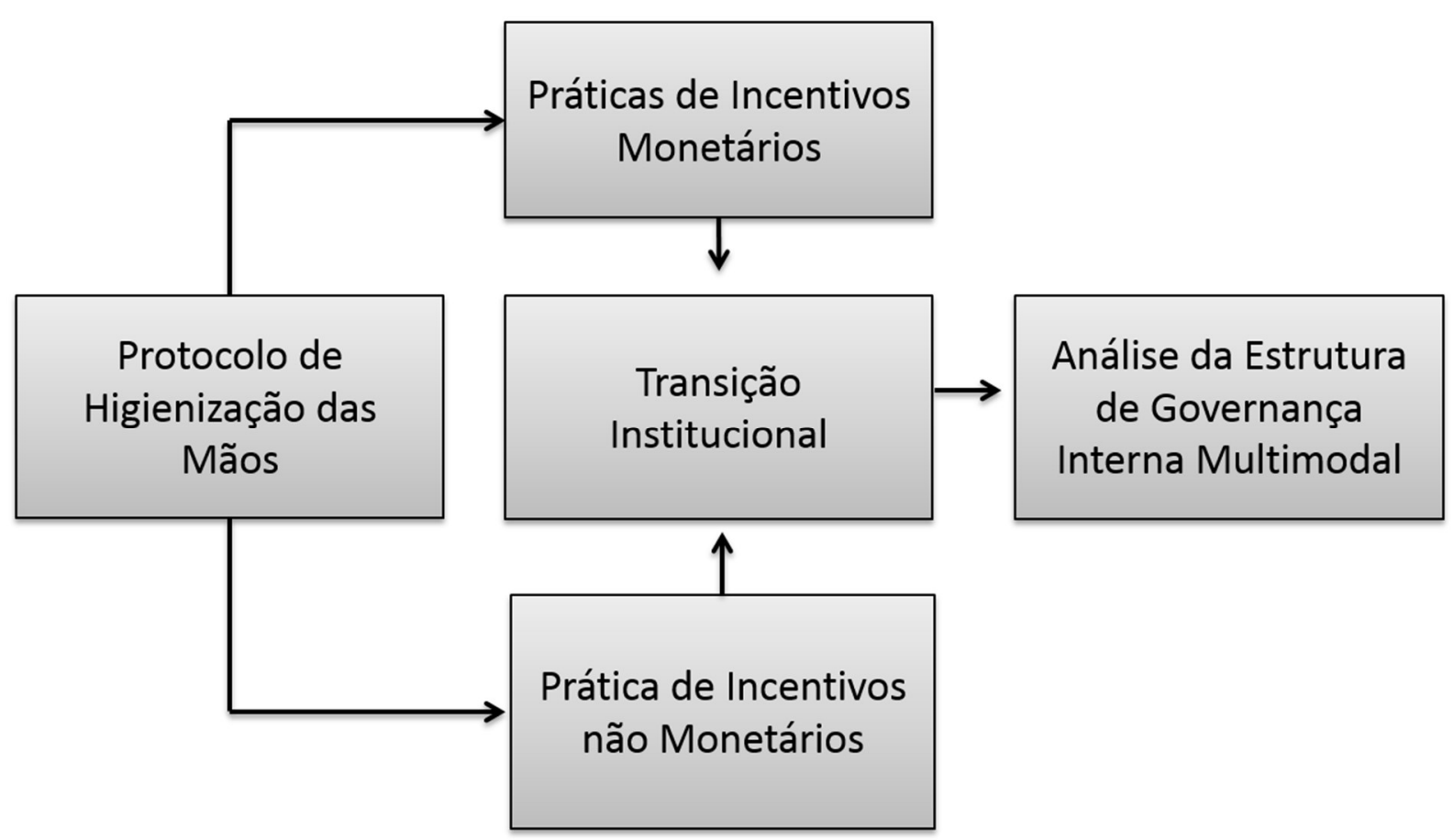

Ao desenvolver soluções para melhorar a motivação dos funcionários, todas as condições de incentivos devem ser consideradas pelos gestores na área da saúde na elaboração de políticas de recursos humanos (Tomo e Todisco, 2018). Nesse sentido, estamos propondo um modelo que integra a visão tanto da teoria econômica que são reportados por meio dos incentivos monetários e os nãos monetários advindos da psicologia organizacional. O nosso modelo sugere que combinar as formas de incentivos a motivação permite que as organizações desenvolvam um ambiente de comprometimento e aumentas as chances de sucesso em responder à mudança institucional (Lut, 2012). Baseado neste modelo conceitual, também propomos duas proposições.

A OMS/WHO reforça que é de responsabilidade de todos os profissionais que prestam cuidados de saúde, trabalhar em cooperação de forma a reduzir os riscos de infecção dos pacientes. Para isso, são recomendadas estratégias institucionais na busca do cumprimento das medidas relacionadas redução dos casos de infecção hospitalar; Estudos anteriores constataram que reuniões com apresentação de relatório de infecção e feedback mensal a equipe, foram fatores motivadores na diminuição dos casos de infecção (WHO, 2011). 
No ambiente hospitalar, os gestores devem criar um ambiente voltado para compartilhamento e aprendizado, isso auxilia na internalização dos objetivos organizacionais, com equilíbrio nos trabalhos de promoção (expressar uma observação) e investigação (escutar os funcionários e suas justificativas das ações). Para isso, é preciso criar uma cultura orientada para o aprendizado oferecendo feedback direcionado os para o aprendizado, com foco na resolução de problemas, além de adotar uma orientação sistêmica alinhando e construindo cuidadosamente os sistemas e processos de apoio contínuo, aos profissionais de saúde que lidam diretamente com paciente (Singer e Clark, 2011; Singer e Vogus, 2013).

A motivação pró-social pode ser alcançada por meio da clareza e desenho das tarefas, além do feedback da atividade realizada. O projeto organizacional pode criar um trabalho que aumenta a confiança dos funcionários e fortalece o interesse e o orgulho pelo mesmo. O feedback sobre a execução da tarefa, nesse caso, de maneira clara sobre os níveis de desempenho também poderá aumentar o sentimento de competência e capacitá-los em suas rotinas diária (Gagné e Deci, 2005; Ryan e Deci, 2000; Weibel et al., 2010).

Por extensão, a higienização das mãos pode ser considerada uma atividade que exige a ação conjunta entre os indivíduos (pró-social). Isto é, é impossível identificar como a ação individual contribui para a infecção de pacientes. Em outras palavras, é muito difícil saber quem não higienizou as mãos de forma correta. Por essa razão, a cooperação entre os indivíduos é fundamental.

As motivações não são estáveis. Indivíduos podem demandar incentivos de diferentes naturezas, inclusive a financeira, não estando limitado a ela. É importante, que os gestores, ao longo do tempo, ofereçam incentivos de compensação, com base em uma avaliação do trabalho das atividades desenvolvida pelo funcionário, levando em conta a sua contribuição para o desempenho da meta alcançada. Essa medida reforça a reciprocidade com a empresa como um todo (Fosgaard, e Foss, 2013; Steg et al., 2016). Desta forma, gestores podem usar diferentes lógicas ou modos de estrutura de governança (mercado, comunitária) no intuito de obter os comportamentos esperados.

Como descrito em Grandori e Furnari, $(2008,2010)$, as firmas podem adotar diferentes estratégias para gerenciar a sua produção interna, podendo combinar elementos das quatro formas de mecanismos de governança as de mercado, burocrático, comunitário e democrático. Essas formas de combinação são denominadas 
pelos autores de forma multimodal, ou seja, será adotado diferentes práticas de incentivos relacionada aos mecanismos de governança.

Já a forma unimodal, é compreendida por apenas uma das categorias dos mecanismos de governança. Como citado por Grandori e Furnari, (2008, 2010), às formas unimodal de elementos organizacionais mercado são um conjunto de mecanismos compostos por pagamento por desempenho individual e pagamento por performance da equipe.

Proposição 1: No processo de mudança institucional os gestores podem utilizar práticas de incentivos de forma unimodal ou multimodal de práticas de incentivos dos mecanismos de governança.

Em Grandori e Furnari $(2008,2010)$ são apresentados pressupostos em que as combinações entre os tipos de práticas de incentivos podem ser eficientes. Elas representam não a falta de coerência da estratégia organizacionais das empresas, mas sim a heterogeneidade entre os mecanismos de governança que podem levar a uma combinação que resulte no desempenho almejado pela empresa, organização em análise. Essas combinações ocorrem devido à complementaridade das abordagens configuracionais que combinam uma ampla forma de atributos organizacionais.

O critério de abordagem do design é complementar, pois considera como fator importante o ajuste sistêmico entendido como a interação multivariada de características estruturais e múltiplo contexto de variáveis que afetam o desempenho das firmas. Entretanto, ressalta-se que, apesar das contribuições teóricas, tal abordagem não consegue explicar e predizer quais práticas organizacionais seriam complementares a outras.

Tendo em vista a mudança institucional (RDC-36 - Protocolo de Higienização das Mãos), nós sugerimos que os gestores fazem uso de diferentes mecanismos de governança.

Proposição 2: O processo de mudança institucional (RDC-36 - Protocolo de Higienização das Mãos) levou os gestores a utilizarem as práticas de incentivos de forma multimodal e com mais frequência no processo adequação da mudança de comportamento em suas equipes.

Em outros estudos, cujo objetivo foi identificar os fatores associados a prevenção da infecção hospitalar (Pires et al., 2017; Render et al., 2011) demonstraram que para melhorar a conformidade dos padrões de higiene das mãos, a combinação entre as iniciativas do programa de segurança do paciente, com programas de trei- 
namento, melhora da comunicação, incentivo ao trabalho em equipe e feedback dos casos de infecção aos liderados, proporcionaram a redução considerável dos casos nos hospitais analisados (Render et al., 2011; Who, 2016).

Ao desenvolver soluções para melhorar a motivação dos funcionários, todas as condições de incentivos devem ser consideradas pelos gestores na área da saúde na elaboração de políticas de recursos humanos (Tomo e Todisco, 2018). Nesse sentido, estamos propondo um modelo que integra a visão tanto da Teoria Econômica que são reportados por meio dos incentivos monetários e os nãos monetários advindos da Psicologia Organizacional. De fato, combinar as formas de incentivos a motivação permite que as organizações desenvolvam um ambiente pensando nos funcionários, criando uma atmosfera de envolvimento, combinando o bem estar e comprometimento (Lut, 2012). 


\section{PROCEDIMENTOS METODOLÓGICOS}

Neste capítulo, discutiremos a escolha da abordagem metodológica (pesquisa qualitativa, por meio de estudos de casos) e os procedimentos metodológicos. Em seguida, vamos apresentar uma breve descrição das organizações escolhidas para esse estudo.

\subsection{Definição da abordagem metodológica}

Devido à natureza da pergunta de pesquisa que orienta este estudo - Como as organizações gerenciam as práticas de incentivos no processo de mudança institucional? - , a pesquisa qualitativa é mais apropriada (Eisenhardt, 1989). As pesquisas qualitativas têm por objetivo analisar os dados em forma de palavra, que são um tipo de linguagem na forma de texto (Miles, Huberman, e Saldana, 2014). Essa abordagem qualitativa ofereceu uma oportunidade de exploração de dados e na descoberta de resultados com maior riqueza e mais próximo da realidade que se objetivava a compreender (Jick, 1979; Miles et al., 2014). Além disso, usando estudos de casos abre espaços para possibilidades dos resultados contribuírem na geração de novas teorias (Jick, 1979; Eisenhardt, 1989; Miles et al., 2014).

O método do estudo de caso é utilizado quando as fronteiras entre um fenômeno e contexto não são claras e quando os pesquisadores recorrem múltiplas fontes de evidência (Yin, 2014). O método de estudo de caso pode compreender em um único caso ou em múltiplos e são utilizados como estratégias de criação de construtos teóricos, proposições e teorias a partir de evidências empíricas (Eisenhardt e Graebner, 2007).

Seguindo as orientações de Eisenhardt (1989), a escolha metodológica por pesquisa de natureza qualitativa via estudos de casos implicou que a amostra de casos não aleatória e proposital baseada em teoria. Isso também implicou que a seleção de casos foi de acordo com o potencial de representação e manifestação dos construtos teóricos desenvolvidos na pesquisa bibliográfica (Patton, 1990; Patton, 2002). O principal objetivo da amostragem proposital foi o de selecionar casos ricos em informação, cujo estudo visasse iluminar as questões propostas na pesquisa em análise. 
Também seguimos as orientações de Yin para uma pesquisa via estudos de casos. O estudo de caso deve ser compreendido como uma estratégia de pesquisa que tem por finalidade desenvolver o funcionamento de determinado fenômeno inserido em dado contexto, através da análise de um ou mais caso (Eisenhardt, 1989). De acordo com Yin, (2014), a elaboração de estudo de caso ocorre em três fases:

\footnotetext{
i. a seleção do caso e dos procedimentos da coleta de dados;

ii. condução do estudo de caso;

iii. a análise dos dados obtidos à luz da teoria utilizada.
}

Em relação à coleta de dados, (Yin et al., 2011), foi estabelecido um protocolo de pesquisa. Tal protocolo incluiu os seguintes passos:

\footnotetext{
i. Realização de uma análise do setor a partir da bibliografia disponível;

ii. Construção de instrumento de pesquisa junto ao setor de recursos humanos dos hospitais, a luz das teorias utilizadas (os questionários encontram-se em Anexo);

iii. Pré-teste do questionário com os produtores para validação;

iv. Aplicação dos questionários e roteiros de entrevistas.
}

Destacaram como as principais fontes de evidência de um estudo de caso, foram às entrevistas, os arquivos, os documentos, a observação de artefatos físicos. Nesse estudo, em diferentes períodos de desenvolvimento dos casos, os principais instrumentos utilizados na coleta de dados, alinhados com a proposta do estudo de caso, foram observação, entrevista exploratória e com questionários semiestruturados (em linha com Miles et al., 2014; Patton, 2002). Na próxima seção, apresentaremos, em maiores detalhes, o processo de seleção dos casos.

\subsection{Seleção dos Casos e Características dos Hospitais}

Seguindo a orientação de Eisenhardt (1989) e Yin (2014), adotou-se um processo bem definido de seleção. De forma geral, buscaram-se utilizar casos que seriam fontes ricas de informação, tais características clássica de pesquisa processuais que levam o tempo como uma variável importante no contexto da análise (Langley, 1999, 2009). Para selecionar os casos desta pesquisa, podemos destacar a utilização de dois critérios: (1) hospitais que adotaram o Protocolo de Higienização das Mãos descrito na RDC-36 no momento da entrevista; e (2) hospitais que utilizaram 
práticas de incentivos no processo de adequação do comportamento descrito no Protocolo de Higienização das Mãos. Lembrando que escolhemos a área de saúde por ser um setor regulado, o que nos permite avaliar com mais clareza o fenômeno explorado nesta tese: mudança institucional (RDC-36) e a mudança organizacional em resposta a essa à mudança institucional.

A realização da parte empírica da pesquisa compreendeu dois hospitais localizados na cidade de Ponte Nova, situada na Zona da Mata do estado de Minas Gerais, Brasil. Um hospital filantrópico que presta serviços há cinquenta anos na região, administrado pela prefeitura municipal, com repasses financeiros do governo estadual e federal. Note-se que hospitais filantrópicos, são entidades particulares sem fins lucrativos que, destinam parte de seus rendimentos para a assistência gratuita a pacientes (Ministério da Saúde, 1985).

O segundo hospital investigado, uma instituição beneficente, que detém recursos próprios oriundos da prestação de serviços particulares, como também da parceria com o sistema público brasileiro de saúde, o Sistema Único de Saúde (SUS), e ainda, por meio de um plano próprio de seguro saúde. Os hospitais beneficentes são designados como de caráter particular e não lucrativo; possuem serviços voltados à assistência de grupos específicos e se mantêm por contribuições de associados ou usuários, embora também possam ter foco no lucro (Ministério da Saúde, 1985).

Ambos os hospitais apresentam características parecidas, tais como, o número de empregados, compreendendo cerca de 500 empregados cada hospital, e o mesmo número de leitos (120 em cada unidade hospitalar). Potencialmente, os dois hospitais tendem a ter baixa rotatividade no quadro de trabalhadores da área saúde do hospital. Esse aspecto é importante para ter acesso à informantes que vivenciaram distintos momentos: i. antes da mudança institucional; ii. durante a resposta à mudança; e iii. após a implantação.

Posteriormente, seguindo a lógica de saturação de Einsehardt (1989), decidimos desenvolver mais um caso em um hospital. Esse caso serviu para complementar a análise dos dados, além de oferecer informações ilustrativas extras dos constructos que emergiram nos dois primeiros casos.

\subsection{Amostra e Coleta dos Dados}


A coleta de dados consistiu em quatro etapas. Na primeira etapa, em 2016, foram realizadas entrevistas muito exploratórias com os gerentes de recursos humanos, diretores técnicos em ambos os hospitais. O objetivo dessas entrevistas foi entender a estrutura de governança dos hospitais, assim como a política de gerenciamento de pessoas e suas práticas de incentivos.

Com os protocolos de pesquisa mais bem desenvolvidos, posteriormente, foram entrevistados os gerentes e coordenadores responsáveis pelo Controle de Infecção Hospitalar (CCIH). Nas entrevistas foram abordadas questões relacionadas às medidas de prevenção das infecções hospitalares, assim como os processos de elaboração dos indicadores de infecção. Essa fase (primeira etapa) de exploração inicial permitiu refinar melhor os protocolos de pesquisa.

Posteriormente, já dotados de um instrumento de pesquisa mais robusto, foram entrevistados os médicos líderes clínicos, entre dezembro de 2016 a fevereiro de 2017. Nesse levantamento (segunda etapa), o objetivo das entrevistas foi o de identificar as práticas de incentivos organizacionais utilizadas no processo de adesão do Protocolo de Higienização das Mãos. Logo após, em 2017, foram realizadas algumas entrevistas complementares para complementar os dados coletados. Nessas foram entrevistadas os gerentes do $\mathrm{CClH}$, assim como a gerência de qualidade — que é encarregado de gerir os processos da instituição.

Em 2017, foram selecionados alguns médicos para serem entrevistados. A escolha dos médicos passou por alguns critérios. Para alcançar o resultado planejado, foram entrevistados somente médicos que ocupavam cargos de liderança desde operacionalização do protocolo de higiene divulgado da RDC-36/2013.

Os instrumentos de coleta de dados foram adaptados segundo a etapa da coleta de dados. Na primeira etapa, fase mais exploratória, foi utilizado questionário semiestruturado - organizado em questões abertas, referentes à percepção do médico sobre os investimentos em ativos (dispenser de álcool, pias para higienização, cartazes conscientizadores) que auxilia no processo de higienização das mãos e possíveis mudanças observadas entre os anos de 2013 a 2017. Nas duas etapas posteriores, no questionário, existiam questões divididas em quatro blocos, com as práticas de incentivos operacionalizadas de forma dicotômica.

A quarta e última etapa envolveu mais duas outras entrevistas, após análise e codificação dos dados das entrevistas. Tais entrevistas ocorreram em 2019 e envolveram os gestores de ambos os hospitais (mais detalhes no próximo tópico). 
Nas quatro etapas, foram entrevistados 33 empregados, que estiveram envolvidos nas estratégias de controle de infecção nos respectivos hospitais. (Ver Tabela 1 - Relação de Entrevistados nos Hospitais). Vale ressaltar que o projeto de pesquisa foi aprovado pelo Comitê de Ética em Pesquisa - CEPE - Prevent Senior Parecer 64841317.3.0000.8114, seguindo, portanto, os preceitos éticos da lei 466/12 do Conselho Nacional de Saúde.

Tabela 1 - Relação dos respondentes na primeira etapa de entrevistas.

\begin{tabular}{|c|c|c|c|c|c|}
\hline \multicolumn{3}{|c|}{$\begin{array}{l}\text { Hospital Público - Nossa Sr. }{ }^{\text {a das }} \\
\text { Dores }\end{array}$} & \multicolumn{3}{|c|}{$\begin{array}{c}\text { Hospital Privado - Arnaldo } \\
\text { Gavazza Filho }\end{array}$} \\
\hline $\begin{array}{l}\text { Entrevistado } \\
\qquad s\end{array}$ & $\begin{array}{c}N .^{\circ} \text { de } \\
\text { Respondente } \\
s\end{array}$ & $\begin{array}{c}\text { Duração } \\
\text { das } \\
\text { Entrevista } \\
s\end{array}$ & $\begin{array}{c}\text { Entrevistado } \\
s\end{array}$ & $\begin{array}{c}N .^{\circ} d e \\
\text { Respondente } \\
s\end{array}$ & $\begin{array}{c}\text { Duração } \\
\text { das } \\
\text { Entrevista } \\
\text { s }\end{array}$ \\
\hline $\begin{array}{l}\text { Diretor } \\
\text { Executivo }\end{array}$ & 2 & $30^{\prime}$ & $\begin{array}{l}\text { Diretor } \\
\text { Executivo }\end{array}$ & 2 & $30^{\prime}$ \\
\hline $\begin{array}{l}\text { Diretor } \\
\text { Técnico }\end{array}$ & 1 & 30 & $\begin{array}{l}\text { Diretor } \\
\text { Técnico }\end{array}$ & 1 & $30^{\prime}$ \\
\hline $\begin{array}{l}\text { Coordenado } \\
\text { r de } \\
\text { Infecção }\end{array}$ & 1 & 2'30" & $\begin{array}{l}\text { Coordenado } \\
\text { r de } \\
\text { Infecção }\end{array}$ & 1 & 2'10" \\
\hline $\begin{array}{l}\text { Gerente de } \\
\text { Infecção }\end{array}$ & 1 & $30^{\prime}$ & $\begin{array}{l}\text { Gerente de } \\
\text { Infecção }\end{array}$ & 1 & $30^{\prime}$ \\
\hline $\begin{array}{l}\text { Médicos em } \\
\text { Cargos de } \\
\text { Liderança }\end{array}$ & 28 & 30 ' cada & $\begin{array}{l}\text { Médicos em } \\
\text { Cargos de } \\
\text { Liderança }\end{array}$ & 22 & $34^{\prime}$ cada \\
\hline
\end{tabular}

\subsection{Coleta Complementar Para llustrar os Novos Constructos}

A partir das entrevistas e dos resultados obtidos nas primeiras etapas da coleta de dados da pesquisa, foi constatado a heterogeneidades na percepção dos funcionários no que tange à utilização das práticas de incentivos, no processo de cons- 
cientização para higienização das mãos. Sendo assim, com base nos achados da coleta de dados empíricos, propomos novos construtos (sinalização, tradução, realce, direcionalidade, coerência/consistência) que ajudam a explicar como as organizações gerenciam as práticas de incentivos no processo de mudança institucional.

O objetivo desta quarta etapa da pesquisa teve o objetivo de refinar os novos construtos nas empresas pesquisadas (Hospital Arnaldo Gavazza e Hospital Nossa Senhora das Dores). Além disso, seguindo as recomendações da Eisenhardt (1989) para estudos de casos múltiplos e para saturação, decidimos realizar um novo estudo de caso, no hospital Ibiapaba localizado na cidade de Barbacena em Minas Gerais. A escolha do hospital Ibiapaba ocorreu devido o hospital ter características (e.g., número de leitos, número de funcionários, quantidade de pacientes atendidos) entre outros aspectos relacionados aos dois hospitais analisados. $\mathrm{Na}$ tabela 2, são apresentados os dados dos respondentes dos três hospitais, assim como a relação dos gestores abordados e duração das entrevistas. 
Tabela 2 - Relação dos respondentes na segunda etapa de entrevistas.

\begin{tabular}{|c|c|c|c|c|c|}
\hline \multicolumn{2}{|c|}{$\begin{array}{c}\text { Hospital N. Sr. }{ }^{a} \text { das } \\
\text { Dores }\end{array}$} & \multicolumn{2}{|c|}{$\begin{array}{c}\text { Hospital Arnaldo } \\
\text { Gavazza Filho }\end{array}$} & \multicolumn{2}{|c|}{ Hospital Ibiapaba } \\
\hline Entrevistados & $\begin{array}{c}\text { Duração } \\
\text { das } \\
\text { Entrevistas }\end{array}$ & Entrevistados & $\begin{array}{c}\text { Duração } \\
\text { das } \\
\text { Entrevistas }\end{array}$ & Entrevistados & $\begin{array}{c}\text { Duração } \\
\text { das } \\
\text { Entrevistas }\end{array}$ \\
\hline $\begin{array}{l}\text { Gerente de } \\
\text { Qualidade - } \\
\text { Segurança } \\
\text { do Paciente }\end{array}$ & $55^{\prime}$ & $\begin{array}{l}\text { Gerente de } \\
\text { Qualidade - } \\
\text { Segurança } \\
\text { do Paciente }\end{array}$ & 30 & $\begin{array}{l}\text { Gerente de } \\
\text { Qualidade - } \\
\text { Segurança } \\
\text { do Paciente }\end{array}$ & 30 \\
\hline $\begin{array}{l}\text { Enfermeira } \\
\text { Responsável } \\
\text { pelo Controle } \\
\text { de Infecção }\end{array}$ & $50^{\prime}$ & $\begin{array}{l}\text { Enfermeira } \\
\text { Responsável } \\
\text { pelo Controle } \\
\text { de Infecção }\end{array}$ & 30 & $\begin{array}{l}\text { Enfermeira } \\
\text { Responsável } \\
\text { pelo Controle } \\
\text { de Infecção }\end{array}$ & $35^{\prime}$ \\
\hline-- & -- & $\begin{array}{l}\text { Médico } \\
\text { Responsável } \\
\text { pelo Controle } \\
\text { de Infecção }\end{array}$ & $45^{\prime}$ & $\begin{array}{l}\text { Médico } \\
\text { Responsável } \\
\text { pelo Controle } \\
\text { de Infecção }\end{array}$ & $40^{\prime}$ \\
\hline
\end{tabular}

\subsection{Operacionalizando o modelo conceitual}

Um aspecto importante deste trabalho foi operacionalizar o modelo conceitual. Apesar de não ser muito comum em pesquisas qualitativas, procuramos deixar mais claro em nossos procedimentos e instrumentos de pesquisa, quais eram as variáveis independentes e a dependente. Essa relação inicial entre variáveis contribuiu para dar mais clareza na análise dos dados.

\subsubsection{Variável Independente: Mecanismos de Governança}

Os mecanismos de governança serão mensurados com base na abordagem proposta por (Furnari e Grandori, 2013; Grandori e Furnari, 2008; Grandori, 2017) (para mais informações, ver o instrumento de coleta de dados apresentado no Apêndice 1). 
Para cada uma das estruturas internas de governança propostas (monetárias, burocráticas, comunitárias e democráticas), foram identificadas quatro práticas organizacionais, para o referido estudo, desmembramos a estrutura de governança comunitária como apresentado no Quadro 2 - Estruturas de Governança Interna e Suas Variáveis.

Quadro 2 - Mudança Institucional e Estrutura de Governança: como as organizações gerenciam as práticas de incentivo

\begin{tabular}{|c|c|c|}
\hline $\begin{array}{l}\text { Estruturas de } \\
\text { Governança }\end{array}$ & \multicolumn{2}{|c|}{ Práticas de Incentivos em Cada Tipo de Estrutura } \\
\hline $\begin{array}{l}\text { Mercado: in- } \\
\text { centivos } \\
\text { Monetários }\end{array}$ & \multicolumn{2}{|c|}{$\begin{array}{l}\text { \#1.1. Pagamento pelo desempenho individual } \\
\text { \#1.2. Pagamento pelo desempenho da equipe } \\
\text { \#1.3. Pagamento pelo desempenho da firma }\end{array}$} \\
\hline Burocrática & \multicolumn{2}{|c|}{$\begin{array}{l}\text { \#2.1. Plano de carreira } \\
\text { \#2.2. Promoção do Funcionário } \\
\text { \#2.3. Alinhamento ao Planejamento Estratégico } \\
\text { \#2.4. Programa e processo de controle da qualidade das ativida- } \\
\text { des e tarefas } \\
\text { \#2.5. Sistema de avaliação de desempenho - feedback } \\
\text { \# 2.6. Programa e processo de controle da qualidade }\end{array}$} \\
\hline \multirow{3}{*}{ Comunitária } & $\begin{array}{l}\text { Compartilhamento de } \\
\text { informações e valores }\end{array}$ & $\begin{array}{l}\text { 2.7. Salas compartilhadas } \\
\text { 2.8.Área de socialização } \\
\text { 2.9. Frequência de confraternização }\end{array}$ \\
\hline & Canal de comunicação & $\begin{array}{l}\text { \#3.0. Mural informativo, jornal, rádio } \\
\# 3.1 \text {. Funcionários colocam suges- } \\
\text { tões de melhorias ou novas ideias } \\
\text { \#3.2. Realiza curso profissionalizantes } \\
\text { de atualização ou assisti palestras } \\
\text { promovidas pelo hospital } \\
\text { \#3.3. Reuniões semanais com os pro- } \\
\text { fissionais de nível superior }\end{array}$ \\
\hline & Trabalho em equipe & $\begin{array}{l}\text { \# 3.4. Reuniões mensais com os pro- } \\
\text { fissionais de nível superior } \\
\text { \# 3.5. Reuniões semanais com a ge- } \\
\text { rência } \\
\text { \#3.0. Possui mural, e-mail corporativo, } \\
\text { outros canais para comunicação com } \\
\text { os funcionários. } \\
\text { \# 3.6. Equipe participa em treinamen- } \\
\text { tos e dinâmica com os grupos }\end{array}$ \\
\hline
\end{tabular}




\begin{tabular}{|l|l|l|}
\hline & $\begin{array}{l}\text { Compartilhamento da } \\
\text { decisão. }\end{array}$ & $\begin{array}{l}\# \text { 3.7. Realiza planejamento com a } \\
\text { equipe para o ano seguinte } \\
\text { \# 3.8 Mudanças nas regras da Anvisa, } \\
\text { o senhor aceita sugestões dos funcio- } \\
\text { nários }\end{array}$ \\
\hline Democrática & $\begin{array}{l}\text { \#3.9. Incentiva os funcionários a participarem de frentes de traba- } \\
\text { Iho, comissão e ou representação de assuntos do hospital } \\
\# 3.10 . \text { Nas decisões importantes na sua equipe é o Sr. (a) quem } \\
\text { decide (voz ao funcionário) } \\
\# 3.11 . \text { A equipe conhece os procedimentos gerencias e proces- } \\
\text { suais do hospital como um todo } \\
\# 3.12 . \text { Estimula o compartilhamento de aprendizado entre os } \\
\text { membros da equipe } \\
\# 3.13 . \text { Permite que seus funcionários exerçam atividades além do } \\
\text { que está previsto } \\
\# 3.14 . \text { Participa com os seus funcionários dos eventos, campa- } \\
\text { nhas de prevenção para infecção do hospital. }\end{array}$ \\
\hline
\end{tabular}

Fonte: Grandori, 2017; Grandori e Furnari, 2008. (Adaptado)

Foram utilizadas as questões que mensuram as práticas predominantes em cada tipo de mecanismo de governança, a partir de variáveis dummy, de forma a compor a operacionalização dos mecanismos de governança nestes hospitais. Cada governança é composta por quatro práticas, conforme descrito no Quadro 2, e a presença de cada prática medida entre 0-1 (0-Não; 1-Sim). Derivando deste resultado, será obtida a intensidade dos mecanismos: mercado, burocrático, comunitário e democrático. Estas questões serão agregadas para a composição de cada grupo de mecanismos de governança e, por fim, comparadas entre as equipes para confrontar as proposições do trabalho.

\subsubsection{Variável Dependente: Desempenho}

As organizações da área da saúde, principalmente os hospitais não tem somente seus desempenho medido por indicadores financeiros e econômicos "Uma boa margem de superávit operacional não pode compensar a mediocridade no atendimento aos pacientes" Porter e Teisberg (2007, p. 144). Seguindo a visão dos autores, outros aspectos devem ser considerados, como os indicadores de desempenho nessas organizações, como por exemplo: indicadores de estrutura, indicadores de 
produção e, indicadores hospitalares de qualidade entre outros (Chiareto, Corrêa, e Cunha, 2018).

Dentro desta perspectiva, utilizamos como variável de desempenho o indicador de infecção nosocomial, descrito nos manuais da Anvisa e são utilizados como ferramenta de apoio na gestão da qualidade das nos hospitais. Este indicador mensura os padrões de comportamentos no que diz respeito a higienização das mãos. Como citado em Coelho, Arruda e Simões (2011), foi constatado que grande percentual de infecções nosocomiais pode ser evitada pelos simples fato dos profissionais higienizarem as mãos de forma correta. A contaminação pode ser adquirida pelo contato entre pessoas ou materiais colonizados ou infectados, que poderia ser eficazmente eliminados através de uma adequada lavagem de mãos, deixando de ser condição básica para a sua disseminação e contaminação de pacientes saudáveis (Brasil, 1998).

O desenvolvimento deste indicador deverá seguir alguns critérios e exigências da legislação brasileira em vigor. A falta de comprometimento das organizações hospitalares em disponibilizar os dados de forma clara, objetiva e honesta pode afetar o repasse de recursos dos planos e saúde como também os do sistema público de saúde (SUS).

Seguindo os manuais da Anvisa a formação desse indicador deverá considerar os seguintes critérios casos de infecção adquirida, inclusive após internação do paciente (setenta e duas horas após a alta) e que se manifeste durante sua permanência no hospital ou mesmo após a alta, uma vez que possa ser relacionada com a hospitalização. O indicador nosocomial mensura os procedimentos a partir de pacientes que deram entrada no pronto atendimento, pacientes que foram submetidos a cirurgias limpas e cirurgias potencialmente contaminadas (Brasil, 2016).

De forma a atender os objetivos dessa pesquisa, foram considerados os indicadores de cirurgia limpa e potencialmente limpa, cujos índices de contaminação remetem ao indicador nosocomial em ambos os hospitais. Ressalta-se que, a pesquisa exploratória realizada para o planejamento da coleta de dados apontou que a infecção nosocomial é considerada de difícil mensuração quanto ao agente contaminante, portanto, tornando inviável medir o percentual individual de cada profissional envolvido nos procedimentos hospitalares. Seguindo essa realidade, os hospitais têm criado incentivos para indução do comportamento na a redução dos casos de infecções nosocomiais. 
Para conseguir desenvolver bom desempenho nos indicadores de infecção nosocomial, a estratégia será a de focar na relação entre práticas de incentivos às equipes de trabalho e a redução do número de pacientes acometidos por infecção nosocomial. Considera-se que um dos procedimentos de prevenção desse tipo de infecção, seria a adoção da prática correta da higienização das mãos, que é um procedimento simples e de baixo custo, além de ser considerado o fator determinante na diminuição das infecções nosocomiais. No entanto, para que esses procedimentos de higienização tenham efeito positivo, acredita-se necessário que os hospitais criem uma cultura de conscientização da importância da prática da higienização das mãos.

Nestas formas de análise do desempenho, dada à dificuldade de mensurar a contribuição marginal de cada empregado, o resultado alcançado passa a ser a contribuição total dos agentes da equipe, enfatizando que engloba todas as ações de cada agente (incluindo monitoramento da equipe de produção) e todos os efeitos destas ações (tanto a longo quanto em curto prazo).

\subsection{Abordagem de Pesquisa Processual}

Como o foco dessa investigação está na transição das estruturas de governança e o controle de infecção, este trabalho se inspirou na abordagem de estudo de processo (Langley, 1999). Estudos de processos tem o objetivo o de compreender como um determinado evento evolui com o tempo e a maneira como eles evoluem. Segundo Langley (1999), a pesquisa processual tem por objetivo explicar a sequência de eventos e ações que levam a um resultado, evidenciando a ordem temporal e os padrões desses eventos e ações. Pesquisas do tipo processual são adequadas para lidar com questões sobre como e por que as coisas surgem, desenvolvem crescem ou terminam ao longo do tempo (Langley, 1999; Langley et al., 2013). Com isso, as pesquisas processuais se concentram em analisar empiricamente a evolução do fenômeno na forma de processo, baseando se em teorias que adquirem progressões temporais como atividades de compreensão (Langley et al., 2013). No presente estudo, procuramos levantar eventos antes da mudança, a resposta organizacional à mudança (e.g., a implantação de novas práticas de incentivo), e posteriormente, para avaliarmos a evolução. 
Neste capítulo, serão apresentados os resultados da presente tese. Inicialmente, foram descritos os dois estudos de caso realizados nos hospitais, com foco na narrativa da utilização das práticas de incentivo no contexto da mudança institucional. Nessa mesma seção, são apresentadas informações sobre os órgãos governamentais e agências de saúde que apoiam a difusão da RDC-36, e a tabulação das porcentagens da utilização de cada prática pelos gestores, separada por hospital e estrutura de governança. Por fim apresentamos a discussão dos novos construtos que surgiram nos resultados da pesquisa.

\subsection{Principais Práticas de Incentivos Sugeridos por Órgãos Governamentais e Agências Para as Estratégias de Adesão das Unidades de Saúde à Higienização das Mãos}

A estratégia de promoção dos casos de infecção no Brasil foi uma ação conjunta entre os diferentes órgãos dos governos (federais; estaduais e municipal) que teve o objetivo de ampliar o hábito de higienização das mãos e controle de infecção nos Estados e municípios. Em uma análise exploratória e documental, foram identificadas que os hospitais possuíam uma baixa adesão aos protocolos de higienização das mãos, não havendo indicadores que medissem os casos nas unidades de saúde, nesse sentido as ações de conscientização passaram a ser ter uma agenda de prevenção nas unidades de saúde.

No contexto do Estado de Minas Gerais, à secretária estadual de saúde teve um importante papel na disseminação das campanhas de conscientização do uso do protocolo. Seguindo esse objetivo, a secretaria de saúde passou a utilizar as recomendações descritas nos manuais da Organização Pan-Americana da Saúde (OPAS) e OMSMHO, focadas no tema "Cuidado Limpo é Cuidado Mais Seguro" (Clean Care is Safer Care), estimulando as organizações de saúde a considerarem a importância da higienização das mãos como prioridade institucional. A ação estratégica do programa abrange os seguintes aspectos: desenvolvimento de planos de ação; criação de campanhas que instrua esses profissionais a higienizarem as mãos de forma correta; fixação de lembretes visuais em pontos estratégicos; e monitoramento das práticas de higienização, por meio de indicadores visíveis de infecção 
hospitalar entre outras ações pertinentes a realidade da unidade de saúde, levando em consideração, aspectos culturais e sociais.

Nos três primeiros anos, foi constatada através de auditorias nas unidades de saúde, a baixa aderência aos protocolos da RDC-36, como consequência desses resultados, em 2016, a Anvisa, com o apoio da OMSMHO, estimulou a melhoria contínua das práticas de higiene das mãos, especialmente nas unidades cirúrgicas, visando à prevenção das infecções acometidas no ambiente hospitalar, focando sempre a segurança do paciente (Anvisa, 2016).

Outra ação estratégica importante a ser considerada foi a escolha de uma data como celebração do dia da higienização das mãos. Com isso, com base nas inciativas da OMS/WHO, passou a considerar o dia 05 de maio, como o Dia Mundial de Higienização das Mãos, isso reforça a necessidade da higienização nos serviços de saúde, pelos profissionais, especialmente à beira do leito do paciente, conforme indicado nos trabalhos de "Cuidado Limpo é Cuidado Mais Seguro" (Clean Care is Safer Care) (OMS/WHO, 2014).

Seguindo as diretrizes da OMS/WHO, no Brasil no mês de maio são desenvolvidas ações que sugerem a realização de ações de conscientização e informação (palestras, treinamento, dinâmicas de grupo) para a prevenção dos casos de infecção com foco no paciente.

Nesse trabalho, através de uma survey, identificamos que nessas campanhas são discutidas as questões da infecção dos pacientes e, são apresentados projeções dos índices global das organizações estudadas. De acordo com os gestores entrevistados, são recompensadas as equipes que tiveram um baixo índice no controle do indicador nosocomial. Essas equipes recebem prêmios do tipo a equipes destaque do mês; tal prática reforça os aspectos positivos dos resultados alcançados.

Por estimulo da secretaria estadual e municipal, no decorrer do ano, algumas medidas são tomadas para que a higienização das mãos ocorra de forma contínua e consciente nas unidades de saúde do Estado em ambos os hospitais. Uma estratégia reconhecimento dos esforços dos funcionários são as premiações no final do ano, os gestores divulgam os resultados das equipes que mantiveram uma média superior no resultado acumulado do ano. Inclusive, placas e certificados com menção honrosa são ofertados. 
A secretaria de saúde municipal oferece cursos de formação para os dois hospitais, que abordam temas higienização das mãos. As organizações enviam um representante para fazer o curso e, esse representante geralmente e do $\mathrm{CCIH}$, participa do curso, quando ele retorna ao hospital, ele repassa toda a informação e conhecimento adquirido através de cursos internos. Os cursos é uma parceria da Anvisa, que tem o objetivo prestigiar os hospitais que apresentam evidências de gestão do controle de infecção.

Cabe ressaltar que cada estado e município no Brasil vivem uma realidade diferente, seja econômica ou demográfica, sendo assim cada unidade de saúde terá seu tempo hábil para adequação das exigências e determinações descritas na regra. Caberá aos gestores estaduais e municipais desenvolverem políticas públicas que auxiliem esses gestores neste processo.

Nas próximas sessões serão detalhados como os gestores desenvolveram estratégias de gestão para conscientizar suas equipes no processo de mudança institucional. Serão demostradas os resultados e as porcentagens de cada prática utilizada no processo de mudança, contrastando os resultados antes e depois da mudança institucional — Protocolo de Higienização das Mãos, RDC-36.

\subsection{Descrevendo Como os Gestores Utilizaram Práticas de Incentivos na Transição de uma Regra Institucional}

Nessa seção, são apresentadas características dos estudos de caso nas organizações hospitalares analisadas nesta pesquisa. Começaremos abordando a (1) localização/contexto dos casos; posteriormente, discutiremos o (2) perfil demográfico dos hospitais; para, enfim, retratamos as (3) estruturas de governança interna, suas práticas organizacionais e suas transformações ao longo do tempo.

\subsection{Localização da Pesquisa}

Os hospitais estudados estão localizados no município mineiro de Ponte Nova, Minas Gerais, cidade com a população de 57390 habitantes. Ponte Nova faz parte do grupo das 37 cidades que têm entre 50 a 90 mil habitantes no estado de Minas Gerais. Essa cidade está localizada na macrorregião leste do Sul da Zona da Mata Mineira, formada por 17 municípios. A cidade presta serviços de saúde para 
toda região, incluindo outras cidades no raio de 100 km (SEMSA/Ponte Nova, 2019). Os dois hospitais estudados são considerados referência para a região onde se localiza Ponte Nova. Além dos dois hospitais, a cidade conta com 36 estabelecimentos de atenção à saúde conforme o Instituto de Brasileiro de Geografia Estatístico (IBGE, 2010).

Figura 3 - Mapa com a localização dos hospitais analisados nos estudos de casos da pesquisa

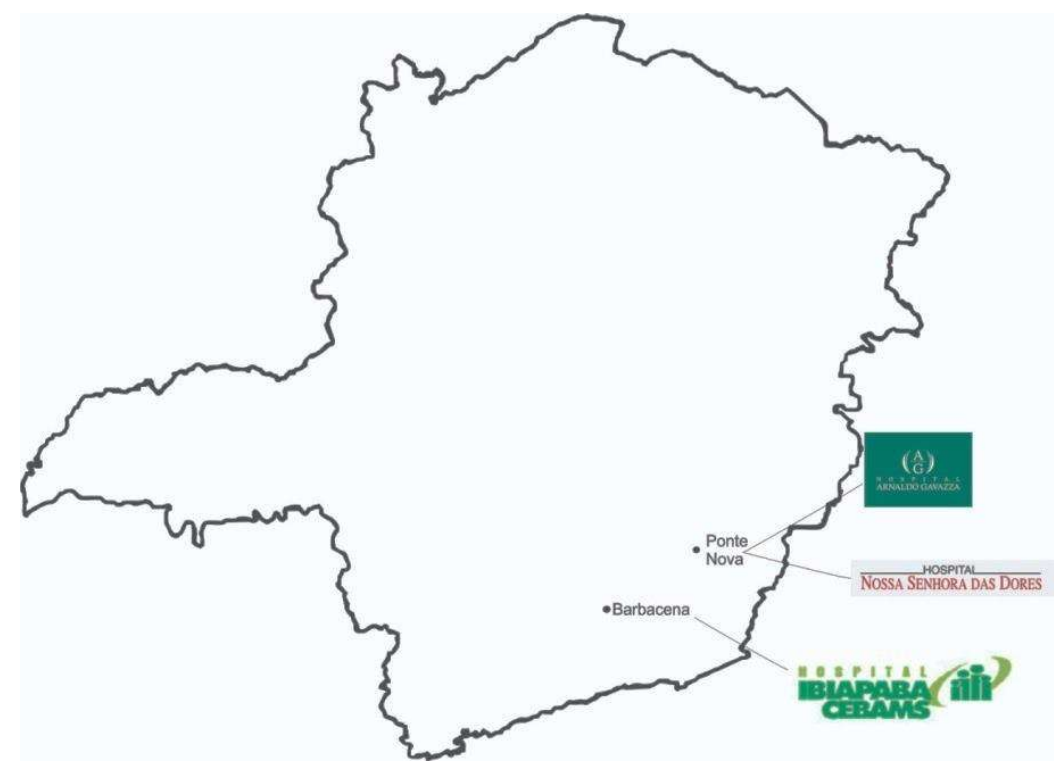

\subsection{Hospital Irmandade de Nossa Senhora das Dores}

\subsubsection{Breve Descrição do Hospital}

O Hospital Filantrópico Irmandade de Nossa Senhora das Dores, fundado no ano de 1873, oferece serviços de saúde a Ponte Nova e região. Atualmente, o hospital atende cerca de 60 mil pacientes por mês, sendo referência no tratamento do câncer, em hemodiálise e em partos. O hospital conta com 120 leitos; e noventa por cento dos pacientes são oriundos do SUS. São realizados, aproximadamente, 500 procedimentos cirúrgicos por mês.

\subsubsection{Apresentação da Estrutura Organizacional}


A estrutura organizacional do hospital é composta pela mesa diretora, que está dividida entre corpo clínico (médicos profissionais da saúde) e técnico (cargos administrativos); essa mesa é responsável por decidir as questões estratégicas da instituição (e.g., adequação das demandas do corpo clínico e administrativo). Tais questões estratégicas são implementadas, sob a coordenação de um administrador, que realiza os desdobramentos do planejamento estratégico. Os demais níveis são compostos por cargos de liderança médicas, tais como coordenadores e gerentes, além do corpo assistencial que é composto por equipes multidisciplinares (enfermeiros, enfermeiras, técnicos de enfermagem, instrumentadores, nutricionistas, assistente social e outros).

\subsubsection{Perfil Demográfico da Amostra de Entrevistados nos Hospitais}

Conforme mencionamos anteriormente, foram entrevistados 26 médicos e duas médicas que ocupavam cargos de liderança. A idade média desses médicos é de 45 anos, sendo todos com idade acima de 30 anos. O tempo médio de exercício da profissão média é de 19 anos, sendo o tempo médio no cargo é de 9 anos. Dos 28 médicos, 25 estudaram em faculdades privadas e 3 estudaram em faculdades

pública. E apenas três médicos realizaram cursos de gestão do tipo pós-graduação e Master Business Administration (MBA). Detalhes dos entrevistados estão descritos na tabela 03. 
Tabela 3 - Dados demográficos das equipes entrevistados.

\begin{tabular}{|c|c|c|c|c|c|}
\hline Especialidade & Idade & $\begin{array}{c}\text { Ano de } \\
\text { Formação }\end{array}$ & $\begin{array}{c}\text { Anos } \\
\text { Exercendo a } \\
\text { Profissão }\end{array}$ & $\begin{array}{l}\text { Instituição } \\
\text { de Ensino }\end{array}$ & $\begin{array}{c}\text { Realizou } \\
\text { Curso de } \\
\text { Gestão }\end{array}$ \\
\hline Anestesia & 36 & 2009 & 8 & Privada & Não \\
\hline Cardiologia & 57 & 1982 & 35 & Privada & Não \\
\hline Cardiologia & 41 & 2000 & 17 & Privada & Não \\
\hline Clínica Geral & 33 & 2012 & 5 & Privada & Não \\
\hline Clínica Geral & 68 & 1978 & 39 & Privada & Não \\
\hline Clínica Médica & 42 & 2007 & 10 & Privada & Não \\
\hline Coloproctologia & 32 & 2011 & 6 & Privada & Não \\
\hline Gastroenterologia & 40 & 2005 & 12 & Privada & Não \\
\hline Ginecologia & 67 & 1975 & 42 & Privada & Não \\
\hline Ginecologia & 32 & 2010 & 7 & Privada & Não \\
\hline Mastologia & 47 & 1998 & 19 & Privada & Não \\
\hline Nefrologia & 52 & 1991 & 26 & Privada & Não \\
\hline Nefrologia & 51 & 1992 & 25 & Privada & Não \\
\hline Nefrologia & 53 & 1989 & 28 & Privada & Não \\
\hline Nefrologia & 53 & 1987 & 30 & Pública & Sim \\
\hline Oncologista & 36 & 2005 & 12 & Privada & Sim \\
\hline Ortopedia & 35 & 2012 & 5 & Privada & Não \\
\hline Ortopedia & 72 & 1972 & 45 & Pública & Não \\
\hline Pediatria & 44 & 1998 & 19 & Privada & Não \\
\hline Pediatria & 62 & 1989 & 28 & Privada & Não \\
\hline Pediatria & 53 & 1992 & 25 & Pública & Não \\
\hline Proctologia & 32 & 2012 & 5 & Privada & Não \\
\hline $\begin{array}{l}\text { Terapia Intensiva } \\
(\mathrm{CTI})\end{array}$ & 50 & 1994 & 23 & Privada & Sim \\
\hline $\begin{array}{l}\text { Terapia Intensiva } \\
\text { (CTI) }\end{array}$ & 40 & 2000 & 17 & Privada & Não \\
\hline $\begin{array}{l}\text { Terapia Intensiva } \\
\text { (CTI) }\end{array}$ & 35 & 2010 & 7 & Privada & Não \\
\hline
\end{tabular}




\begin{tabular}{llllll}
\hline Urologia & 44 & 1995 & 22 & Privada & Não \\
Urologia & 42 & 2000 & 17 & Privada & Não \\
Urologia & 31 & 2010 & 7 & Privada & Não \\
\hline
\end{tabular}

\subsubsection{Estruturas de Governança Interna}

Os resultados das entrevistas foram caracterizados a luz dos trabalhos de (Grandori, 2016; Grandori e Furnari, 2008), conforme descrito no capítulo de Procedimentos metodológicos. O levantamento dos dados seguiram duas etapas: as práticas de incentivos adotadas, antes e depois da efetivação da RDC-36 — protocolo de higienização em cada hospital estudado.

\subsubsection{Estrutura de Governança Mercado}

Conforme relataram os entrevistados, as ações para controle de infecção é uma questão tratada no hospital desde a sua fundação, dada a importância do tema para os hospitais. Os casos de infecção aumentam os custos com a internação, e nos casos mais graves podem aumentar o número de óbitos. Os casos de infecção hospitalar podem estar diretamente ligados ao fato dos médicos higienizarem ou não as mãos de forma incorreta. Tais aspectos aumentam a importância do Protocolo de Higienização das Mãos, que, segundo relatos, é considerado um marco nas políticas internas dos hospitais. Os dados sobre a percepção dos gestores sobre práticas de incentivo (governança mercado) antes e depois da mudança institucional estão apresentados na tabela 4 .

Nas entrevistas com os gestores do hospital, que teve como um dos objetivos analisar as principais estratégias realizadas pelos gestores, antes e depois da mudança institucional - RDC-36. Analisando os dados foi constatado que o hospital não pagava valores monetários extras aos seus funcionários para aderirem aos protocolos de higienização das mãos ou pelo desempenho na questão das infecções. Os pagamentos são os salários e os direitos trabalhista tais como vale transporte, ticket refeição e demais direitos trabalhistas previstos na lei.

Nós detectamos, de maneira muito exploratória, que o pagamento de valores monetários (bônus) aos funcionários é uma iniciativa de alguns médicos para incen- 
tivar suas equipes, principalmente na hora da realização dos procedimentos cirúrgicos.

Tabela 4 - Utilização das práticas de incentivos (antes e depois da mudança institucional).

\begin{tabular}{l|c|c|c|c}
\cline { 2 - 5 } \multicolumn{1}{c|}{ Práticas } & \multicolumn{2}{c|}{ Antes } & \multicolumn{2}{c}{ Depois } \\
\hline \#1.1.Bônus por desempenho individual & Não & Sim & Não \\
\hline \#1.2.Bônus pelo desempenho da equipe & 0 & $100 \%$ & 0 & $100 \%$ \\
\#1.3. Bônus pelo desempenho do hospital no final do ano & 0 & $100 \%$ & 0 & $100 \%$ \\
\hline
\end{tabular}

\subsubsection{Estruturas de Governança Burocrática}

Conforme o nosso modelo conceitual, a segunda estrutura de governança é a burocrática composta por seis práticas organizacionais.

Com base nos resultados das entrevistas, foi identificado que o hospital não contemplava seus funcionários com um plano de carreira estruturado e nem plano de progressão (tabela 4). Nas entrevistas, não foi sinalizado pelos respondentes à existência de plano de promoção de funcionários que levava em conta o potencial de crescimento ou contribuição para implantação das novas práticas de higienização.

De acordo com os entrevistados, e os resultados relacionados à prática 2.3 que trata de planejamento com os seus funcionários, do total de gestores respondentes, $11 \%$, percebem a utilização da prática de incentivos relacionada com seus funcionários antes da RDC-36. Após a RDC-36, essa percepção cresceu em 64\% comparado com total de respondentes.

Os respondentes quando questionados sobre a participação e utilização da assessoria de qualidade nos processos de redução de infecção hospitalar - como descrito na prática 2.4. Do total da amostra, $4 \%$ dos médicos entrevistados afirmaram não perceber a participação de suas equipes em programas e processos para controle da qualidade relacionado a processos de controle de infecção. Com o advento da RDC-36, essa percepção aumentou para $96 \%$ do total de entrevistados. Isso ocorreu devido a melhor divulgação de parcerias entre as áreas, assim como 
alguns padrões de mudança na gestão hospitalar requeridas pela Anvisa, para meIhor adesão do Protocolo de Higienização das Mãos.

Os funcionários receberam treinamento de higienização, nos quais foram discutidas as melhores estratégias para ampliação da higienização das mãos. Os informantes reportaram que foram disponibilizados cursos de atualização para preenchimento de protocolos de segurança do paciente. Esses cursos foram oferecidos para as diferentes equipes do hospital, isso ocorreu devido parcerias entre o $\mathrm{CCIH} \mathrm{e}$ assessoria da qualidade.

Comparando as transições da mudança institucional, as percepções sobre a realização de feedbacks individuais como descrito na prática 2.5 (Conversa individualmente com os seus funcionários sobre os resultados de desempenho). Antes da RDC-36, essa percepção de utilização da prática entre os gestores era de $39 \%$ em suas equipes. Essa porcentagem após a RDC-36 subiu para 93\% - isto é, para 93\% dos informantes, passou a ser usada após a implantação; esses feedbacks tratam sobre os indicadores de infecção, em caso de aumento dos índices; tais feedbacks também envolvem orientações de como agirem para reduzir os casos de infecção e, consequentemente, melhorar os indicadores.

Tabela 5 - Utilização das práticas de incentivos (antes e depois da mudança institucional).

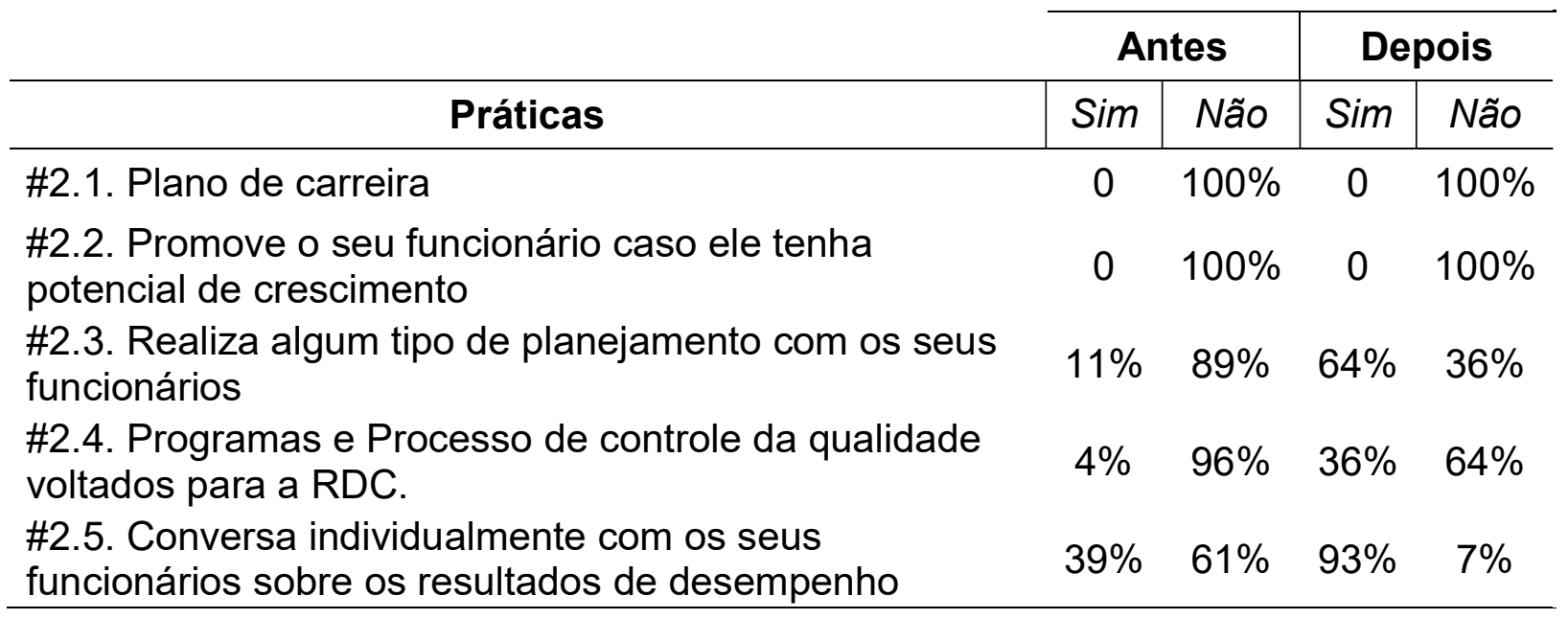




\subsubsection{Estrutura de Governança Comunitária}

A tabela 6 está relacionada à governança comunitária e suas práticas de incentivos. Analisando a primeira prática descrita no item 2.7, que teve o objetivo verificar o compartilhamento de decisões no dia-dia, foi constatado que houve um aumento de $54 \%$ na percepção dos gestores no compartilhamento de decisões. Segundo os respondentes, as decisões acerca dos protocolos de higienização, como reduzir os casos de infecção, entre outros aspectos, foram compartilhadas entre médicos e enfermeiras e, entre enfermeiras e técnicos da área da saúde.

A utilização das áreas de socialização (descrita na prática 2.8) é importante para troca de conhecimentos por meio de conversas informais entre gestores e membros da equipe (conforme indica da literatura). No caso, o hospital tem uma área verde com bancos para conversas, descansos fora do ambiente organizacional e assistencial. Sendo assim, analisando as respostas dos gestores, antes da RDC36 , aproximadamente $25 \%$ dos médicos utilizavam essas áreas para realizar algum tipo de conversa relacionada aos processos hospitalares. Após a RDC-36, a percepção dos médicos passou para $43 \%$ do total da amostra de entrevistados.

Quando os entrevistados foram questionados sobre a participação deles em eventos de confraternização com a equipe multidisciplinar, como representado na prática 2.9, antes da RDC-36, eles mencionaram que participavam somente da festa promovida pelo hospital no final do ano - a percepção dos gestores quanto à participação nesses eventos antes da RDC-36 foi 39\% do total de entrevistados na amostra. Depois da RDC-36, a percepção sobre a participação em eventos passou para $61 \%$ dos entrevistados.

Outra prática de incentivos analisada na governança comunitária foram os canais de comunicação presente na prática do item 3.0. O hospital utiliza murais expostos em lugares estratégicos para comunicação dos dados de infecção, que ficam situados nas salas de passagem de plantão médico. Os hospitais não dispõem de email corporativo para comunicação interna, nem telefones privativos. Antes da RDC36 , a percepção de utilização desta prática era de $36 \%$ da amostra de gestores entrevistados. Nessa época (antes de 2013), o hospital só utilizava o mural informativo, com a popularização do uso do aplicativo passaram se a usar os dois, isso deu maior agilidade à troca de informações. É importante ressaltar que a RDC divulga em seu texto, a importância da comunicação entre as equipes. Com base nas orienta- 
ções propostas pela RDC, a percepção de utilização dos canais de comunicação, após a RDC-36, passou para 75\% do total de entrevistados.

Como apresentado na prática 3.1, que trata sobre as sugestões dos funcionários. Os respondentes indicaram que recebiam sugestões dos membros de suas equipes de melhoria em processos e selecionavam quais sugestões deveriam ser aplicadas. Nesse sentido, antes da RDC-36, 57\% dos gestores percebiam a importância do controle infecções. Após a mudança institucional, a percepção da utilização desta prática passou para $96 \%$ na percepção de acordo com o total de entrevistados da amostra.

Na prática de incentivos descrita na prática do item 3.2 que trata sobre a realização de treinamentos para higienização das mãos. São oferecidos pelo hospital por meio de iniciativas do SUS e hospitais de referência no Estado de Minas Gerais. Geralmente, os treinamentos internos são voltados para higienização das mãos e demais assuntos. Relacionado a esses treinamentos, antes da RDC-36 em 2012, $36 \%$ dos gestores percebiam a importância do treinamento na eficácia para higienização das mãos em suas equipes. Após a RDC, houve um aumento na percepção de $39 \%$ do total da amostra — os respondentes mencionaram a importância da realização e participação nos cursos profissionalizantes. Ainda nesse tocante, de acordo com os respondentes, esse aumento está relacionado ao fato de o hospital ter incrementado os treinamentos relacionados à higienização das mãos. Nas entrevistas, identificamos que esses treinamentos são realizados com intervalo de 3 meses; nem sempre com grande adesão dos funcionários.

Com o objetivo de identificar o trabalho em equipe, foi levantada a prática de reuniões entre os gestores médicos e os demais profissionais. Nesse sentido, as reuniões são realizadas de forma hierárquica, entre médicos, enfermeiros e profissionais de nível técnicos e profissionais de nível superior. Foi identificada a existência de uma reunião (quinzenal) entre a equipe do $\mathrm{CCIH}$ e as demais áreas envolvidas no processo, na qual envolve representantes do corpo clinico, gerentes de qualidade e equipe assistencial.

Por meio de entrevistas, foram levantadas as duas formas nas quais as reuniões ocorrem no hospital. Primeira, os médicos se reúnem com as enfermeiras chefes e o gerente do $\mathrm{CCIH}$. Em tais reuniões, são abordados assuntos relacionados à medicação para o paciente. Posteriormente, as enfermeiras se reúnem com os técnicos e outros profissionais para desdobramento das ações da primeira reunião. 
Ambas as reuniões ocorrem mensalmente, ou semanalmente caso ocorra alguma contingência no hospital. À título de exemplo, levantamos casos de reuniões para responder ao aumento dos casos de infecção.

Para a próxima analisada (3.3), que trata da reunião semanal entre profissionais de nível superior antes da RDC-36, inicialmente $14 \%$ da amostra mencionou o emprego de tais práticas, com o propósito de discutir vários aspectos, entre os quais ligados à higienização das mãos. Com a efetivação da RDC-36, a percepção de utilização passou para $57 \%$ no total da amostra. Já o item 3.4 - que trata das reuniões mensais com os profissionais de nível superior, antes da RDC, a percepção de utilização dos gestores era de 14\%; com a efetivação da RDC-36, essa percepção passou para $57 \%$ no total da amostra dos entrevistados.

Para tratar de assuntos de infecção hospitalar, a presença do médico do $\mathrm{CCIH}$ é requisitada, uma vez ele define a utilização de medicamentos e tratamentos apropriados para o paciente. As reuniões entre os médicos e o médico do $\mathrm{CCIH}$ não tem uma periodicidade certa vai depender da demanda de cada paciente infectado.

Já na prática 3.5 - que trata de reuniões semanais com a gerência, foi constatado que a percepção antes da RDC-36 era de 14\% - isso se deve pelo fato dos gestores reunirem com os gerentes somente em casos esporádicos até a efetivação da RDC-36. Com a chegada da RDC-36 essa percepção passou para 54\% do total dos entrevistados. Essa ampliação está condizente com a ampliação das sugestões de reunião descrita no texto da RDC-36.

Foram realizadas também dinâmicas de grupo com a temática higienização das mãos - como descrito na prática - 3.6. Antes da RDC-36, apenas 7\% da população entrevistada percebia a importância da participação nas dinâmicas de grupo para ampliar a concepção do processo de higienização das mãos; após a RDC-36, essa percepção aumentou para $61 \%$ no total de entrevistados. Em tais dinâmicas, buscavam-se discutir estratégias para higienizar as mãos de forma correta, seguindo um protocolo bem definido.

Sobre a prática que trata da realização de planejamento estratégico - segundo os dados das entrevistas, antes da RDC-36, os gestores realizavam não planos de trabalho estruturados e detalhados para a questão da infecção hospitalar, como descrito na prática 3.7. Geralmente, era um simples planejamento interno, que a equipe do $\mathrm{CCIH}$ e alguns médicos concebiam. Antes da RDC-36, a percepção dos gestores quanto ao desenvolvimento de planos para o controle de infecção girava 
em torno de $21 \%$. Nós identificamos que apenas alguns médicos utilizavam essa prática antes de 2013. Com o advento da RDC, o hospital passou a exigir dos gestores participassem do planejamento, com foco controle de infecção. Participavam do planejamento médicos do centro cirúrgico, o $\mathrm{CClH}$, além de outros convidados, tais como funcionários do corpo assistencial - todos reunidos com o objetivo de estabelecer planos para o controle de infecção. Os planos de trabalho com foco no controle de infecção passaram a ser elaborado por diferentes profissionais envolvidos no processo. Nesse sentido, a percepção da utilização do aumento dos planos de trabalho para controle de infecções aumentou 46\% após a RDC.

Quando questionados sobre a aceitação de sugestões por parte dos funcionários, mais especificamente sobre mudanças da Anvisa - prática de incentivo 3.8, os gestores responderam que o sistema de sugestão tem sido aprimorado desde as mudanças institucionais proposta pela Anvisa. Nesse sentido, em relação da RDC36, não houve mudança nesse processo de sugestão. Quando comparado à percepção dos gestores antes com o depois da normativa, os resultados mantiveram o mesmo, com cerca de $32 \%$ do total respondendo que aceitam sugestões dos funcionários.

Tabela 6 - Utilização das práticas de incentivos (antes e depois da mudança institucional).

\begin{tabular}{|c|c|c|c|c|}
\hline \multirow[b]{2}{*}{ Práticas } & \multicolumn{2}{|c|}{ Antes } & \multicolumn{2}{|c|}{ Depois } \\
\hline & Sim & Não & Sim & Não \\
\hline $\begin{array}{l}\text { \#2.7. Compartilha com os seus funcionários as decisões } \\
\text { do dia a dia }\end{array}$ & $32 \%$ & $68 \%$ & $86 \%$ & $14 \%$ \\
\hline \#2.8. Hospital tem área de socialização & $25 \%$ & $75 \%$ & $43 \%$ & $57 \%$ \\
\hline \# 2.9. Confraternização com seus funcionários & $39 \%$ & $61 \%$ & $61 \%$ & $39 \%$ \\
\hline $\begin{array}{l}\text { \#3.0. Possui mural, e-mail corporativo, outros canais para } \\
\text { comunicação com os funcionários }\end{array}$ & $36 \%$ & $64 \%$ & $75 \%$ & $25 \%$ \\
\hline $\begin{array}{l}\text { \#3.1. Funcionários colocam sugestões de melhorias ou } \\
\text { novas ideias }\end{array}$ & $57 \%$ & $43 \%$ & $96 \%$ & $4 \%$ \\
\hline $\begin{array}{l}\text { \#3.2. Realiza curso profissionalizantes de atualização ou } \\
\text { assisti palestras promovidas pelo hospital }\end{array}$ & $36 \%$ & $64 \%$ & $93 \%$ & $7 \%$ \\
\hline $\begin{array}{l}\text { \# 3.3. Reuniões semanais com os profissionais de nível } \\
\text { superior }\end{array}$ & $14 \%$ & $86 \%$ & $57 \%$ & $43 \%$ \\
\hline $\begin{array}{l}\text { \# 3.4. Reuniões mensais com os profissionais de nível } \\
\text { superior }\end{array}$ & $14 \%$ & $86 \%$ & $43 \%$ & $57 \%$ \\
\hline \# 3.5. Reuniões semanais com a gerência & $14 \%$ & $86 \%$ & $54 \%$ & $46 \%$ \\
\hline \# 3.6. Equipe participa em treinamentos e dinâmica com & $7 \%$ & $93 \%$ & $61 \%$ & $39 \%$ \\
\hline
\end{tabular}


os grupos

\# 3.7. Realiza planejamento com a equipe para o ano seguinte

$21 \% \quad 79 \% \quad 46 \% \quad 54 \%$

\# 3.8 Mudanças nas regras da Anvisa, o senhor aceita sugestões dos funcionários

$32 \% \quad 68 \% \quad 32 \% \quad 68 \%$

\subsubsection{Estruturas de Governança Democrática}

Na governança democrática, foram utilizadas cinco práticas de incentivos que visou verificar sua utilização no processo de adequação a RDC-36. Os levantamentos procurou investigar se as práticas utilizadas estavam relacionadas a uma estrutura de governança democrática. A primeira prática a do item 3.9 buscou investigar se o líder incentivava os funcionários a participarem de frentes de trabalho e a representação de assuntos relacionados ao hospital. Um exemplo de uma prática de incentivos foi a de trabalhar na comissão de prevenção de infecção. Antes da normativa, a percepção dos respondentes era de18\% no total da amostra confirmavam a importância da participação dos funcionários nessas comissões. Para o caso em análise, após a normativa 100\% dos médicos afirmaram ser importante a participação dos liderados nas comissões internas do hospital (no contexto do protocolo de infecção - RDC-36).

Quando questionados sobre o compartilhamento das decisões médicas como descrito na prática 3.10 os gestores responderam que as decisões técnicas relacionadas ao pacientes são de responsabilidade do corpo clínico. Existem situações que outros profissionais (enfermeiros e técnicos) são consultados para melhor tomada de decisão do médico, pois quem acompanha a evolução do paciente no cotidiano por mais horas de dedicação são os profissionais assistenciais. Antes da regra, por não haver uma política de atenção ao processo, apenas $21 \%$ tinham a percepção de que compartilhava decisões com a equipe; após a RDC-36, 79\% dos entrevistados alegaram que passaram a ser compartilhadas com a equipe informações sobre controle de infecção nosocomial.

Os gestores foram questionados sobre a percepção da utilização da prática de incentivo relacionada ao conhecimento dos funcionários sobre a gestão dos procedimentos gerenciais e processuais do hospital. Nesse caso, os gestores por meio dessa prática deverão traduzir para os funcionários todos os procedimentos gerencias - como descrito na prática 3.11 (indicadores financeiros e de qualidade) e pro- 
cessual (adequação de exigências institucionais aos procedimentos médicos). De acordo com respondentes, foi constatado que, antes da RDC-36, a percepção da utilização desta prática era de $14 \%$ do total de entrevistados da amostra. Após a efetivação da RDC-36, a percepção da utilização dessa prática passou para $64 \%$.

A prática de incentivos - 3.12 que trata de compartilhamento de aprendizado entre os membros da equipe e gestores. Antes da RDC-36, o compartilhamento de conhecimento era percebido entre $29 \%$ dos gestores entrevistados. Com a efetivação da RDC-36, essa percepção passou a ser 79\% do total de respondentes. Essa mudança aconteceu devido a reestruturação das práticas de incentivos no processo de adequação e aprendizado das especificações da RDC-36.

Já a prática 3.13 que diz respeito à permissão para os funcionários realizarem atividades além do previsto, os gestores responderam que vai depender do tipo da atividade, pois tem atividades que somente o profissional médico pode realizar, ou a enfermeira, não havendo nenhuma barreira institucional a permissão é concedida, mas tudo depende do perfil do médico. Sendo assim, antes da RDC-36, a percepção dessa prática girava em cerca 14\%. Após a efetivação da RDC-36 a percepção da utilização desta prática aumentou para $71 \%$.

$\mathrm{Na}$ última prática (3.14) que foi utilizada para medir a participação dos gestores em eventos e treinamentos oferecidos pelo hospital ou por entidades externas, foi constatado de acordo com os entrevistados, 14\% participava de eventos e campanhas promovidas pelo hospital para o controle de infecção, palestras educativas na semana de infecção hospitalar. 
Tabela 7 - Utilização das práticas de incentivos (antes e depois da mudança institucional).

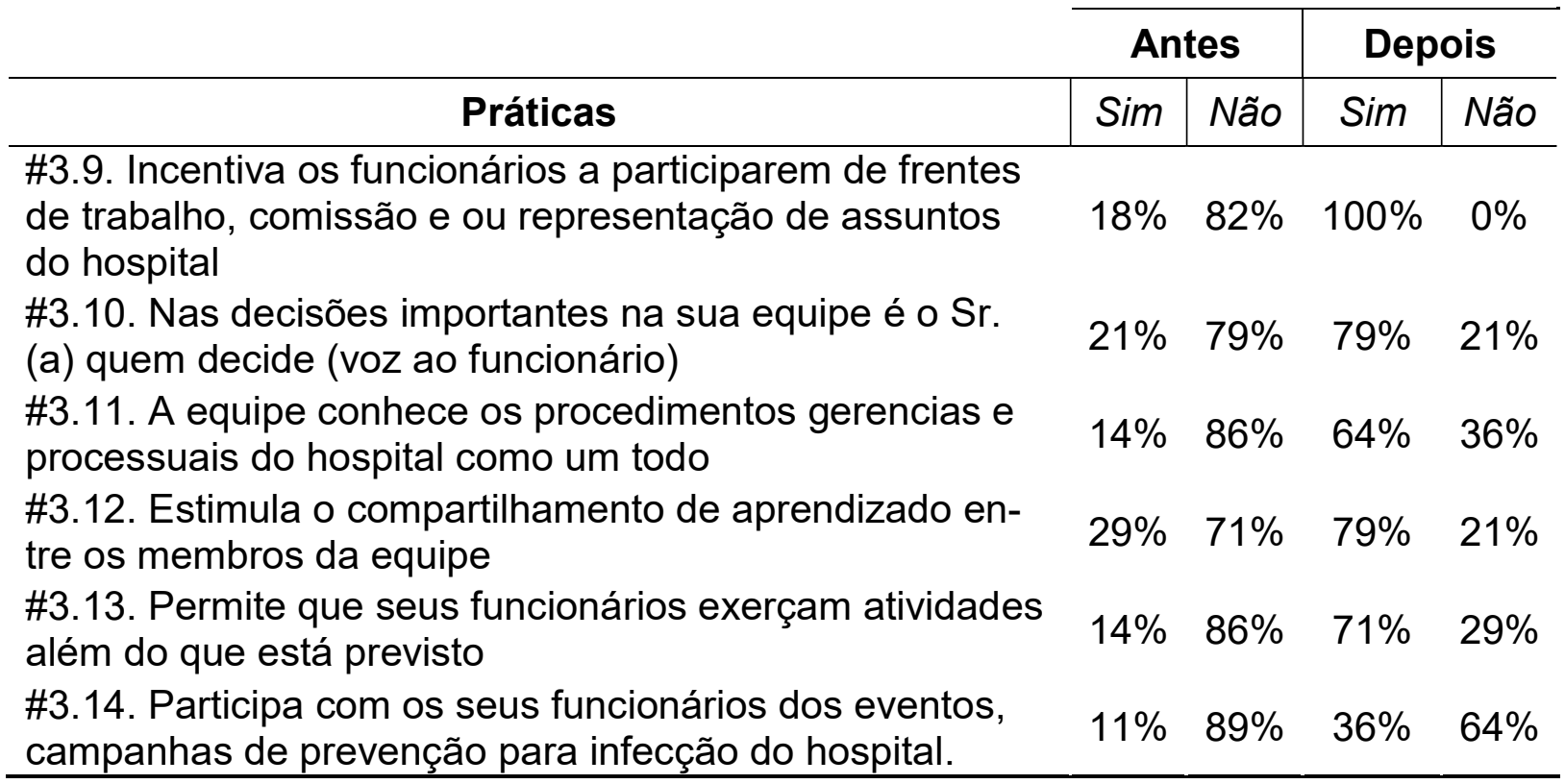

\subsection{Hospital Saúde Arnaldo Gavazza Filho}

\subsubsection{Breve descrição do hospital}

O hospital Saúde Arnaldo Gavazza Filho foi idealizado no início da década de 1960. O hospital foi desenvolvido por dirigentes da Minascana, com recursos financeiros do Instituto do Açúcar e do Álcool (IAA). A construção começou em 1972, sendo inaugurado o hospital em 14/5/1976.

No início dos anos 90, com a criação da Fundação Filantrópica e Beneficente de Saúde Arnaldo Gavazza Filho, o hospital se consolidou como um dos maiores complexos hospitalares do interior do Estado de Minas Gerais, atendendo uma região com 35 municípios, onde vivem cerca de 450 mil pessoas. Atualmente, o hospital conta com 120 leitos, atendendo uma média de 100 mil pessoas por ano realizando uma média de 5.612 cirurgias anuais; e destacando-se como especialista nas áreas de ortopedia, cardiologia e oftalmologia.

O hospital intensificou suas ações de controle de infecção desde a promulgação da Lei n. ${ }^{\circ} 9431$ de 6 de janeiro de 1997, que dispõe sobre a obrigatoriedade da manutenção pelos hospitais de Programa de Controle de Infecções Hospitalares. Ao longo dos anos diferentes portarias que tratavam do controle de infecção foram adotadas pelo hospital, tais como a Portarias de $n^{\circ} 930$ que dispunha sobre normas ge- 
rais para o controle de infecções hospitalares e revoga a Portaria n 196/83 e a Portaria de $n^{\circ} 158$ Comissão Nacional de Prevenção e Controle de Infecção Relacionada à Assistência à Saúde entre outras leis e portarias. Mas foi em 2013 que o hospital passou a adotar o Protocolo de Higienização das Mãos descrito na RDC-36, nesse momento houve uma série de medidas internas para adequação do protocolo.

\subsection{Breve Apresentação da Estrutura Organizacional}

A estrutura organizacional do hospital é composta por presidente - que é um membro externo à instituição - vice-presidente, secretário e conselheiros. Como regra da instituição, são realizadas reuniões quinzenais para a discussão de assuntos estratégicos do hospital, no âmbito gerencial e assistencial. A execução das decisões do conselho é gerida atualmente por uma superintendente-executiva que administra os desdobramentos estratégicos das áreas que compõem o hospital. Os demais níveis são compostos por cargos de lideranças médica, assistencial e administrativa, tais como coordenadores e gerentes, além do corpo assistencial que é composto por equipes multidisciplinares - enfermeiros, enfermeiras, técnicos de enfermagem, instrumentadores, nutricionistas, assistente social e outros. Na organização, atualmente trabalham 592 funcionários em diferentes funções, sendo 120 médicos.

\subsection{Perfil Demográfico da amostra de entrevistados}

De forma a atender os objetivos da tese, realizamos um segundo estudo de caso para melhor ilustração das estratégias gerenciais dos gestores em um hospital beneficente. Para isso, foram entrevistados diferentes profissionais ligados ao controle de infecção, sendo eles: médico coordenador, esse profissional tem um papel importante no controle de infecção, pois ele é a ponte entre as ações de prevenção dos casos de infecção e as equipes médicas. Foram entrevistadas também duas enfermeiras da Comissão de Controle de Infecções Hospitalares ( $\mathrm{ClH}$ ), além de vinte e dois médicos cirurgiões líderes de equipes, que ocupavam os cargos de no mínimo cinco anos.

No hospital Arnaldo Gavazza Filho, a idade média dos entrevistados foi de 45 anos, sendo o mais novo com 33 anos e o mais velho com 70 anos. A média de 
anos exercendo a profissão é de 19 anos e o tempo no cargo segue uma média de 12 anos. Somente dois médicos cursaram uma pós-graduação em gestão de negócios e um MBA.

Tabela 8 - Dados demográficos das equipes entrevistadas.

\begin{tabular}{|c|c|c|c|c|c|}
\hline Especialidade & Idade & $\begin{array}{c}\text { Ano de } \\
\text { Formação }\end{array}$ & $\begin{array}{c}\text { Anos } \\
\text { Exercendo a } \\
\text { Profissão }\end{array}$ & $\begin{array}{l}\text { Instituição } \\
\text { de Ensino }\end{array}$ & $\begin{array}{c}\text { Realizou } \\
\text { Curso de } \\
\text { Gestão }\end{array}$ \\
\hline Angiologia & 50 & 1994 & 23 & Privada & Sim \\
\hline Cardiologia & 33 & 2006 & 11 & Privada & Não \\
\hline Cardiologia & 33 & 2009 & 8 & Privado & Não \\
\hline Cirurgia Geral & 66 & 1978 & 39 & Pública & Não \\
\hline Clínica Geral & 37 & 2009 & 8 & Privada & Não \\
\hline Clínica Geral & 33 & 2012 & 5 & Privado & Não \\
\hline Gastrenterologia & 44 & 2003 & 14 & Pública & Não \\
\hline Hemodinâmica & 47 & 1999 & 18 & Privado & Não \\
\hline Nefrologia & 51 & 1992 & 25 & Privada & Não \\
\hline Nefrologia & 53 & 1989 & 28 & Privado & Não \\
\hline Nefrologia & 53 & 1987 & 30 & Pública & $\operatorname{Sim}$ \\
\hline Neurologia & 46 & 1997 & 20 & Pública & Não \\
\hline Ortopedia & 70 & 1972 & 45 & Privada & Não \\
\hline Ortopedia & 37 & 2005 & 12 & Privada & Não \\
\hline Otorrinolaringologia & 42 & 2001 & 16 & Privada & Não \\
\hline Otorrinolaringologia & 46 & 1994 & 23 & Pública & Não \\
\hline Pediatria & 62 & 1989 & 28 & Privado & Não \\
\hline Pneumologia & 49 & 1994 & 23 & Privada & Sim \\
\hline $\begin{array}{l}\text { Terapia Intensiva } \\
(\mathrm{CTI})\end{array}$ & 44 & 1999 & 18 & Privada & Não \\
\hline $\begin{array}{l}\text { Terapia Intensiva } \\
\text { (CTI) }\end{array}$ & 40 & 2000 & 17 & Privado & Não \\
\hline $\begin{array}{l}\text { Terapia Intensiva } \\
(\mathrm{CTI})\end{array}$ & 35 & 2010 & 7 & Privado & Não \\
\hline Urologia & 41 & 2001 & 16 & Privada & Não \\
\hline
\end{tabular}

\subsection{Estrutura de Governança Mercado}


De acordo com os entrevistados, o hospital não detém de práticas de incentivos monetários para o controle de infecção. Similar ao caso anterior, nas entrevistas com os gestores, foi constatado que em alguns casos específicos, médicos bonificam seus liderados (pagamento individual e por equipe) frente aos resultados obtidos relacionados à RDC-36.

Nossos informantes sugeririam que tais premiações eram ofertadas aos funcionários que se destacaram ao longo do ano. Essas premiações consistiam em viagens, material para construção de casa, além de outros aspectos. Nossos entrevistados também indicaram que Aas bonificações podiam acontecer quando a equipe tem êxito em uma dada cirurgia, ou quando os índices mensais de infecção estavam dentro do espectro esperado ou abaixo da média estipulada pelo $\mathrm{CCIH}$.

Tabela 9 - Utilização das práticas de incentivos (antes e depois da mudança institucional).

\begin{tabular}{l|c|c|c|c}
\cline { 2 - 5 } \multicolumn{1}{c|}{ Práticas } & Sim & Não & Sim & Não \\
\hline \#1.1.Bônus por desempenho individual & 0 & $100 \%$ & 0 & $100 \%$ \\
\#1.2.Bônus pelo desempenho da equipe & 0 & $100 \%$ & 0 & $100 \%$ \\
\#1.3. Bônus pelo desempenho do hospital no final do ano & 0 & $100 \%$ & 0 & $100 \%$ \\
\hline
\end{tabular}

\subsection{Estrutura de Governança Burocrática}

Nas entrevistas com os gestores, quando questionados sobre a utilização de plano de carreira (prática 2.1) em suas equipes, $100 \%$ responderam que antes de 2013 não utilizavam tal prática de incentivos, por não existir um sistema de gestão de pessoas no hospital. Referente à prática 2.2, que trata da promoção dos funcionários, de acordo com os entrevistados, nem antes e nem depois da RDC-36 não existiam regras claras de promoção para cargos e salários. Informalmente, para alguns casos, o líder podia promover ou oferecer aumento de salário caso achasse necessário.

No que diz respeito à realização de planejamento, como descrito na prática 2.3, antes da RDC, a percepção da utilização pelos entrevistados dessa prática era de $27 \%$ os informantes alegaram que o planejamento era algo simples, sem a participação dos profissionais multidisciplinares, sendo mais um processo interno do $\mathrm{CCIH}$. Após a RDC-36, tornou-se obrigatório a estruturação de um planejamento na 
segurança do paciente. Assim, as atividades planejamento integraram diferentes setores (além do $\mathrm{CCIH}$ ) tais como: gerência de qualidade e os médicos liderem.

As reuniões foram ampliadas - antes da mudança institucional, tais reuniões eram somente em casos esporádicos relacionados a surtos de infecção. Em nossas entrevistas, levantamos que reuniões de planejamento passaram a acontecer de forma mais sistemática; em tais reuniões, os informantes apontaram que eram discutidos aspectos, inclusive ligados aos protocolos de higienização das mãos, ações para minimizar infecção hospitalar, etc. Após a ação conjunta entre as áreas no desenvolvimento do planejamento estratégico, a percepção da utilização da prática entre os gestores passou de $27 \%$ para $50 \%$ no total dos gestores do Hospital Arnaldo Gavazza.

A próxima analisada foi a 2.4 , acerca do papel da gestão da qualidade nos processos e controle de infecção. Essa prática desmandou o mapeamento de processos ligados a RDC-36. A gerência de qualidade passou a oferecer treinamentos relacionados aos protocolos da RDC-36 para as equipes do hospital. De acordo com os respondentes, antes da RDC-36, cerca de 18\% dos médicos tinham a percepção da existência dos processos e ações conjuntas entre a gerência de qualidade e o CCIH. Com isso, após a divulgação da RDC-36 e seus protocolos, as informações sobre a ação conjunta entre a área da qualidade nos processos de disseminação e adequação da RDC passou a ser em $41 \%$ na percepção dos gestores. Esse aumento da percepção e a utilização da prática ajudaram a melhorar o entendimento do protocolo nas equipes.

No que diz respeito às conversas individuais com os funcionários, como descrito na prática 2.6, a percepção da utilização da prática antes da RDC-36 era de $45 \%$ do total de entrevistados. Ou seja, os médicos já canais de comunicações sobre infecção com seus liderados - vale a pena destacar, que, segundo nossos entrevistados, tais conversas envolviam principalmente enfermeiras e médicos. Após a RDC-36, a percepção dos médicos a respeito das conversas individuais entre os profissionais tiveram um aumento de $82 \%$.

Tabela 10 - Utilização das práticas de incentivos (antes e depois da mudança institucional). 


\begin{tabular}{|c|c|c|c|c|}
\hline Práticas & Sim & Não & Sim & Não \\
\hline \#2.1. Plano de carreira & $0 \%$ & $100 \%$ & $0 \%$ & $50 \%$ \\
\hline $\begin{array}{l}\text { \#2.2. Promove o seu funcionário caso ele tenha } \\
\text { potencial de crescimento }\end{array}$ & $0 \%$ & $100 \%$ & $0 \%$ & $100 \%$ \\
\hline $\begin{array}{l}\text { \#2.3. Realiza algum tipo de planejamento com os seus } \\
\text { funcionários }\end{array}$ & $27 \%$ & $73 \%$ & $50 \%$ & $50 \%$ \\
\hline $\begin{array}{l}\text { \#2.4. Programas e Processo de controle da qualidade } \\
\text { voltados para a RDC. }\end{array}$ & $18 \%$ & $82 \%$ & $41 \%$ & $59 \%$ \\
\hline $\begin{array}{l}\text { \#2.5. Conversa individualmente com os seus } \\
\text { funcionários sobre os resultados de desempenho }\end{array}$ & $45 \%$ & $55 \%$ & $82 \%$ & $18 \%$ \\
\hline
\end{tabular}

\subsection{Estrutura de Governança Comunitária}

Serão apresentadas nessa seção porcentagens da percepção dos médicos na utilização das práticas de incentivos utilizadas pelos gestores antes e depois da RDC-36, ao final os dados serão consolidados na Tabela 11.

De acordo com os médicos (prática 2.7), antes da RDC-36. a percepção dos entrevistados sobre o compartilhamento das decisões era de $59 \%$ (isto é, $59 \%$ dos entrevistados). Depois da mudança institucional, essa percepção entre os entrevistados aumentou para $91 \%$. As decisões acerca dos protocolos de higienização das mãos passaram a ser discutidas com mais frequência, inclusive com a participação do $\mathrm{CCIH}$ no processo de prevenção de casos de infecção.

Já a prática de incentivos descrita no item 2.8 (a utilização de áreas de socialização - no caso, salas de conforto médico) está relacionada a eventuais conversas sobre o controle de infecção. Foi verificado que a antes da RDC-36, a percepção utilização desses espaços era em torno de $27 \%$ de acordo com os gestores entrevistados nessa pesquisa. Após a RDC-36, a percepção dos entrevistados sobre a utilização desses espaços teve um aumento em 41\%. Uma possível explicação para esse aumento é que, após a RDC-36, houve uma ampliação da atenção aos casos de infecção na organização.

No que tange à percepção sobre a participação dos gestores nas confraternizações com os funcionários, como descrito no item 2.9 da governança comunitária, antes da RDC-36, 59\% entrevistados percebiam a importância da ida a esse tipo de eventos. Após a efetivação da RDC-36, houve uma queda na percepção para 55\%: apenas destacando que o hospital não promove festas de final de ano. 
No que se refere às formas de comunicação entre os médicos e sua equipe acontecem em diferentes formas, sendo as mais utilizadas são por de aplicativo de mensagens, e-mail e mural de comunicação. Quando o médico não está presente no atendimento, os informantes mencionaram que são utilizados aplicativos de mensagens. O e-mail é utilizado com menor frequência. Outra forma de comunicação é o mural de comunicação, nesse espaço são fixados assuntos relacionados aos pacientes e também são disponibilizados para apresentar os indicadores de infecção hospitalar.

Os murais são afixados nas salas dos médicos e em ambientes de circulação dos profissionais da saúde. Quando questionados sobre a utilização dessa prática de incentivos (item 3.0), para se comunicarem com seus funcionários, a percepção de utilização, antes da RDC n. ${ }^{\circ} 36$, era cerca de $41 \%$. De acordo com os gestores, com as novas medidas sugeridas após RDC-36, a divulgação dos dados tornou-se mais frequente, e com isso, a percepção da utilização desta prática aumentou para $68 \%$ do total da amostra de entrevistados,

As sugestões de melhorias estão relacionadas aos processos que envolvem médicos e sua equipe. De acordo com os nossos entrevistados, as enfermeiraschefes e outros médicos foram os únicos a sugerirem de melhorias para processos ou procedimentos hospitalares. De acordo com os entrevistados, a percepção de uso da prática (item 3.1) era de $55 \%$ da amostra. Em uma comparação, depois da RDC-36, essa percepção de melhoria passou a ser entre $86 \%$ dos entrevistados. De acordo com os gestores, quando a Anvisa ou qualquer outro órgão do governo institucionaliza uma regra, é natural que o hospital e suas equipes ajam de forma conjunta, em um processo de maior cooperação. É válido ressaltar que os médicos afirmaram que escutam as sugestões, mas isso não quer dizer que eles acatam as decisões à risca. Há limitações na qualidade das sugestões e na existência de recursos para implantação de tais sugestões.

No que tange reuniões, as equipes realizam reuniões mensais e semanais para discutirem os casos de pacientes, inclusive com infecção hospitalar. Nossos entrevistados sugeriram que, nessas reuniões, participavam: o médico responsável pela equipe, médico infectologista e enfermeira especialista em infecção do $\mathrm{CCIH}$. As reuniões entre o médico coordenador do $\mathrm{CClH}$ e os demais médicos ocorrem sem uma periodicidade certa, mediante contingências (e.g., casos de pacientes infectados). 
Na prática de incentivos 3.2, que trata sobre a realização de treinamentos para higienização das mãos, nossos entrevistados mencionaram que são oferecidos pelo hospital por meio de iniciativas do SUS e treinamentos internos. Os treinamentos internos e externos são direcionados ao Protocolo de Higienização das Mãos. Relacionado a esses treinamentos, antes da RDC-36 em 2012, 50\% do total dos gestores entrevistados percebiam a importância do treinamento para o processo de higienização das mãos. Após a RDC-36, houve um acréscimo na percepção para $77 \%$ do total da amostra, isto é, $77 \%$ dos respondentes mencionaram a importância da realização e participação nos treinamentos ligados à higienização das mãos.

Na prática 3.3, que aborda as reuniões semanais com os profissionais de nível superior, de acordo com os entrevistados, antes da RDC-36, a percepção da utilização dessa prática era de $32 \%$ do total de entrevistados. Após a efetivação da RDC-36, essa percepção passou a ser de $45 \%$ do total de entrevistados. Já para a prática 3.4, que aborda as reuniões mensais com os profissionais de nível superior (reuniões entre médicos e enfermeiros do $\mathrm{CCIH}$ ), antes da RDC-36, a percepção dos gestores entrevistados era de $36 \%$ sobre a utilização dessa prática. Com o processo de implementação da RDC-36, essa percepção passou a ser de $45 \%$ do total dos entrevistados.

Por fim, a prática descrita no item 3.5 (reuniões semanais com a gerência), foi destacada por $18 \%$ dos gestores entrevistados. Em outras palavras, $18 \%$ dos gestores percebiam a importância da utilização da prática. Após a efetivação da RDC-36, essa percepção passou para $50 \%$ do total da amostra de entrevistados. Os entrevistados mencionaram que tais reuniões passaram a ser mais frequentes no hospital.

A prática 3.6 trata da participação dos funcionários nos treinamentos e dinâmicas de grupos promovidos pelo hospital. De acordo com os respondentes, antes da RDC-36, apenas $23 \%$ da amostra percebiam a utilização dessa prática. Como mencionado, os treinamentos ofertados aos funcionários é uma orientação presente no texto da RDC n. ${ }^{\circ} 36$. Consequentemente, os treinamentos com dinâmicas de grupos foram intensificados. Devido às mudanças, os gestores afirmam que a percepção acerca da participação nos cursos passou a ser de $45 \%$ do total de entrevistados.

No que tange à prática 3.7 (planejamento com a equipe para o ano seguinte), antes da RDC-36, a percepção da utilização desta prática era de $9 \%$ do total dos 
gestores. Após a mudança institucional, esse valor passou a ser percebido por $32 \%$ dos gestores entrevistados.

Já sobre a prática descrita no item 3.8, que verifica a percepção dos gestores sobre as sugestões em caso de mudanças institucionais, antes da RDC-36, 18\% dos gestores percebiam o uso dessa prática, inclusive para o controle de infecções. Após a RDC-36, essa percepção aumentou para $32 \%$ dos gestores entrevistados na amostra.

Tabela 11 - Utilização das práticas de incentivos (antes e depois da mudança institucional).

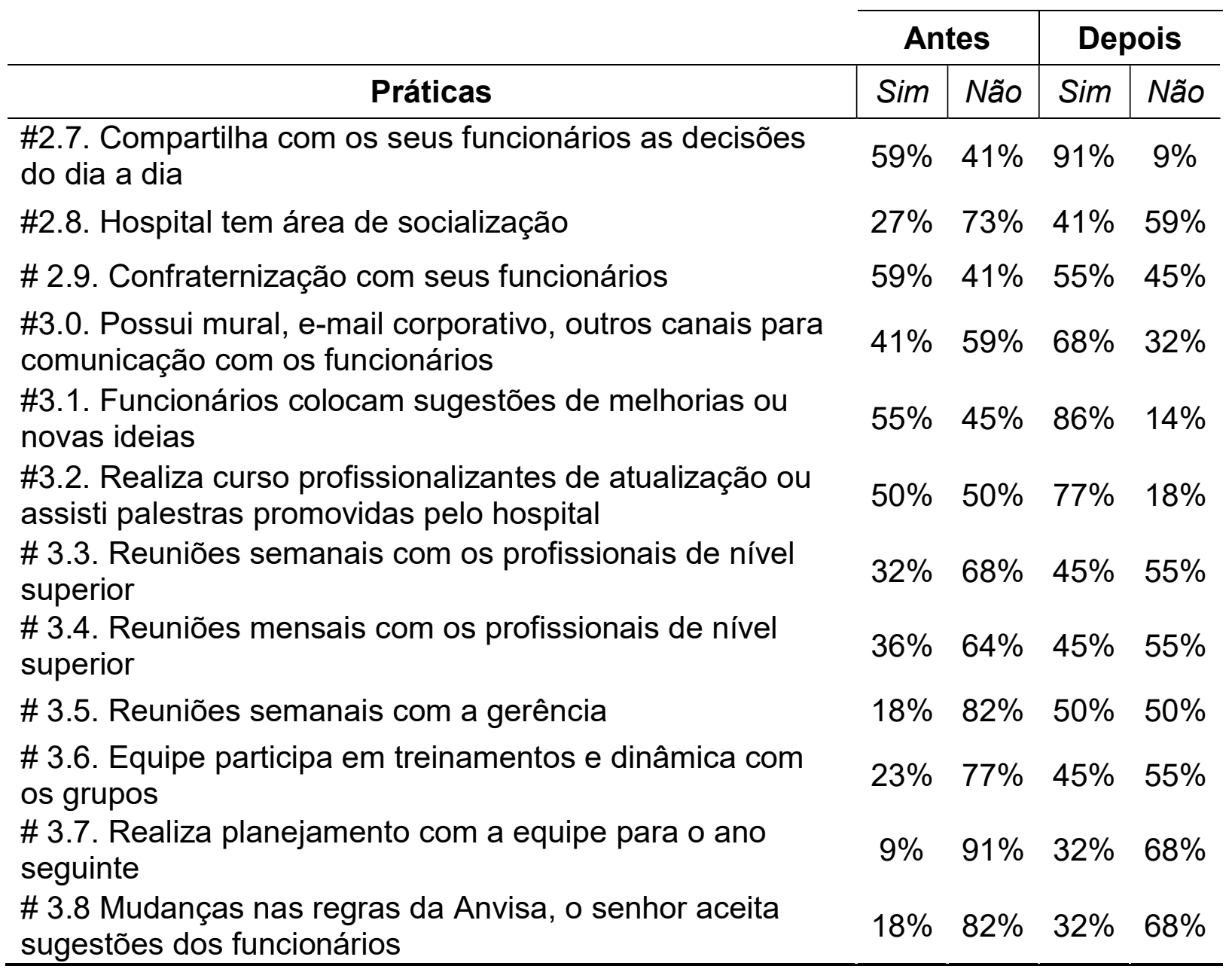

\subsection{Governanças Democráticas}

Na prática 3.11 (Tabela 12), os médicos foram questionados se incentivam os funcionários a participarem de frentes de trabalho (comissões, grupos interdisciplina- 
res para RDC-36 dos processos e procedimentos) no hospital. No que se refere à comissão para o controle infecção, antes da RDC-36, apenas $18 \%$ do total dos médicos sugeriu a utilização das práticas nesse período. Após a RDC-36, a percepção dos gestores entrevistados passou para $100 \%$ do total da amostra. Os gestores passaram a utilizar os funcionários para a difusão de procedimentos para o controle de infecção.

Na prática 3.12, que trata do compartilhamento de decisões, de acordo com os entrevistados, as decisões médicas, conforme mencionado anteriormente, são feitas pelo corpo médico; já no que refere aos assuntos multidisciplinares, inclusive novos protocolos para higienização das mãos, as decisões são compartilhadas com o corpo de enfermagem, mas os demais funcionários não são formalmente envolvidos. Antes da RDC-36, 21\% dos entrevistados percebiam que existia o compartiIhamento mais sistemático das decisões com a enfermeira-chefe (ou corpo de enfermagem) e com o médico responsável pelo controle de infecção. Após a RDC-36, de acordo com os entrevistados, a percepção desse compartilhamento mudou para $79 \%$.

Já sobre as práticas da governança democrática (3.13), foi questionado aos gestores se os funcionários conhecem os procedimentos do hospital como um todo (processos e procedimentos). Essa pergunta visou investigar se a equipe entendia os impactos da infecção hospitalar e seus impactos em outras áreas do hospital como, por exemplo, nas finanças, gestão de leitos e outros setores. Sobre o compartiIhamento de aprendizado dos padrões de higienização das mãos, antes da RDC-36, 29\% responderam que estimulava a transferência de conhecimento. Nessa mesma época, era sabido que a cultura de se falar em higienização das mãos não era disseminada na organização em estudo. Depois da RDC-36, as ações de compartilhamento sobre o objeto de estudo, a higienização das mãos teve um aumento de $79 \%$, segundo a percepção dos gestores entrevistados.

No item 3.14, foi questionado sobre a permissão de atividades acima do que está previsto, de acordo com os entrevistados isso depende até mesmo do conselho de cada profissão. Eles afirmaram ter técnicos mais experientes que médico, deu como exemplo o trabalho de alguns técnicos no processo de passagem de sonda em pacientes, esses técnicos trabalham no hospital por mais de vinte anos e tem uma experiência valiosa nos procedimentos do hospital e no tratamento do paciente. 
Relacionado à prática 3.15 - que permite que os funcionários exerçam atividades além do que está previsto (novas atividades), foi relatado pelos entrevistados que antes da RDC-36; 14\% dos médicos percebiam tal prática na realização das atividades além do que eram delegados, por exemplo: entubar um paciente. $O$ fato da permissão de atividade além de o previsto não ter sempre uma relação direta com a RDC-36, mas alguns procedimentos podem ser fatores contaminação, caso o profissional não faça a higienização das mãos de forma correta. Sendo assim, de acordo com os entrevistados, os processos de higienização ficaram mais disseminados no hospital, o que ampliou a confiança entre os líderes e equipes no que se refere ao controle de infecção (segundo os entrevistados). Essa mudança ampliou a percepção dos entrevistados para $71 \%$ sobre o uso dessa prática.

Na prática 3.16 (a participação em eventos e campanha de prevenção de infecção), antes da RDC-36, segundo os entrevistados, existia uma preocupação com o controle de infecção, mas não havia uma cultura de palestras, cursos sobre a higienização das mãos e controle de infecção. Nesse sentido, a participação nesses eventos era baixa devida a pouca oferta de eventos - a percepção de utilização dessa prática era de $11 \%$ do total de entrevistados. Após a RDC-36 a percepção da participação dos médicos aumentou para 36\%, do total dos médicos entrevistados, um dos fatores preponderantes para o aumento dessa percepção foi devido o aumento dos eventos internos no hospital.

Tabela 12 - Utilização das práticas de incentivos (antes e depois da mudança institucional)

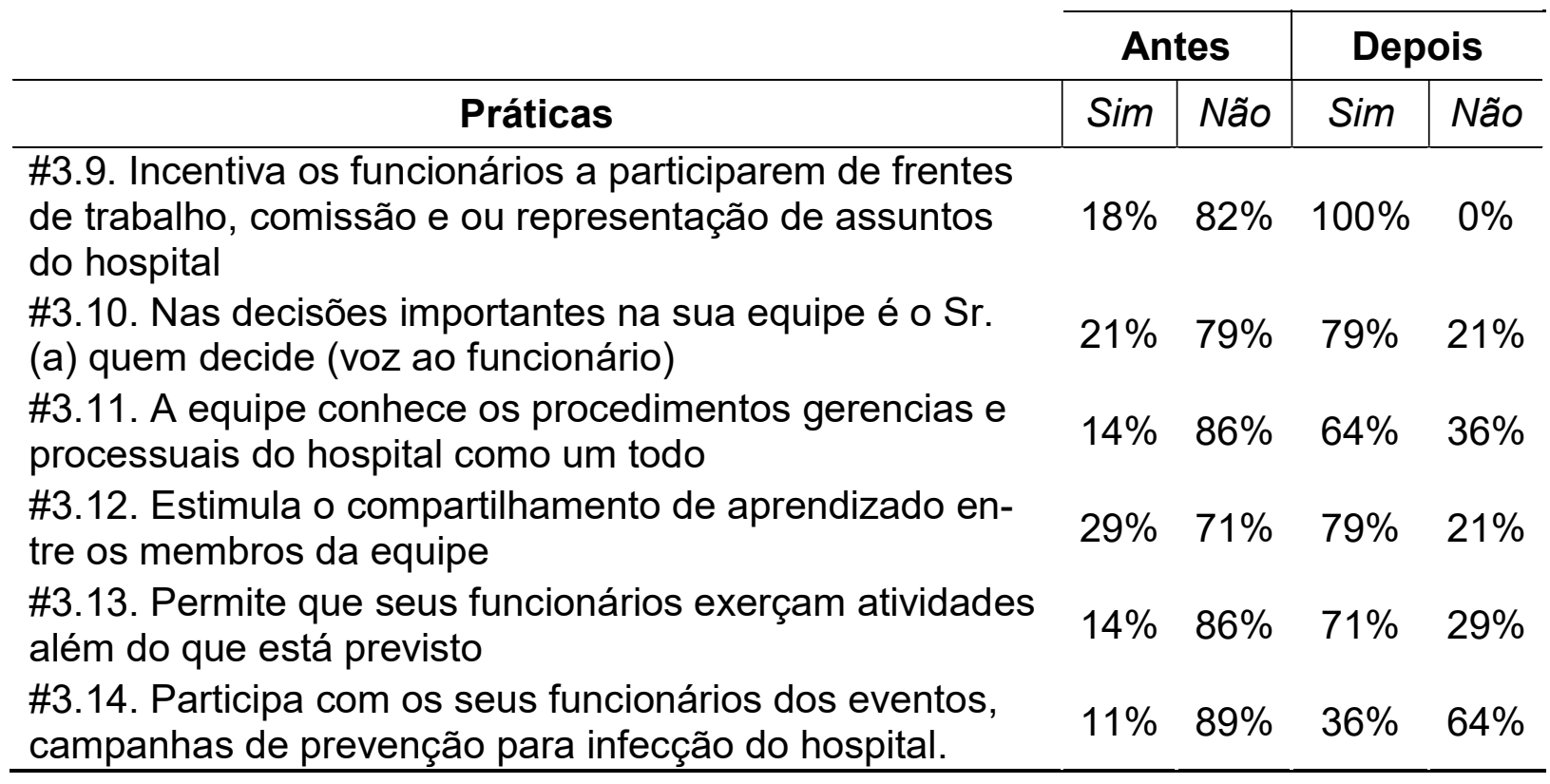




\section{PROPOSIÇÃO DE UM FRAMEWORK EXPLORATÓRIO PARA: COMO AS EMPRESAS PODEM GERENCIAR AS ESTRUTURAS DE GOVERNANÇA}

Os achados empíricos provêm insights em três aspectos. Primeiro, os achados mostram que mudanças institucionais afetam os microfundamentos da empresa. Esses resultados ilustram uma importante busca teórica, capitaneada por Felin et al. (2015) acerca do desenvolvimento dos microfundamentos da estratégia e a sua relação com o ambiente institucional. O nosso estudo ilustra que a introdução da RDC36 levou à importantes alterações nos processos de gestão e estruturas de governança. Segundo, o estudo ilustra o uso de diferentes práticas de incentivo e estruturas de governança no processo de mudança institucional. Avançando a proposição teórica de Grandori e colegas, o nosso estudo mostra de forma rica que as organizações usam práticas de forma heterogênea. Acima de tudo, os casos investigados ilustram que os gestores e funcionários têm percepções diferentes sobre o uso das práticas de governança. Nós argumentamos que tal aspecto tem importantes implicações para o desenvolvimento de novos mecanismos para a gestão da estrutura de governança.

Reconhecendo que essas diferenças de percepção são comuns em estudos qualitativos (Eisenhardt, 1989), mas o fato de termos entrevistados diferentes atores nas organizações e feito triangulação dos dados, permite que essas diferenças de percepção podem estar relacionadas também ao modo que os gestores gerenciam as estruturas de governança. Comparando antes e depois da RDC-36, foi possível identificar que gestores e funcionários têm percepções distintas sobre as práticas de incentivo da estrutura de governança. Por exemplo, na tabela 13, sobre a estrutura de governança, nós identificamos a dificuldade dos funcionários perceberem exatamente qual a estrutura de governança predomina. Ou mesmo dentro de uma determinada prática (e.g., 3.5 do segundo caso), diferentes atores dentro do hospital perceberam o uso de uma determinada prática. Em uma primeira análise, isso é um indicativo da heterogeneidade de percepção acerca da estrutura de governança. Em parte, isso decorre porque as organizações em questão não tem formalmente um processo de planejamento, definição, revisão, implementação e controle da estrutura de governança. Embora a literatura ofereça um rico entendimento sobre o que compõe as estruturas de governança, ela é também relativamente muda sobre como gerir as estruturas de governança. Nos dois casos analisados, nós identificamos, por 
meio das entrevistas e falas, que as pessoas não percebem qual é a estrutura de governança atual (ou o seu mosaico), o comportamento que essa estrutura formalmente está incentivando (ou não), qual é a mudança das práticas de incentivo e como essa mudança das práticas está alinhada ao comportamento desejado ou o objetivo organizacional a ser atingido.

Se nos casos analisados, os hospitais fazem uso incipiente das práticas de incentivo ligadas à estrutura de governança do tipo mercado, o mesmo não foi verificado acerca das outras práticas. Existe um processo de gestão, que, apesar de não codificado e formalizado, leva à alteração das práticas de governança. Seguindo um processo interativo de análise dos dados (a partir das entrevistas, e dos resultados obtidos) e confrontação com o modelo teórico que guia essa pesquisa, nós estamos propondo alguns novos constructos que podem auxiliar as empresas organizações a gerenciar as estruturas de governança em situações de mudança institucional:

- Sinalização. É quando os gestores sinalizam qual(is) aspectos da estrutura de governança vai mudar (em termos de conteúdo, intensidade, relevância) para ativar um determinado comportamento;

- Tradução. Que consiste no gestor traduzir como os aspectos das estruturas estão ligados aos comportamentos e objetivos esperados;

- Realce. As estruturas sobrepõem-se, então as pessoas não sabem qual é a mais importante naquele momento. As empresas investigadas não escoIhem de forma criteriosa qual é a estrutura ou prática mais relevante para um dado momento - a coexistência de várias estruturas ou diversos aspectos destas estruturas;

- Direcionalidade. Quando a empresa deseja mudar a estrutura, ela precisa indicar qual ou quais aspectos são os mais relevantes;

- Coerência/Consistência da Governança. Uma relação causal entre aspectos e comportamentos esperados. As organizações vão implementando práticas sem olhar o todo.

Nossos resultados indicam que gestores modificam diferentes aspectos ou elementos da estrutura de governança com determinado fim ou objetivo, isto é, nos dois casos, diminuir as ocorrências de infecções. Baseado em tal entendimento, propomos o conceito de gestão de estruturas de governança: consiste no ato de modificar, alterar, projetar, implementar e controlar os aspectos ou toda a estrutura de governança com determinado objetivo. A partir da interação entre o nosso mode- 
lo teórico e os casos, nós propomos um conjunto de constructos que ajudam a explicar como os gestores gerenciam as estruturas de governança.

\subsection{Gestão das estruturas de governança: sinalização}

O primeiro constructo identificado é a sinalização. Por sinalização, nós definimos que ocorre quando os gestores sinalizam qual (is) aspectos da estrutura de governança vai mudar (em termos de conteúdo, intensidade, relevância) para ativar um determinado comportamento. Por meio das entrevistas, nós captamos que os gestores agiram de forma deliberada para implementar as mudanças necessárias de processos e rotinas para se adequar a nova regulamentação (RDC-36). A sinalização envolve comunicar aos atores envolvidos quais são as práticas de incentivo que foram ou serão alterados. Para tanto, os gestores nas duas organizações realizaram reuniões, nas quais, explicitaram os novos procedimentos relacionados à higienização, assim como as práticas de incentivo para ativar determinado comportamento: reuniões, compartilhamento de decisões, entre outros.

Como destacamos, após a mudança institucional, algumas práticas passaram a ser mais utilizadas (como mostramos os resultados apresentados anteriormente). De forma geral, algumas práticas foram determinadas pela alta direção do hospital (quadro); mas os médicos nas duas organizações escolhem como e quando as equipe irão implementar tais práticas. A utilização de uma prática para a mudança de comportamento pode levar em conta o grau de infecção de paciente, e se a utilização de tais práticas estão associadas com resultados positivos. Os médicos sinalizam quais aspectos das governanças estão sendo modificadas para contribuir para uma bem sucedida implementação de uma dada prática. 
Quadro 3 - Evidências iniciais do construto sinalização nos casos.

\begin{tabular}{|c|c|c|c|}
\hline & $\begin{array}{c}\text { Evidências do } \\
\text { caso: Hospital } \\
\text { Arnaldo } \\
\text { Gavazza (Caso } \\
\text { 1) }\end{array}$ & $\begin{array}{c}\text { Evidências do } \\
\text { caso: Hospital } \\
\text { Nossa Senhora } \\
\text { das Dores } \\
\text { (Caso 2) }\end{array}$ \\
\hline & Entrevistados & $\begin{array}{l}\text { Enfermeiras do } \\
\text { Controle de } \\
\text { Infecção }\end{array}$ & $\begin{array}{l}\text { Gerente de } \\
\text { Qualidade e } \\
\text { Enfermeiras do } \\
\text { Controle de } \\
\text { Infecção }\end{array}$ \\
\hline Constructo & Definição & & \\
\hline Sinalização & $\begin{array}{l}\text { É quando os } \\
\text { gestores } \\
\text { sinalizam } \\
\text { qual(is) aspectos } \\
\text { da estrutura de } \\
\text { governança vai } \\
\text { mudar (em } \\
\text { termos de } \\
\text { conteúdo, } \\
\text { intensidade, } \\
\text { relevância) para } \\
\text { ativar um } \\
\text { determinado } \\
\text { comportamento. }\end{array}$ & $\begin{array}{l}\text { "Sim sempre, os } \\
\text { resultados dos } \\
\text { casos sempre } \\
\text { eram divulgados. } \\
\text { Como higienizar } \\
\text { as mãos é lei, } \\
\text { todos deviam } \\
\text { estar cientes da } \\
\text { necessidade de } \\
\text { mudança." } \\
\text { Gerente de } \\
\text { Qualidade } \\
\text { "No plano de } \\
\text { ações do CCIH, } \\
\text { eram divulgadas } \\
\text { o porquê das } \\
\text { ações e para que } \\
\text { elas estavam } \\
\text { sendo } \\
\text { implementadas." } \\
\text { Enfermeiras do } \\
\text { Controle de } \\
\text { Infecção } \\
\text { "O que as vezes } \\
\text { eram diferente } \\
\text { era as formas de } \\
\text { abordagens entre } \\
\text { os profissionais." } \\
\text { Gerente de } \\
\text { Qualidade }\end{array}$ & $\begin{array}{l}\text { "Repassava aos } \\
\text { médicos e todas } \\
\text { as informações } \\
\text { para alcançar o } \\
\text { comportamento } \\
\text { esperado } \\
\text { (esperava que os } \\
\text { funcionários } \\
\text { higienizassem } \\
\text { mais as mãos)" } \\
\text { Gerente de } \\
\text { Qualidade e } \\
\text { Enfermeiras do } \\
\text { Controle de } \\
\text { Infecção }\end{array}$ \\
\hline
\end{tabular}




\subsection{Gestão das Estruturas de Governança: Tradução}

Sinalizar quais práticas serão acrescentadas ou retiradas não é suficiente para se gerenciar as estruturas de governança. Como nós mencionamos anteriormente, os dados coletados via entrevistas sugerem que os atores nas duas organizações possuíam diferentes percepções sobre qual estrutura ou quais estruturas de governança estavam presentes ou sendo implementados. Dito em outras palavras, muitos atores tinham entendimentos diferentes sobre as práticas de incentivo e a sua relação com o comportamento/resultado esperado. A partir da análise dos dados, nós identificamos que os médicos gestores cumprem um importante papel na gestão das estruturas de governança: a tradução (Quadro 4).

Nós definimos a tradução como ato de explicar como as práticas de incentivos das estruturas de governança estão ligadas aos comportamentos e objetivos esperados. Por exemplo, gestores explicam que mudanças nas reuniões e no compartiIhamento de decisões, esses incentivos são para que os atores adotassem práticas ligadas à higienização das mãos. Nessas situações, médicos indicavam que as reuniões e discussões de procedimentos relacionados à higienização referem-se a busca de se diminuir os casos de infecção.

Analisando os casos, nós argumentamos que a tradução é um aspecto fundamental da gestão das estruturas de governança. Enquanto a sinalização indica quais aspectos estão sendo alterados, a tradução oferece uma relação (causal, associativa) entre a prática modificada, adicionada ou retirada e o comportamento esperado da equipe. Esse processo de tradução é fundamental para reduzir as ambiguidades relacionadas à mudança institucional, e os objetivos esperados a serem alcançados. 
Quadro 4 - Evidências iniciais do construto tradução nos casos.

\begin{tabular}{|c|c|c|c|}
\hline & $\begin{array}{l}\text { Evidências do } \\
\text { caso: Hospital } \\
\text { Arnaldo } \\
\text { Gavazza }\end{array}$ & $\begin{array}{l}\text { Evidências do } \\
\text { caso: Hospital } \\
\text { Nossa Senhora } \\
\text { das Dores }\end{array}$ \\
\hline & Entrevistados & $\begin{array}{l}\text { Enfermeiras do } \\
\text { Controle de } \\
\text { Infecção }\end{array}$ & $\begin{array}{l}\text { Gerente de } \\
\text { Qualidade e } \\
\text { Enfermeiras do } \\
\text { Controle de } \\
\text { Infecção }\end{array}$ \\
\hline Constructo & Definição & & \\
\hline Tradução & $\begin{array}{l}\text { Consiste no } \\
\text { gestor traduzir } \\
\text { como os } \\
\text { aspectos da } \\
\text { estruturas estão } \\
\text { ligados aos } \\
\text { comportamentos } \\
\text { e objetivos } \\
\text { esperados. }\end{array}$ & $\begin{array}{l}\text { "A equipe do } \\
\text { CCIH tomava } \\
\text { frente das ações } \\
\text { de higienização } \\
\text { das mãos, e } \\
\text { sempre que } \\
\text { havia a } \\
\text { necessidade de } \\
\text { utilizar alguma } \\
\text { prática, era } \\
\text { explicando os } \\
\text { objetivos da } \\
\text { utilização das } \\
\text { práticas e suas } \\
\text { associações." } \\
\text { Enfermeiras do } \\
\text { Controle de } \\
\text { Infecção } \\
\text { "Às vezes para } \\
\text { um público mais } \\
\text { técnico de forma } \\
\text { lúdica e para o } \\
\text { outro de forma } \\
\text { mais processual, } \\
\text { através de } \\
\text { treinamento e } \\
\text { seguindo o } \\
\text { próprio protocolo" } \\
\text { Enfermeiras do } \\
\text { Controle de } \\
\text { Infecção }\end{array}$ & $\begin{array}{l}\text { "Antes da RDC, } \\
\text { não havia ações } \\
\text { sólidas para } \\
\text { higienização das } \\
\text { mãos. Com a } \\
\text { RDC, deixou de } \\
\text { ser uma questão" } \\
\text { subjetiva, para } \\
\text { algo protocolar, } \\
\text { ou seja, } \\
\text { processual." } \\
\text { "Foram formadas } \\
\text { comissões } \\
\text { voltadas para a } \\
\text { segurança do } \\
\text { paciente e uma } \\
\text { comissão para } \\
\text { higienização das } \\
\text { mãos. Toda a } \\
\text { equipe de saúde } \\
\text { era influenciada } \\
\text { a higienizarem as } \\
\text { mãos." Gerente } \\
\text { de Qualidade e } \\
\text { Enfermeiras do } \\
\text { Controle de } \\
\text { Infecção }\end{array}$ \\
\hline
\end{tabular}




\subsection{Gestão das Estruturas de Governança: Realce e Direcionalidade}

Enquanto a sinalização oferece um guia de quais aspectos (práticas de incentivos) estão sendo modificados, acrescentados ou retirados, os gestores podem complementar a sua atuação via o realce. O realce refere-se a um problema existente na gestão de estruturas governanças. Nos dois hospitais, conforme indicado nos achados empíricos, as estruturas (os seus elementos) sobrepõem-se. Ou seja, há práticas de incentivos ligados às estruturas de governança burocrática, comunitária e democrática. Consequentemente, nós identificamos que as os gestores e os seus liderados podem ter dificuldades em saber qual é a estrutura de governança (ou práticas, conjunto de práticas) é mais importante em um dado momento. Nossas entrevistas indicaram que as organizações investigadas não explicitam de maneira formal qual é a estrutura mais relevante para um dado momento. Os resultados sugerem a coexistência de várias estruturas ou diversos aspectos dessas estruturas ao mesmo tempo.

Nos casos estudados, os dados sugerem que houve uma combinação de práticas de incentivo das estruturas de governança. Nós identificamos que elas podem ser destacadas por um determinado tempo, por meio de um mecanismo, o realce: isto é, em momentos específicos, determinadas práticas de incentivos são utilizadas, tendo maior destaque em relação à outras. No início da mudança organizacional, em resposta à RDC n. 36, práticas de incentivo ligadas à estrutura burocrática foram usadas com maior incidência (e.g. planejamento) em face de outras. O realce pode ocorrer dentro de uma mesma estrutura de governança (não usar plano de carreira, mas destacar o uso do planejamento das ações) ou entra práticas de diferentes estruturas de governança (e.g., não usar incentivos financeiros, mas apostar no compartilhamento de decisões (com sugere os dois casos analisados). Nesse sentido, o realce das práticas de incentivo ajuda na alocação de atenção dos gestores e seus liderados para as práticas de governança mais relevantes em um dado momento. 
Quadro 5 - Evidências iniciais do construto realce nos casos.

\begin{tabular}{|c|c|c|c|}
\hline \multicolumn{2}{|c|}{ Entrevistados } & $\begin{array}{l}\text { Evidências do } \\
\text { caso: Hospital } \\
\text { Arnaldo Gavazza } \\
\text { (Caso 1) }\end{array}$ & $\begin{array}{l}\text { Evidências do } \\
\text { caso: Hospital } \\
\text { Nossa Senhora } \\
\text { das Dores (Caso } \\
\text { 2) }\end{array}$ \\
\hline Constructo & Definicão & & \\
\hline Realce & $\begin{array}{l}\text { As estruturas } \\
\text { sobrepõem-se, } \\
\text { então as pessoas } \\
\text { não sabem qual é } \\
\text { a mais importante } \\
\text { naquele momento. } \\
\text { As empresas } \\
\text { investigadas não } \\
\text { escolhem de forma } \\
\text { criteriosa qual é a } \\
\text { estrutura mais } \\
\text { relevante para um } \\
\text { dado momento - } \\
\text { a coexistência de } \\
\text { várias estruturas } \\
\text { ou diversos } \\
\text { aspectos destas } \\
\text { estruturas. }\end{array}$ & 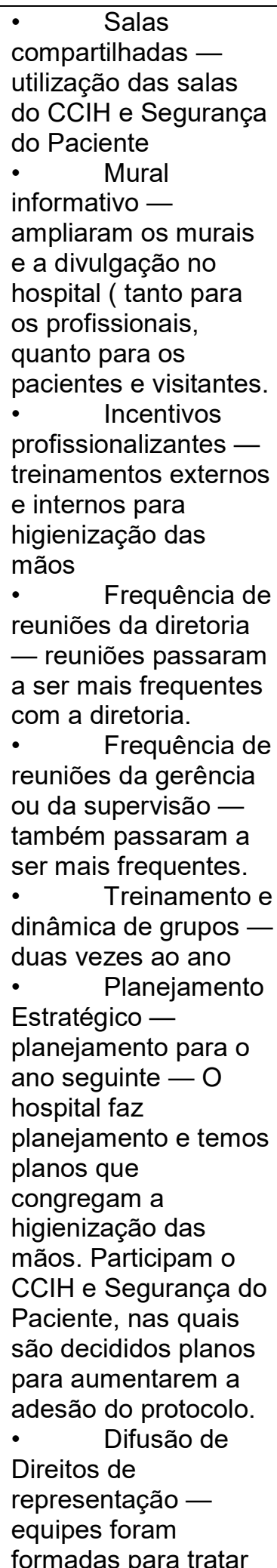 & $\begin{array}{l}\text { - Foi montada uma } \\
\text { comissão para } \\
\text { desenvolver o } \\
\text { processo da RDC, } \\
\text { coordenação } \\
\text { médica. Das } \\
\text { principais } \\
\text { mudanças } \\
\text { realizadas para } \\
\text { induzir os } \\
\text { funcionários a } \\
\text { cumprirem a meta } \\
\text { estabelecida pelo } \\
\text { hospital foram: } \\
\text { - Mural informativo } \\
\text { - Aumentaram os } \\
\text { cartazes } \\
\text { informativos no } \\
\text { hospital como um } \\
\text { todo } \\
\text { - Sistema ou forma } \\
\text { de comunicação - } \\
\text { - Incentivos } \\
\text { profissionalizantes } \\
\text { - Cursos } \\
\text { ofertados pelo SUS } \\
\text { e replicados pela } \\
\text { pessoa que } \\
\text { aprendia nos cursos } \\
\text { fora do hospital. } \\
\text { - Frequência de } \\
\text { reuniões da } \\
\text { diretoria (com a } \\
\text { Responsável por } \\
\text { cuidar dos casos de } \\
\text { infecção no } \\
\text { - Hospital). } \\
\text { - Treinamento e } \\
\text { dinâmica de grupos } \\
\text { Eratégicnto - } \\
\text { - começaram a } \\
\text { ter mais } \\
\text { - Difusão de Direitos } \\
\text { de representação } \\
\text { - foram formadas } \\
\text { comissões médicas } \\
\text { e multidisciplinares } \\
\text { para tratar do caso. } \\
\text { - Informal } \\
\text { - }\end{array}$ \\
\hline
\end{tabular}




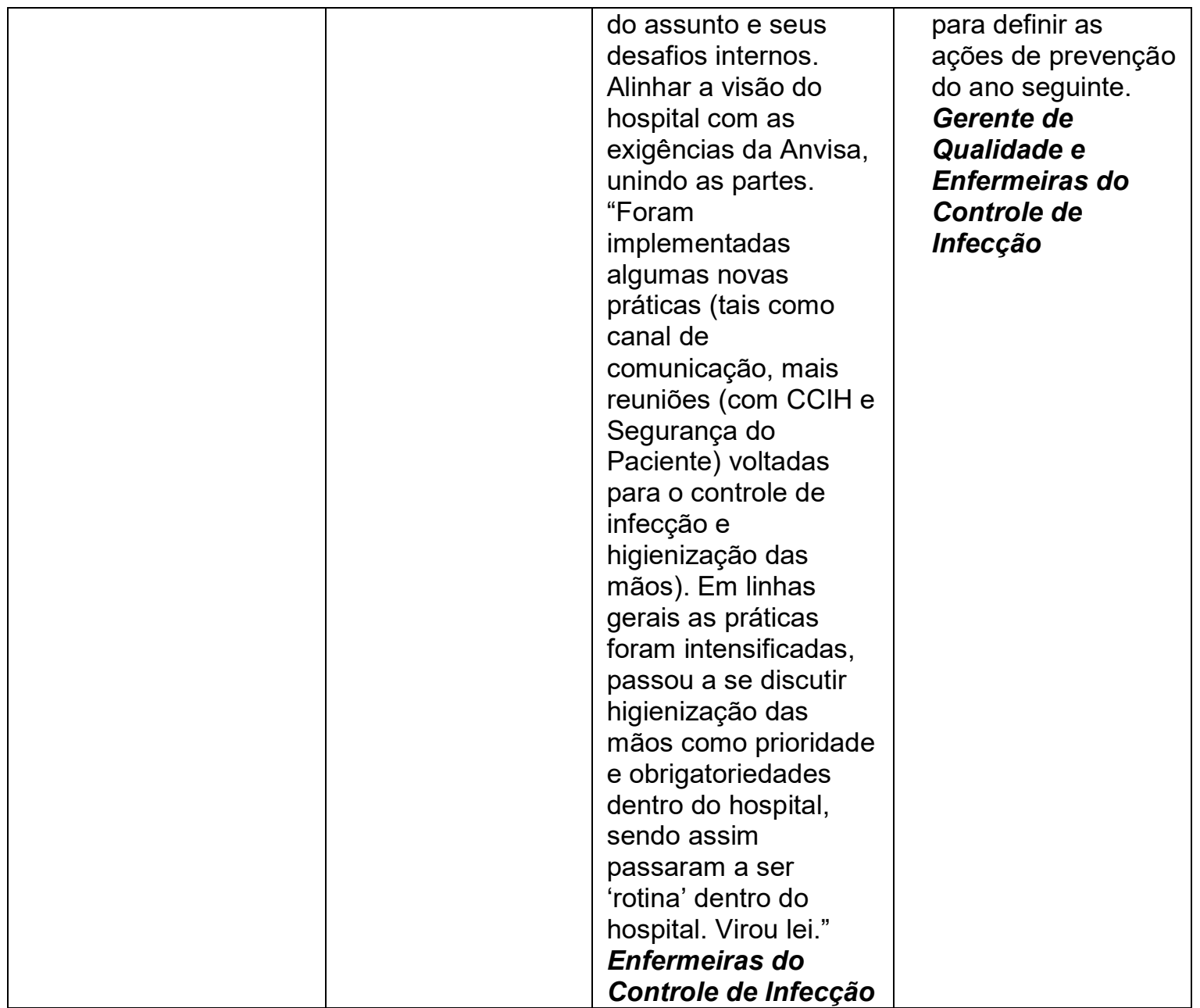

O outro constructo que emergiu dos dados é a direcionalidade (quadro 6): quando a empresa deseja mudar a estrutura, uma organização pode indicar qual arquétipo de estrutura de governança irá prevalecer e por quanto tempo. A direcionalidade por indicar que uma organização está saindo de uma estrutura mais comunitária ou democrática para uma mais burocrática. Apesar de nossos resultados serem ainda muito preliminares e não ser possível afirmar que houve ou existiu uma prevalência de uma determinada estrutura de governança sobre outra, é possível inferir que as organizações passaram a ter uma estrutura de governança mais burocrática, ligada à questão de higienização das mãos. 
Quadro 6 - Evidências iniciais do construto direcionalidade nos casos.

\begin{tabular}{|c|c|c|c|}
\hline \multicolumn{2}{|l|}{ Entrevistados } & $\begin{array}{l}\text { Evidências do } \\
\text { caso: Hospital } \\
\text { Arnaldo Gavazza } \\
\text { (Caso 1) }\end{array}$ & $\begin{array}{l}\text { Evidências do } \\
\text { caso: Hospital } \\
\text { Nossa Senhora } \\
\text { das Dores } \\
\text { (Caso 2) }\end{array}$ \\
\hline Constructo & Definição & & \\
\hline Direcionalidade & $\begin{array}{l}\text { Quando a } \\
\text { empresa } \\
\text { deseja mudar } \\
\text { a estrutura, ela } \\
\text { precisa indicar } \\
\text { qual ou quais } \\
\text { aspectos são } \\
\text { os mais } \\
\text { relevantes }\end{array}$ & $\begin{array}{l}\text { "Antes não se falava } \\
\text { em higienização das } \\
\text { mãos de forma } \\
\text { processual, como } \\
\text { regra. Não havia uma } \\
\text { cultura de se falar } \\
\text { sobre o assunto - } \\
\text { Era algo abstrato. } \\
\text { Como virou uma } \\
\text { obrigação, passaram } \\
\text { a se ter estas ações } \\
\text { (como eu te disse) } \\
\text { para tornar a regra } \\
\text { dentro do hospital e } \\
\text { mais processual. A } \\
\text { comunicação era por } \\
\text { parte do CCIH e o } \\
\text { escritório de } \\
\text { segurança do } \\
\text { Paciente, as } \\
\text { informações eram } \\
\text { repassadas para os } \\
\text { profissionais } \\
\text { (enfermeiras, } \\
\text { farmacêuticos, } \\
\text { técnicos), de saúde, e } \\
\text { para os médicos as } \\
\text { informações eram } \\
\text { repassadas nas } \\
\text { reuniões que } \\
\text { acontece somente } \\
\text { entre eles - No caso } \\
\text { do Dr. Rovilson é } \\
\text { representante dos } \\
\text { médicos no CCIH. Ele } \\
\text { comunica a equipe } \\
\text { médica sobre as } \\
\text { informações". } \\
\text { Enfermeiras do } \\
\text { Controle de Infecção }\end{array}$ & $\begin{array}{l}\text { Antes da RDC, } \\
\text { não havia ações } \\
\text { solidas para } \\
\text { higienização das } \\
\text { mãos. Com a } \\
\text { RDC, deixou de } \\
\text { ser uma questão } \\
\text { subjetiva, para } \\
\text { algo protocolar, ou } \\
\text { seja, processual. } \\
\text { Foram formadas } \\
\text { comissões } \\
\text { voltadas para a } \\
\text { segurança do } \\
\text { paciente e uma } \\
\text { comissão para } \\
\text { higienização das } \\
\text { mãos. Toda a } \\
\text { equipe de saúde } \\
\text { era influenciada a } \\
\text { higienizarem as } \\
\text { mãos". } \\
\text { Enfermeiras do } \\
\text { Controle de } \\
\text { Infecção }\end{array}$ \\
\hline
\end{tabular}




\subsection{Gestão das Estruturas de Governança: Coerência/Consistência da Governança}

Organizações implementam diferentes práticas de incentivos ligadas a distintas estruturas. Nossos dois casos sugerem que tais alterações nas práticas também ocorrem diante de uma mudança institucional. Um ponto sugerido em nossas entrevistas é a análise da consistência das práticas das estruturas de governança em uma organização. Por consistência da governança, nós sugerimos uma relação causal ou associativa das e entre as práticas das estruturas de governança e comportamentos esperados. Em nosso estudo identificamos que os hospitais utilizam oficialmente três das quatro estruturas de governança (burocrática, comunitária e democrática). As práticas foram implantadas ao longo do tempo nos hospitais, algumas são decisões do RH outras são decisões próprias da equipe, como por exemplo, as práticas que ocorrem na governança comunitária. Nós identificamos que os gestores se questionavam ou refletiam sobre a coerência/consistências dessas práticas de incentivo e como elas levariam ao resultado esperado (redução dos quadros de infecção por problemas de higienização das mãos).

Quadro 7 - Evidências iniciais do construto Coerência/consistência nos casos.

\begin{tabular}{|c|c|c|c|}
\hline \multicolumn{2}{|l|}{ Entrevistados } & \multirow[t]{2}{*}{$\begin{array}{l}\text { Evidências do caso: } \\
\text { Hospital Arnaldo } \\
\text { Gavazza (Caso 1) }\end{array}$} & \multirow[t]{2}{*}{$\begin{array}{l}\text { Evidências do } \\
\text { caso: Hospital } \\
\text { Nossa Senhora } \\
\text { das Dores } \\
\text { (Caso 2) }\end{array}$} \\
\hline Constructo & finição & & \\
\hline $\begin{array}{l}\text { Coerência/consistê } \\
\text { ncia }\end{array}$ & $\begin{array}{l}\text { Uma relação } \\
\text { causal entre } \\
\text { aspectos e } \\
\text { comportament } \\
\text { os esperados. } \\
\text { As } \\
\text { organizações } \\
\text { vão } \\
\text { implementand } \\
\text { o práticas sem } \\
\text { olhar o todo. }\end{array}$ & $\begin{array}{l}\text { "Não havia conflito, era uma } \\
\text { decisão do governo em } \\
\text { ampliar a cultura de } \\
\text { higienização das mãos, e o } \\
\text { hospital foi adequando ao } \\
\text { protocolo gradualmente. } \\
\text { Sendo uma ordem } \\
\text { institucional fica mais fácil } \\
\text { de conduzir internamente. } \\
\text { Sim, sempre era explicado } \\
\text { para que era tal prática e o } \\
\text { que se esperava (tornar } \\
\text { hábito a higienização das } \\
\text { mãos). E também havia } \\
\text { cooperação entre área de }\end{array}$ & $\begin{array}{l}\text { "Antes da RDC, } \\
\text { não havia ações } \\
\text { solidas para } \\
\text { higienização das } \\
\text { mãos. Com a } \\
\text { RDC, deixou de } \\
\text { ser uma questão } \\
\text { subjetiva, para } \\
\text { algo protocolar, } \\
\text { ou seja, } \\
\text { processual. } \\
\text { Foram formadas } \\
\text { comissões } \\
\text { voltadas para a }\end{array}$ \\
\hline
\end{tabular}




\begin{tabular}{|c|c|c|c|}
\hline & & $\begin{array}{l}\text { qualidade e de SP. Sempre } \\
\text { era enfatizado que as } \\
\text { práticas eram para } \\
\text { aumentar a adesão da } \\
\text { higienização das mãos e e } \\
\text { diminuir os indicadores. } \\
\text { Eram utilizados cartazes, } \\
\text { reuniões, dinâmicas da luz } \\
\text { entre outras dinâmicas entre } \\
\text { as práticas já citadas. O RH } \\
\text { não participou do processo. } \\
\text { Às vezes fazer o pessoal } \\
\text { participar de treinamentos e } \\
\text { reuniões era um pouco } \\
\text { difícil, mas no geral todos } \\
\text { participavam. E algumas } \\
\text { práticas para algumas } \\
\text { pessoas tinham melhor } \\
\text { adesão e para outras nem } \\
\text { tanto. Os niveis mais } \\
\text { operacionais tem melhores } \\
\text { resultados com atividades } \\
\text { lúdicas. Em época de frio e } \\
\text { com o aumento do número } \\
\text { de procedimentos invasivos, } \\
\text { aumenta o número de casos } \\
\text { de infecção - dado a } \\
\text { natureza dos procedimentos } \\
\text { ou por falta de higienização } \\
\text { das mãos mesmo." } \\
\text { Enfermeiras do Controle } \\
\text { de Infecção }\end{array}$ & $\begin{array}{l}\text { segurança do } \\
\text { paciente e uma } \\
\text { comissão para } \\
\text { higienização das } \\
\text { mãos. Toda a } \\
\text { equipe de saúde } \\
\text { era influenciada } \\
\text { a higienizarem as } \\
\text { mãos". } \\
\text { Enfermeiras do } \\
\text { Controle de de } \\
\text { Infecção }\end{array}$ \\
\hline
\end{tabular}

\subsection{Caso Complementar: Ilustrando os Constructos}

\subsubsection{Hospital Ibiapaba - Barbacena, Minas Gerais}

O presente estudo de caso tem o objetivo de verificar os construtos propostos com base nos resultados dos estudos de casos anteriores. Um dos resultados apontados na primeira etapa da pesquisa, concluiu que os gestores utilizam as práticas de incentivos de forma multimodal, ou seja, não existe um critério linear, lógico para utilização das práticas de incentivos. Essa gestão das práticas é categorizada por Grandori (2017); Grandori e Furnari $(2008,2010)$ de forma multimodal no gerencia- 
mento das práticas de incentivos no processo de mudança organizacional e melhoria continua no contexto de transição institucional, a RDC-36.

O nosso objetivo aqui neste estudo de caso é o de verificar os construtos tradução, sinalização, realce, direcionalidade, coerência/consistência da governança - propostos nos resultados, que visa auxiliar as organizações, hospitalares ou não, no contexto da mudança organizacional a gerenciarem suas estruturas de governança internas.

\subsubsection{Breve Descrição do Hospital}

O Hospital Ibiapaba teve seu primeiro projeto de construção realizado no ano de 1964, no município de Barbacena, MG, sendo inaugurado em 1967. O hospital é considerado referência em alta complexidade, em oncologia, atendendo uma média de 400 pacientes/mês. Em 2005, foi publicada a Portaria do Ministério da Saúde que credenciou a Unidade de Alta Complexidade Cardiológica do Hospital Ibiapaba como referência macrorregional (região da Zona da Mata e Campos da Vertente), atingindo uma população estimada em 750 mil pessoas em 51 cidades da Região CentroSul de Minas Gerais.

Atualmente, a área física do hospital é superior a $7200 \mathrm{~m}^{2}$, com 120 leitos e uma média de 380 funcionários diretos - distribuídos em cargos de gestão e assistência à saúde. $O$ corpo clínico é composto por 120 médicos de diferentes especialidades, com isso soma-se um total de 500 funcionários.

\subsubsection{Apresentação da estrutura organizacional}

A estrutura organizacional do hospital é composta pela mesa diretora, que está dividida entre corpo clínico - médicos especialistas - , dois procuradores e os membros fiscais. As questões estratégicas são executadas por um administrador que realiza os desdobramentos do conselho. Os demais níveis são compostos por cargos de liderança médicas e administrativas, entre outras, tais como coordenadores e gerentes. 


\subsubsection{Informações Gerais dos Entrevistados}

Neste caso, entrevistamos os funcionários responsáveis pela gestão e implantação dos processos de qualidade continua no controle de infecção hospitalar. Respeitando esses critérios, foram entrevistados: a gerente da segurança do paciente que trabalha no hospital a mais de vinte anos, que é também responsável pela e gestão da qualidade do hospital. Essa mesma gestora foi responsável pelo desenvolvimento e institucionalização dos protocolos da RDC-36 no hospital.

Também entrevistados também os dois gestores do $\mathrm{CCIH}$, o enfermeiro, que está na instituição a quinze anos. Ele é responsável pelos indicadores de infecção do hospital, além das medidas de disseminação da cultura de higienização das mãos no hospital e, por fim o médico infectologista, que está na instituição a seis anos. Esse médico, é o gestor responsável pelo controle de infecção no ambiente hospitalar e nos pacientes, é ele quem sugere e decide a prescrição das medicações os pacientes infectados. Além da gestão do $\mathrm{CClH}$, ambos compõem a comissão multidisciplinar de gestão da adequação do Protocolo de Higienização das Mãos e outros assuntos relacionados à RDC-36 no hospital.

\subsubsection{Estruturas de governança interna}

O hospital começou sua estratégia de controle de infecção desde sua fundação. As ações de controle de infecção eram focadas em casos de infecções endógenas (casos internos), na qual os fatores determinantes estão associados ao organismo do paciente. Após esse período as ações de controle da infecção intensificaram com a lei sancionada em 06 de janeiro 1997 de n. ${ }^{\circ} 9431$.

Após a sanção desta lei, o hospital começou a ampliar as medidas internas para melhorar os padrões de higienização das mãos, acrescentando em seus indicadores os casos de infecção nosocomial, não dispensando as outras formas de infecção adquirida. Entre 1997 e 2012, o hospital desenvolvia algumas medidas para criar padrões de higienização das mãos entre os funcionários. De acordo com relatos dos profissionais entrevistados, a higienização das mãos era um tema tratado de forma abstrata pelos funcionários do hospital, não havia medidas lineares e concretas para a motivação dos funcionários. Mesmo assim o $\mathrm{CCIH}$ neste período atuava 
em casos relacionados a infecção endógena, não havendo outros departamentos envolvidos nos procedimentos e higienização das mãos. As principais práticas implementadas naquele período estão apresentadas no quadro 7, abaixo:

Quadro 8 - Práticas de incentivos utilizadas antes da RDC-36.

\# 3.0. Canal de comunicação - possui mural, e-mail corporativo, outros canais para comunicação com os funcionários.

\# 3.2. Trabalho em equipe - Realiza cursos profissionalizantes de atualização ou assisti palestras promovidas pelo hospital.

\# 3.6. Trabalho em equipe - Equipe participa de treinamentos e dinâmica com os grupos.
'O CCIH de forma simples buscava desenvolver campanhas para apresentar como se higienizava as mãos e os indicadores eram mais gerais"

- Gestora do Núcleo de Segurança do Paciente e da qualidade.

"Havia sim, mas não contemplava a temática higienização das mãos; mas sim controle de infecção". Gestora do Núcleo de Segurança do Paciente e da qualidade.

"Havia poucos, mas com pouca adesão e participação dos funcionários"; Gestora do Núcleo de Segurança do Paciente e da qualidade.

\begin{abstract}
"Não havia uma cultura de higienização das mãos, eram realizadas poucas ações e de forma vaga, sem muito empenho e medição dos resultados. $O$ tema não era tratado de forma obrigatória pela direção do hospital, os casos de infecção endógena havia mais assistência por parte da direção" Gestora do Núcleo de Segurança do Paciente e do Setor de Qualidade.
\end{abstract}

Em 2013, com a RDC-36 o hospital desenvolveu diferentes estratégias para que o processo de higienização das mãos tornasse um hábito entre suas equipes, mas para isso a direção teve que realizar algumas mudanças para que adquirissem o hábito, seguindo as especificidades da regra. Seguindo os critérios da norma, foram realizados investimentos físicos na estrutura do hospital adequando-o as exigências da RDC-36. Foram feitos os seguintes investimentos: Dispenser de álcool, que foi colocado desde a porta de acesso ao hospital, nos corredores e dentro dos quartos dos pacientes. Investiram também lavabos nos quartos dos pacientes e nos consultórios médicos, foram afixados murais que contém cartazes explicando os momentos de como higienizar as mãos, em conformidade com o protocolo contido na RDC-36.

Outras medidas desenvolvidas, com foco na mudança comportamental, foram para induzir os profissionais no processo de adesão da cultura de higienização das mãos. Para se alcançar os resultados, as agências sanitárias e organização mundial 
da saúde, desenvolveram relatórios que apoiam os gestores das instituições de saúde nas decisões e planos ações a serem desenvolvidas nas unidades de saúde. Como bases nesses relatórios e estratégias conjuntas da equipe multidisciplinar ( $\mathrm{CCIH}$, Segurança do Paciente e Gestão da Qualidade) foram desenvolvidas e utilizadas as seguintes práticas de incentivos no hospital lbiapaba, apresentadas no quadro 8. Os respondentes das perguntas referente ao protocolo - 2, foram a Gestora do Núcleo de Segurança do Paciente e do Setor de Qualidade e Gestores do $\mathrm{CCIH}$.

Quadro 7 - Práticas de incentivos utilizadas depois da RDC-36.

\begin{tabular}{|c|c|}
\hline Práticas de Incentivos & Como são utilizadas atualmente. \\
\hline \#2.3. Planejamento Estratégico & $\begin{array}{l}\text { "É realizado uma vez por ano com a presença de um } \\
\text { membro do CCIH e a gerencia de Qualidade e } \\
\text { Segurança do Paciente e outros setores envolvidos" } \\
\text { Gestora do Núcleo de Segurança do Paciente e da } \\
\text { qualidade. }\end{array}$ \\
\hline $\begin{array}{l}\text { \#2.4. Programa e processo de } \\
\text { controle da qualidade das } \\
\text { atividades e tarefas }\end{array}$ & $\begin{array}{l}\text { "Após a RDC-36 foi criado um setor de qualidade para } \\
\text { desenvolver os protocolos [da RDC] e outros processos } \\
\text { da instituição relacionado a saúde" Gestora do Núcleo } \\
\text { de Segurança do Paciente e da qualidade. }\end{array}$ \\
\hline $\begin{array}{l}\text { \#2.5. Sistema de a } \\
\text { desempenho - fee }\end{array}$ & $\begin{array}{l}\text { "Foi adicionada ao sistema de avaliação de } \\
\text { desempenho, a avaliação do uso de equipamentos de } \\
\text { proteção individual, que inclui higienização das mãos" } \\
\text { Gestora do Núcleo de Segurança do Paciente e da } \\
\text { qualidade. }\end{array}$ \\
\hline $\begin{array}{l}\# 2 . \varsigma \\
\text { cont }\end{array}$ & $\begin{array}{l}\text { "Uma vez por ano o hospital realiza um encontro com } \\
\text { todos os funcionários. Nesse encontro tem se uma } \\
\text { premiação relacionada ao controle de infecção" Gestora } \\
\text { do Núcleo de Segurança do Paciente e da qualidade. }\end{array}$ \\
\hline $\begin{array}{l}\text { \#3.0. Canais de Comunicaçãa a } \\
\text { (Mural informativo e outros). }\end{array}$ & $\begin{array}{l}\text { "Nas áreas em comum e dentro dos consultórios e nos } \\
\text { quartos pacientes foram colocados murais para fixação } \\
\text { de cartazes autoexplicativos. Em algumas sessões são } \\
\text { expostos os índices de infecção hospitalar nesses } \\
\text { murais" Gestora do Núcleo de Segurança do } \\
\text { Paciente e da qualidade. }\end{array}$ \\
\hline $\begin{array}{l}\text { \#3.1. Sistema ou forma de } \\
\text { comunicação com os } \\
\text { funcionários/pacientes para } \\
\text { sugestões ou novas ideias. }\end{array}$ & $\begin{array}{l}\text { "Serviços de Intranet para os funcionários e sistema de } \\
\text { sugestões para os pacientes. Nesse caso, os assuntos } \\
\text { podiam ser relacionados ou não à higienização das } \\
\text { mãos" Gestora do Núcleo de Segurança do Paciente } \\
\text { e da qualidade. }\end{array}$ \\
\hline $\begin{array}{l}\text { \# 3.2. Realiza cursos } \\
\text { profissionalizantes de atualização } \\
\text { ou assisti palestras promovidas }\end{array}$ & $\begin{array}{l}\text { "Participa as seguintes áreas: CCIH, Segurança do } \\
\text { Paciente e Qualidade e a Gestão da Qualidade". } \\
\text { Também participa a Diretora administrativa do hospital. }\end{array}$ \\
\hline
\end{tabular}




\begin{tabular}{|l|l|}
\hline pelo hospital. & $\begin{array}{l}\text { Antes de eu assumir o cargo de gestora da qualidade, } \\
\text { ela era a gestora" Gestora do Núcleo de Segurança } \\
\text { do Paciente e da qualidade. }\end{array}$ \\
\hline $\begin{array}{l}\text { \#3.5. Frequência de reuniões da } \\
\text { gerência ou da supervisão. }\end{array}$ & $\begin{array}{l}\text { "Passaram a ser mensalmente: uma reunião com o } \\
\text { CCIH e a outra com o núcleo de segurança do } \\
\text { paciente". Participa um membro de cada equipe, das } \\
\text { comissões do hospital" Gestora do Núcleo de } \\
\text { Segurança do Paciente e da qualidade. }\end{array}$ \\
\hline $\begin{array}{l}\text { \#3.7. Quem participa do } \\
\text { planejamento para o ano } \\
\text { seguinte. }\end{array}$ & $\begin{array}{l}\text { "Toda a equipe do hospital é envolvida no processo de } \\
\text { gestão. Para cada departamento é convidado um } \\
\text { Gestor. No caso do controle de infecção participam o } \\
\text { CClH, Gestora do Núcleo de Segurança do Paciente } \\
\text { e da qualidade. }\end{array}$ \\
\hline $\begin{array}{l}\text { \#3.9. Incentiva os funcionários a } \\
\text { participarem de frentes de } \\
\text { trabalho, comissão e ou } \\
\text { representação de assuntos do } \\
\text { hospital. }\end{array}$ & $\begin{array}{l}\text { "Existem representações dos diretos de representação. } \\
\text { São divididos por categoria e conselhos". No caso da } \\
\text { comissão de segurança do paciente (higienização das } \\
\text { mãos) temos um representante de cada departamento" } \\
\text { Gestora do Núcleo de Segurança do Paciente e do } \\
\text { Setor de Qualidade. }\end{array}$ \\
\hline
\end{tabular}

\subsubsection{Ilustrando os Constructos de Gestão das Práticas de Incentivo}

As entrevistas com o hospital Ibiapaba tiverem o objetivo analisar quais foram às estratégias utilizadas pelo hospital para analisar o comportamento de higienização das mãos na instituição antes e depois da RDC-36. Para obter informações detalhadas do processo de mudança, foram entrevistados funcionários responsáveis pelo gerenciamento de controle de infecção no hospital, sendo eles: gerente de qualidade, gerente de segurança do paciente, enfermeiro e médico infectologista gestores do $\mathrm{CClH}$.

De acordo com a gerente de segurança do paciente, que trabalha na instituição há vinte e um anos, antes da promulgação da RDC-36, o hospital tinha uma política pouco abrangente sobre a conscientização da higienização das mãos. As práticas de incentivos que existiam estão citadas no quadro 9. Observou-se a falta de incentivos monetários neste processo de mudança.

Ainda de acordo com a gerente de segurança do paciente, não existia uma cultura de higienização das mãos no hospital; pouco se falava em higienização das mãos e sua real importância. Até o ano de 2012, as questões relacionadas à infecção eram uma atividade exclusiva do $\mathrm{CClH}$, com o foco voltado paras as infecções endógena e sazonal. O setor ainda se mantém atuante no hospital, auxiliando os médicos nas prescrições de medicamentos e geração de informações sobre o controle de infecção do hospital. 
Em 2013, com a institucionalização da RDC-36, o hospital passou por algumas mudanças para atender a nova regulamentação. As principais medidas estão descritas no quadro 9. As práticas de incentivos foram desenvolvidas de acordo com o mapeamento dos eventos adversos, casos de infecção nosocomial ocorridos no hospital ao longo dos anos. A gestora sugeriu que as práticas de incentivos foram aos poucos sendo implementadas para atender a mudança institucional - a RDC36. A gestora indicou que houve incorporação de práticas a processos já existentes e também intensificação da utilização de outras na rotina da instituição.

A coleta de dados nesse caso complementar também ofereceu exemplos ilustrativos acerca dos novos construtos emergidos nos resultados das pesquisas anteriores - Hospital Nossa Senhora das Dores e Hospital Arnaldo Gavazza Filho -, de forma a traduzir o entendimento no processo de transição e escolha das práticas de incentivos e estrutura de governança.

\subsubsection{Realce}

Para atingir os resultados, foram utilizadas diferentes práticas de incentivos, principalmente as das estruturas de governança - burocrática, comunitária e democrática. Essas práticas foram utilizadas de forma sincronizada, seguindo alguns critérios da organização, tais como prioridade, ampliação da comunicação e disseminação da informação, no caso higienização das mãos. A estrutura de governança mercado não está presente na gestão do lbiapaba.

De uma forma geral, foram utilizadas as seguintes práticas de incentivos: campanhas de conscientização e treinamentos, com as práticas com os indicadores que monitoram essas infecções relacionadas à saúde, engajamento social, treinando as pessoas a cobrar do outro a higienização das mãos e hoje a sociedade está muito esclarecida, as pessoas estão atentas uns aos outros.

Segundo a gestora, algumas práticas existentes foram reforçadas e destacadas durante o processo de mudança. De acordo com a gestora, foram confeccionados cartazes ilustrativos e placas sobre higienização das mãos. Também foram criados o plano da segurança do paciente em 2018, em conjunto com a (equipe multidisciplinar); nesse plano, eram discutidos os protocolos da RDC-36.

$\mathrm{Na}$ visão da gestora, as práticas de incentivos citadas acima foram consideradas essenciais no processo de transição. De uma forma geral, cada nível da estrutu- 
ra organizacional compreende uma prática de incentivo com mais facilidade, mas coube aos gestores e representantes de cada setor, frisar a importância de cada prática no processo de mudança organizacional.

\subsubsection{Tradução}

Todo o processo de disseminação das práticas para higienização das mãos foi um processo de muita reflexão dentro do hospital, de acordo com a gestora. Ela argumentou que sempre era prefaciado e enfatizando que a utilização de uma determinada prática de incentivo era para incentivar a higienização das mãos. A gestora destacou o papel de explicar que diferentes tipos de práticas de incentivos estavam ligadas aos objetivos organizacionais de higienização das mãos e controle de infecção, de acordo com o contexto/contingência.

A gestora destacou que a organizações adotou ações mais lúdicas para engajar o nível mais operacional, tais como técnicos em enfermagem, faxineiros entre outros. Com os médicos e demais gestores, foram adotadas as reuniões com a apresentação de indicadores. Como por exemplo, aumentamos as reuniões em dois encontros, essa mudança ampliou a consciência do engajamento dos atores envolvidos na diminuição dos indicadores.

\subsubsection{Sinalização}

O processo de transição institucional, fez com que o hospital organizasse todo o seu processo de gestão. Algumas práticas, tal como planejamento para o ano seguinte, são discutidos como serão abordado as mudanças na organização, como por exemplo: ampliação das reuniões, intensificação das práticas de incentivos no mês de maio dentre outros. De acordo com a Gestora de Qualidade e Segurança do Paciente, "ficava claro sim (o porquê da utilização de cada prática), pois tudo era direcionado a higienização das mãos... reuniões, quadros com informações o uso da intranet, redes sociais, tudo de certa forma foi intensificado".

Um exemplo citado pelo médico gestor do $\mathrm{CCIH}$, será a implementação de uma nova prática para 2020 , os médicos receberão um certificado constando que ele foi o médico com o maior índice de contaminação no mês. Na visão da gestora, essa prática visa melhorar o padrão de comportamento do médico, principalmente 
no processo de higienização das mãos. Nesse certificado, contém dados de infecção de todas as especialidades.

\subsubsection{Direcionalidade}

Passou a ter mais conscientização, utilizamos mais os canais de comunicação, tais como: as redes sociais, murais. Passou a ter mais divulgação (ficou mais divulgado). Antigamente era mais falado, com muito déficit em fazer, hoje é o contrário se faz mais, tem uma cultura melhor que antes. Está mais na "cabeça" das pessoas, elas estão mais conscientes [com o processo de higienização das mãos]. (palavras da gestora) - do Núcleo de Segurança do Paciente e do Setor de Qualidade.

É percebido que foi intensificada, as práticas das estruturas de governança burocrática (Planejamento estratégico e Programa e processo de controle da qualidade) e comunitária (Compartilhamento de informações e valores, Canal de comunicação, Trabalho em equipe, Compartilhamento da decisão), a estrutura de governança democrática, também tiveram aumento da sua importância; principalmente com as comissões de representação, no caso da RDC-36, cada um dos protocolos teve um time de representante.

\subsubsection{Coerência}

De acordo com a gestora de dualidade e segurança do paciente, entrevistada não havia conflito entre as práticas: "aqui na organização não incentivamos a competição entre os funcionários, temos a metodologia de recompensá-los, motivá-los, ensinar a fazer. Nas dinâmicas, existe um sistema de recompensa (e.g.: pequenos presentes e lembranças)."

Desde que a organização, introduziu a gestão da qualidade, a gestora destacou que:

"A gente começa a trabalhar os colaboradores com essa questão dos processos (Protocolo de Higienização das Mãos) e a atuação de cada um em sua atividade. Atualmente as pessoas estão maduras quanto às metas e resultados (relacionadas à higienização das mãos). Antigamente, não tinha essa maturidade, eram passados, eram informados, mas infelizmente as pessoas não conseguia assimilar. Com a ajuda da qualidade, cada vez mais aprimorando as pessoas (criou-se uma cultura), tirando que, hoje aqui o turn over é alto, isso faz com que temos que sempre está treinando o funcioná- 
rio, que ás vezes chega aqui, sem nenhuma orientação sobre a higienização das mãos. "Até instituir uma cultura de higienização em uma pessoa, demora um pouco e tempo" Gestora do Núcleo de Segurança do Paciente e do Setor de Qualidade.

Existe um tempo de assimilação da utilização das práticas de incentivos, como citado pela gestora. "Até as pessoas aderirem à mudança de comportamento, ou seja, a nova cultura para a higienização das mãos demorou um pouco, mas com as ações que tivemos para prover as mudanças, fomos conquistando aos poucos" (nas palavras da gestora).

Quadro 8 - Exemplos ilustrativos dos constructos, a partir dos dados coletados do Hospital Ibiapaba.

\begin{tabular}{|l|l|}
\hline Constructo & Evidências do estudo de caso com o Hospital Ibiapaba \\
\hline "Então o que acontece, aqui no Hospital já lida com \\
sistema de Gestão da Qualidade, então a gente tem \\
algumas certificações, igual a ISO 9001:2008, a gente \\
têm alguns requisitos que a gente precisa estar atuando. \\
E as infecções relacionadas a assistência a saúde tá \\
envolvido nesse processo, a higienização das Mãos. \\
Não teve nenhum incentivo de forma financeira e \\
nenhuma agregação em questão de planos de carreira. \\
A gente lida muito aqui com a conscientização, com as \\
práticas com os indicadores que monitoram essas \\
infecções relacionadas à saúde. Fazemos campanhas \\
de conscientização e treinamentos utilizamos, como nós \\
somos um hospital filantrópico setenta por cento SUS e \\
trinta por cento de convênios e particulares, nós \\
recebemos estagiários, aonde a gente trabalha com \\
esses estagiários a conscientização, tanto de pacientes, \\
acompanhantes e colaboradores (eles atuam como \\
sentinelas) fazemos o seguinte: a gente educa as \\
pessoas a cobrar do outro a higienização das mãos e \\
hoje a sociedade está muito esclarecida, as pessoas \\
estão atentas uns aos outros. Quando alguém do \\
atendimento não higieniza as mãos, o paciente \\
acompanhante pergunta" Gestora do Núcleo de de \\
Segurança do Paciente e Gestores do CcllH." \\
"Fizemos cartazes ilustrativos e placas sobre \\
higienização das mãos. A nossa parte mesmo, é de \\
campanhas educativas, treinamentos introdutórios \\
(aonde falamos dessa prática com o CCIH), em Maio a \\
gente comemora a campanha mundial de higienização \\
das mãos. Atuamos mais na parte educativa a gente faz \\
e monitora indicadores".
\end{tabular}




\begin{tabular}{|c|c|}
\hline & $\begin{array}{l}\text { "Passou a ter mais reuniões... mensalmente a gente tem } \\
\text { a reunião da CCIH, também passou a ter a reunião do } \\
\text { núcleo de segurança do paciente, aonde agente tem } \\
\text { mensalmente, nessa reunião são discutidos os } \\
\text { indicadores. A gente criou dentro do plano da segurança } \\
\text { do paciente no ano passado em } 2018 \text {, criamos um time } \\
\text { (equipe multidisciplinar) relacionados aos protocolos da } \\
\text { RDC-36 - dentro no núcleo nos dividimos os protocolo } \\
\text { entre cada um do time. E tem o Protocolo de } \\
\text { Higienização das Mãos" Gestora do Núcleo de } \\
\text { Segurança do Paciente e Gestores do CCIH. } \\
\text { "Quando as práticas são mais lúdicas, como por } \\
\text { exemplo, quando fazemos a dinâmica de usar tinta } \\
\text { guache e manda-a fazer o processo, quando a pessoas } \\
\text { tira a venda olha pra sí (para as mãos) e vê como não } \\
\text { soube usar o processo de higienização das mãos } \\
\text { adequadamente. Tudo que envolve a parte lúdica, } \\
\text { dinâmica, tudo que envolve música, mais que a parte } \\
\text { muito teórica" Gestora do Núcleo de Segurança do } \\
\text { Paciente e Gestores do CClH. }\end{array}$ \\
\hline Tradução & $\begin{array}{l}\text { "Todo o processo de conscientização da higienização } \\
\text { das mãos, sempre era prefaciado, sempre enfatizando } \\
\text { que aquela ação era para higienização das mãos, o que } \\
\text { mudava talvez fossem os tipos de práticas em } \\
\text { determinada circunstância" Gestora do Núcleo de } \\
\text { Segurança do Paciente e Gestores do CCIH. }\end{array}$ \\
\hline Sinalização & $\begin{array}{l}\text { "Ficava claro sim... (o porquê da utilização de cada } \\
\text { prática), pois tudo era direcionado a higienização das } \\
\text { mãos...reuniões, quadros com informações o uso da } \\
\text { intranet, redes sociais, tudo de uma certa forma foi } \\
\text { intensificado" Gestora do Núcleo de Segurança do } \\
\text { Paciente e Gestores do CCIH. }\end{array}$ \\
\hline Direcionalidade & $\begin{array}{l}\text { "Passou a ter mais conscientização, passou a utilizar } \\
\text { mais as redes sociais, murais. Passou a ter mais } \\
\text { divulgação (ficou mais divulgado). Antigamente era mais } \\
\text { falado, com muito déficit em fazer, hoje é o contrário se } \\
\text { faz mais, tem uma cultura melhor que antes. Está mais } \\
\text { na cabeça das pessoas, elas estão mais conscientes } \\
\text { (com o processo de higienização das mãos)" Gestora } \\
\text { do Núcleo de Segurança do Paciente e Gestores do } \\
\text { CClH. }\end{array}$ \\
\hline Coerência & $\begin{array}{l}\text { "Não havia conflito entre as práticas. Aqui na } \\
\text { organização não incentivamos a competição entre os } \\
\text { funcionários, temos a metodologia de recompensá-los, } \\
\text { motivá-los, ensinar a fazer. Nas dinâmicas damos um } \\
\text { bombom como recompensa, sempre incentivando". } \\
\text { "O sistema de disseminação dos processos de } \\
\text { higienização das mãos acontecem via reuniões entre os } \\
\text { coordenadores e as comissões (CCIH, Segurança do } \\
\text { Paciente e qualidade). Nessas reuniões, são definidas } \\
\text { as metas e práticas de incentivos serem utilizadas } \\
\text { naquele momento. Em seguida cada coordenador reunia }\end{array}$ \\
\hline
\end{tabular}




\begin{tabular}{|c|}
\hline 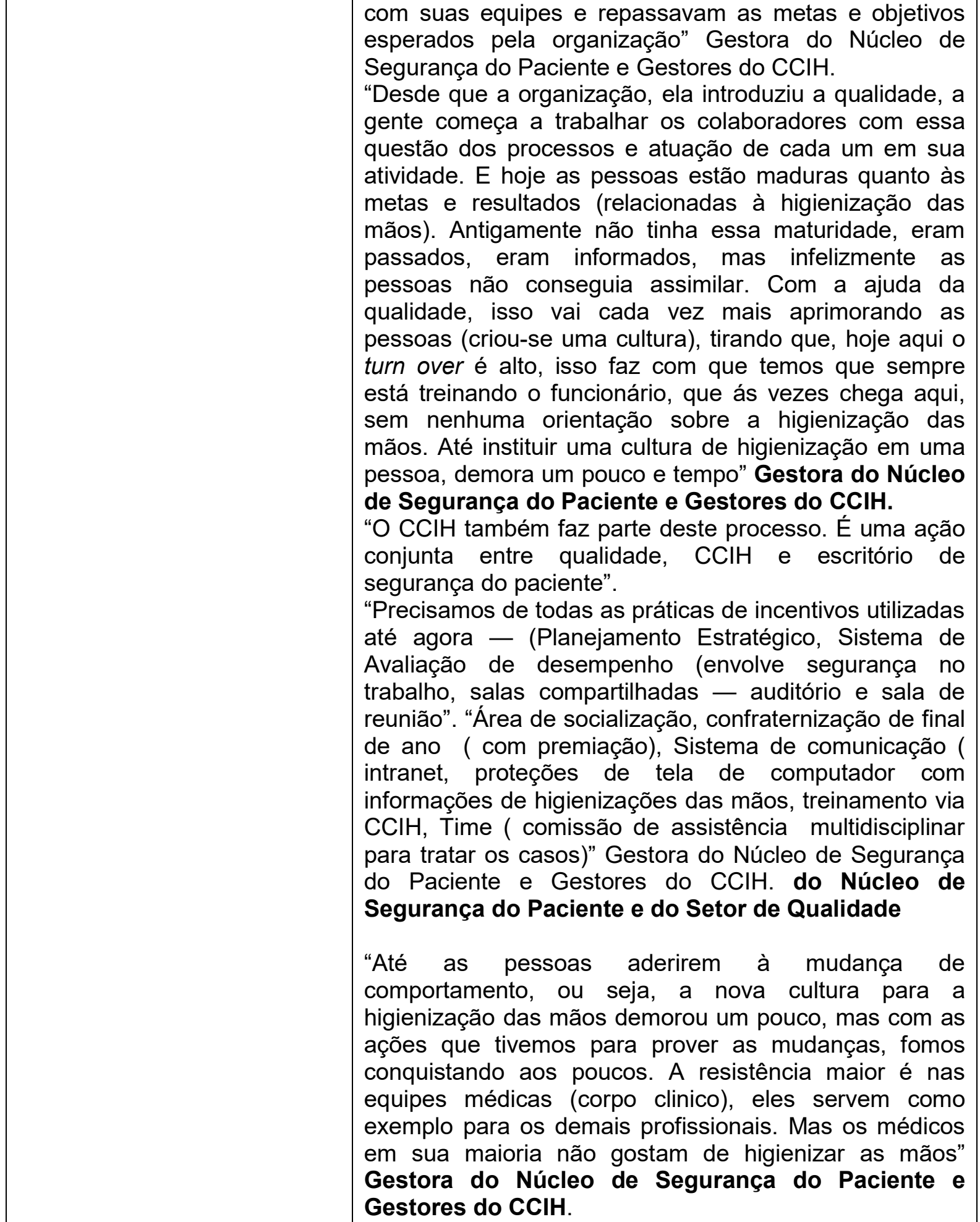 \\
\hline
\end{tabular}

\subsubsection{Propondo um Framework Para a Gestão das Estruturas de Governança}

Baseados nos achados empíricos, novos constructos emergiram (quadros $8 \mathrm{e}$ 9). Esses constructos oferecem um entendimento de como as organizações geren- 
ciam as suas estruturas de governança, em resposta a mudança institucional. Embora a literatura um rico portfólio de estruturas de governança (e.g., Grandori e Funari, 2008, 2010), ela não aborda que as pessoas em uma organização podem ter diferentes entendimentos ou percepções sobre tais estruturas. Nossos dados empíricos mostram que, nas três organizações, os funcionários, de diferentes níveis hierárquicos e funções, têm percepções diferentes quando comparado o antes com o depois da estrutura de governança.

Esse resultado ilumina um novo entendimento acerca das estruturas de governança: a heterogeneidade de percepção acerca da estrutura de governança. Os resultados sugerem que os atores nessas três organizações possuem dificuldades em perceber qual é a estrutura de governança atual. Consequentemente, não são factíveis de identificar o comportamento que esta estrutura formalmente está incentivando (ou não). Isso implica que a efetividade da mudança institucional pode ser comprometida diante dessa dificuldade em perceber qual é a estrutura de governança atual. Também, atores podem ter dificuldades em compreender qual é a mudança e como essa mudança está alinhada ao comportamento desejado ou o objetivo organizacional a ser atingido.

Baseado nesses achados e nos constructos que emergiram a partir dos casos, nós propomos um framework exploratório e emergente para a gestão das estruturas de governança (figura 9). Similar a vários outros estudos (e.g.,(Gomes, Facin, Salerno, e Ikenami, 2018), esse framework representa uma ponte entre o modelo conceitual do trabalho e os achados empíricos. Esse framework sugere que o gatilho para a mudança organizacional é alguma alteração no ambiente institucional. As organizações em questão possuem diferentes estruturas de governança, que são compostas por um conjunto de práticas de incentivo. Analisando a necessidade de mudança organizacional (e.g., o objetivo organizacional ou o desempenho a ser atingido), gestores podem ter que modificar, adicionar ou retirar determinadas práticas de incentivo. Para tanto, eles pode usar dois constructos: sinalização e direcionalidade. Enquanto a sinalização está mais relacionada quais estruturas (e.g., mercado) ou quais práticas serão adicionadas, retiradas ou alteradas, a direcionalidade se refere se uma da estrutura está se tornando mais proeminente ou se tornará no futuro (e.g., mais burocrática). A sinalização pode ser um importante instrumento para comunicação e engajamento dos atores organizações no processo de mudança organizacional e das práticas de incentivo. Já a direcionalidade por fornecer um ro- 
admap dessa mudança, servindo de guia como o portfólio atual de práticas de incentivos será modificado.

Figura 4 - framework exploratório de como as organizações podem gerenciar suas equipes.

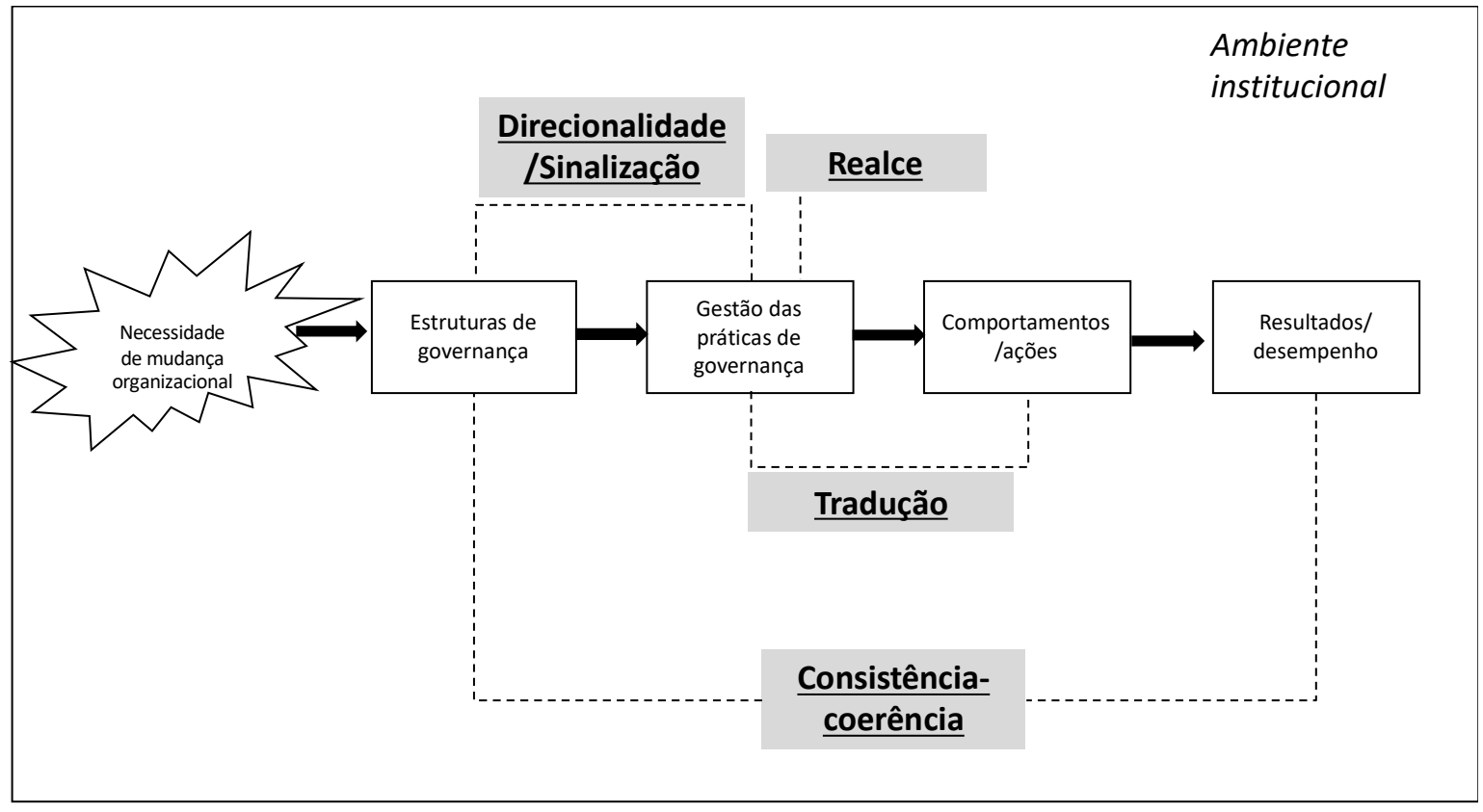

Elaborado pelo autor

Nem sempre os atores organizacionais compreendem como as mudanças nas práticas de incentivo estão associadas ao resultado organizacional esperado. $O$ nosso emergente framework sugere que os gestores podem fazer uso da tradução. Por exemplo, gestores podem comunicar que o uso de reuniões ou o compartilhamento de decisões visam criar e disseminar novas rotinas de trabalho visando um determinado objetivo. Nesse sentido, a tradução envolve um processo de construir sentidos individuais e coletivos, nos quais os atores organizacionais criam relações (causais ou associativas) entre as práticas de incentivos e ações demandadas ou realizadas. A existência de múltiplas práticas de incentivo pode gerar ambiguidades acerca de quais são as mais prioritárias. Daí, o nosso framework sugere que os gestores podem usar o realce (destacar quais as práticas são as mais relevantes).

A adição, modificação e subtração de práticas podem gerar ambiguidades, contradições e tensões entre as práticas e estruturas de governança. Daí, um mecanismo que pode ser utilizado pelos gestores é coerência/consistência. Gestores podem avaliar se os resultados atingidos estão dentro do esperado. Em caso contrário, 
podem analisar se o problema reside no portfólio das práticas de incentivo e nas estruturas da governança.

\subsubsection{Conclusão do Capítulo}

Neste capítulo, apresentamos os principais resultados da pesquisa empírica. Nós identificamos que as organizações fazem uso de diferentes práticas durante o processo de mudança institucional. Além disso, identificamos que os atores organizacionais possuem diferentes percepções sobre de tais práticas de incentivo. E, baseado nos resultados empíricos, e na interações de tais resultados com o modelo conceitual desta tese, novos constructos emergiram. Esses constructos fornecem indicativos de como as organizações gerenciam as práticas de incentivo.

No próximo capítulo, discutimos os resultados obtidos e, principalmente, as implicações para teoria e prática. 
DISCUSSÃO DOS RESULTADOS E IMPLICAÇÕES PARA A TEORIA E PARA A PRÁTICA

Neste capítulo, discutiremos como os resultados obtidos avançam o conhecimento, principalmente no tocante à gestão das práticas de incentivo mediante mudança institucional. Principalmente, explicamos como os resultados obtidos, além de refinar o modelo conceitual (construído a partir da revisão de literatura), responde à pergunta de pesquisa que orienta o presente trabalho: Como as organizações gerenciam as práticas de incentivos no processo de mudança institucional?. Nesta toada, também destacamos como os resultados obtidos provem evidências iniciais que as proposições de pesquisa (duas) foram confirmadas.

\subsection{Como o Trabalho Contribui Para o Conhecimento e Prática}

Esse trabalho contribui para um debate contínuo e relevante: compreender como as instituições e, principalmente, a mudança institucional afetam as estruturas de governança interna nas organizações. O nosso modelo conceitual reconhece o papel da mudança institucional e a sua relação com a estrutura de governança e indivíduos (e.g., Hodgson, 2019, 2002, 2007; Williamson,1993; North, 1990). Ainda nesse sentido, o nosso modelo conecta esse debate com a literatura sobre mudança organizacional (Zhang, Wang e O'Kane, 2019; Suddaby e Foster, 2016), e estruturas de governança e incentivos (Grandori e Furnari, 2008, 2010;Burton e Obel, 2018).

Esse trabalho está também alinhando ao recente movimento na literatura de gestão e estratégia: os microfundamentos Felin et al (2015) destacam a importância de se analisar como as mudanças organizacionais a partir da interação entre os níveis macro (ambiente institucional, capacitações) e micro (processos internos, gestão de pessoas, entre outros) para desempenho organizacional. O nosso modelo conceitual captura diversos aspectos desse movimento (Barney e Felin, 2013; Aguinis e Molina-Azorín, 2015; Lindenberg e Foss, 2017, Foss e Linder, 2019) para investigar como as organizações gerenciam as estruturas de governança em face à mudança institucional. Baseados em estudos de casos múltiplos, nós propomos um framework embrionário de como os atores gerenciariam as estruturas de governança em hospitais para responder a adequação do Protocolo de Higienização das Mãos $-\mathrm{RDC}-36$. 
De forma geral, o trabalho contribui ilustrando que as instituições são importantes para promover a mudança organizacional. Além disso, o trabalho ilustra que o contexto institucional é importante para compreendermos a gestão das organizações e o processo de decisão (em linha com Foss et al., 2018; Felin, Foss, Heimeriks e Madsen, 2012; Foss, Husted, \& Michailova, 2010). Em linha com Zylbersztajn (1995), as “instituições importam” e que as organizações não podem ser compreendidas e investigadas, sem levar em consideração o ambiente institucional na qual uma organização está inserida. Nesse tocante, mudanças no ambiente institucional funcionam como deslocadores do equilíbrio podendo induzir formas alternativas de estruturas de governança (Felin e Foss, 2019; Felin e Foss, 2013; Hodgson, 2019, 2002, 2007; Williamson, 1993).

O nosso trabalho mostra que gestores intensificaram a utilização de incentivos e modificaram rotinas internas a partir da RDC-36. Os nossos casos ilustram que gestores modificaram as práticas de incentivos a partir da interação entre o ambiente institucional e o comportamento dos indivíduos/equipes, em busca de um dado objetivo organizacional - nos casos investigados, o controle de infecções por meio da higienização das mãos.

Os nossos resultados chamam a atenção para a importância da gestão das práticas de incentivos, para se alcançar determinados objetivos, indo além da questão da hierarquia e poder (clássica noção presente em (Mintzberg \& Quinn, 2003): gerir as práticas de incentivos pode contribuir para que os funcionários criem uma expectativa em receber incentivos, reforçando as suas motivações no processo de mudança organizacional; contribuindo assim para um melhor alinhamento de interesses da organização e dos indivíduos (Shin, Taylor e Seo, 2012; Foss e Lindenberg, 2013; Lindenberg e Foss, 2011).

O modelo conceitual proposto na tese e o nosso framework chamam atenção para uma questão essencial: as práticas de incentivos podem tornar os indivíduos mais engajados e preparados para atingirem as metas no processo de mudança. Daí, decorre a necessidade de se gerenciar tais práticas. Tanto o modelo conceitual como os resultados empíricos ilustram essa importância, destacando, que as práticas de incentivo podem ir além de questões monetárias, sendo consistente com a literatura existente: Shin et al. (2012); Maheshwari e Vohra (2015); e Paren (2015).

O nosso framework exploratório (figura 04) procura estabelecer uma ponte entre o ambiente institucional, processos internos e objetivos organizacionais. A par- 
tir de uma mudança institucional (como a RDC-36), os gestores identificam e fazem sentido da necessidade de modificar as estruturas de governança e fazer gestão das práticas de incentivos, em vista determinados comportamentos e ações esperados, e consequentemente, os resultados obtidos. Nesse sentido, o nosso framework ilustra uma questão importante para o movimento dos microfundamentos (e.g.: Foss e Linder, 2019): para analisar o processo de mudança organizacional, é preciso compreender as variáveis macro (e.g., indústria ou fatores ambientais e sociais, externos, que levam à mudança) e micro (e.g., processos internos, gestão de pessoas entre outros) (Stouten, Rousseau, e De Cremer, 2018).

O framework, construído a partir dos casos, destaca que pesquisadores e gestores devem procurar compreender como mudanças em aspectos estratégicos, tais como estruturas de governança e suas práticas de incentivos, se relacionam com os aspectos micros (no framework, gestão das equipes, novos procedimentos para higienização das mãos). 0 nosso framework procura estabelecer uma conexão entre aspectos micro e macro, oferecendo pistas de como os atores e os seus papéis contribuem para o resultado coletivo (nos casos, os índices de infecção dos hospitais). Em outras palavras, o framework oferece pistas muito inicias de como as escolhas, habilidades, expectativas e motivações contribuem para um resultado coletivo, em linha os argumentos de recente estudos (e.g.: Foss e Linder, 2019; Felin e Foss 2015; Bridoux et al, 2017).

Os nossos casos ilustram e o nosso framework exploratório sugere que, o modo que gerenciamos os indivíduos pode afetar os resultados obtidos em uma mudança institucional. Mais do que apenas considerar o capital humano, como o "ingrediente-chave para o sucesso e fracasso da organização" (Baron \& Kreps, 1999, pág 4), os nossos resultados destacam que a capacidade de criar estruturas de governança e de incentivos pode ser fundamental para ativar as ações e comportamentos adequados nos processos organizacionais (em linha com Felin et al., 2012; Foss e Pedersen, 2016). Consistem com estudos prévios (Foss e Lindenberg, 2013; Lindenberg e Foss, 2011), o nosso framework sugere que gestores devem buscar o alinhamento das estruturas de governança, das práticas de incentivo e dos comportamentos organizacionais em busca de diferenciação competitiva e eficiência.

O nosso framework também oferece pistas sobre a heterogeneidade das organizações. Consistente com trabalhos prévios (e.g.: Barney, 1991), nosso trabalho mostra como as percepções dos indivíduos são diferentes sobre o uso das práticas 
de incentivo no interior da organização e a percepção em relação ao ambiente institucional. Como citado por Barney (1991), a percepção e motivação interagem de forma complexa, e os resultados de tais processos diferem nas organização. Isso também implica que a intervenção seletiva para uma boa causa pode ser confundida com intervenção para algo não positivo, e vice-versa. Por exemplo, nem todos compreendem como determinadas práticas de incentivo (mais reuniões, mas espaços de socialização) contribuíam para melhorar os índices de infecção. Tais diferenças podem ser suficientes para produzir diferenças (implícitas) na relação entres líder e liderado (Barney, 1991).

Com base nos resultados obtidos nos estudos de casos, apresentamos uma importante contribuição da tese: com os constructos que ajudam a explicar como as organizações gerenciam as práticas de incentivos. No contexto da mudança e institucional e organizacional (Oreg, Bartunek, Lee, \& Do, 2018), a sinalização e a tradução demostraram-se importantes estratégias para o alcance dos resultados, indicando quando/como/porque uma determinada prática de incentivo pode ser necessária para obter esperado pelos gestores. Organizações podem ter um conjunto variado de práticas de incentivos (Grandori, 2017; Jardim et al., 2013; Grandori e Furnari, 2008, 2010). No processo de mudança organizacional, gestores precisam sinalizar quais práticas de incentivos das estrutura de governanças vão mudar. Nesse sentido, gestores precisam analisar as estruturas de governança e ver a necessidade de adicionar, retirar ou modificar algumas práticas. Inicialmente, isso pode ser meio da sinalização, no qual esses gestores destacam e comunicam a necessidade de tais mudanças no arcabouço das práticas de incentivo. Nem sempre, os outros atores organizacionais compreendem de imediato dois aspectos: o por quê e como essa prática de fato está relacionada a determinados comportamentos/ações. Nossos resultados sugerem que os gestores podem usar tradução, por meio de um processo de sensemaking (Weick, Sutcliffe, e Obstfeld, 2005).

A adição, retirada e modificação de práticas de incentivo podem contribuir para uma certa ambiguidade na relação entre práticas e comportamentos/ações esperados. Essa ambiguidade pode também estar relacionada à dificuldade dos atores organizacionais em perceber o que é mais importante (i.e., qual prática é mais relevante). Nossos resultados sugerem que, para diminuir essa ambiguidade, os gestores podem usar o realce, isto é, informar aos funcionários quais práticas de incentivos estão sendo utilizadas e para quê fim pretende-se ou pretendeu-se a sua utiliza- 
ção. Os gestores precisam orientar a utilização das práticas de incentivos. Em nossos casos, os gestores reforçaram qual(is) foi(ram) a(s) mais importante(s) e, o porquê dessa utilização (e.g.: no hospital Ibiapaba). Dessa forma, as práticas eram divididas por nível hierárquico, os profissionais do corpo clínico e assistências (tais como enfermeiras, nutricionistas, fisioterapeuta e outros) eram discutidas os índices de infecção em reuniões. Para os demais profissionais de nível técnico os índices eram informados através de canais de comunicação e com menor frequência em reuniões com a enfermeira chefe do setor.

Muitas vezes, para fornecer um roadmap (ou guia) sobre a evolução das práticas de incentivos (para um determinado modal - mercado, democrática), gestores podem fazer o uso da direcionalidade. A direcionalidade é fundamental para tentar aumentar o alinhamento entre diversas áreas funcionais da organização (Phaal et al., 2004). Em alguns momentos (e.g.: epidemia de infecção, pacientes vulneráveis a infecção, falta de recursos financeiros e investimentos), os gestores gerenciavam quais práticas de incentivos eram consideradas mais relevantes no momento e proviam indicativos de como as práticas seriam modificadas (adicionadas ou subtraídas) (usando a sinalização), buscando positivamente para o alinhamento.

A adição, prática e modificação de práticas podem trazer implicações para a coerência/consistência das estruturas de governança (e os seus mecanismos), tais como tensões (práticas incentivam comportamentos e ações contraditórios) ou ambiguidades (dificuldade em associar como os mecanismos de governança incentivam determinados comportamentos e ações). Nesse sentido, os gestores tendem a utilizar práticas sem a harmonia das estruturas de governança. Muita heterogeneidade na utilização das práticas de incentivos pode levar à dificuldade na gestão do comportamento que se espera dos funcionários. Nessa lógica, os gestores podem avaliar, ao longo do tempo, avaliar quais práticas de incentivos estão relacionadas ao comportamento.

Em linha com estudos prévios (e.g.: Prendergast, 2008), o framework sugere que o design do ambiente organizacional (e.g.: práticas de incentivos) pode ser importante para influenciar os comportamentos em um contexto de mudança institucional e, consequentemente organizacional. Como o nosso estudo revela, as organizações podem usar diferentes práticas de incentivo para atingir os seus objetivos organizacionais. Isso também é coerente com outros estudos que mostram uso de incen- 
tivos nas empresas e como a variedade e configurações de incentivos melhoram o desempenho Grandori e Furnari $(2008,2010)$.

O modelo exploratório framework contempla duas naturezas da gestão das estruturas de governança e das práticas de incentivos: preditiva e emergente. Essa caracterização (preditiva e emergente) não é nova e está relacionada aos trabalhos de (Mintzberg, 1979) sobre estratégias deliberadas (fruto de uma atividade de planejamento) e estratégias emergentes (fruto de um padrão que emerge ao longo dos anos e do aprendizado). Já no contexto da gestão das práticas de incentivos, as organizações podem deliberadamente mudar os mecanismos e as práticas de incentivos. Isso, inclusive, está em linha com os estudos de Grandori e Furnari (2008, 2010), que afirmam que a abordagem preditiva, por meio das combinações de mecanismos governança (e suas práticas de incentivos), pode contribuir positivamente para um melhor desempenho das organizações. Nós também sugerimos que, a partir do comportamento/ações e, principalmente dos resultados, gestores podem adicionar, modificar ou subtrair práticas de incentivos. Ainda nesse cerne, os gestores podem informalmente testar novas práticas de incentivos, antes de formalizá-las na estrutura de governança das organizações. Isso amplia o portfólio de atuação dos gestores para lidar com a mudança institucional e, consequentemente, mudança organizacional via a gestão das práticas de incentivos.

Esses novos construtos podem ter interessantes implicações para a prática, contribuindo para a gestão das organizações hospitalares. Como contribuição para o setor, os resultados podem fornecer guias a elaboração de políticas de recursos humanos, e melhorias de processos organizacionais. Dessa forma, os resultados podem contribuir para direcionar as escolhas da utilização das estruturas de governanças das organizações hospitalares.

\subsection{Discussão das Proposições}

Baseado nos resultados empíricos, discutimos, agora, se as duas proposições que orientaram este trabalho foram refutadas ou não:

Proposição 1: No processo de mudança institucional, os gestores podem utilizar práticas de incentivos de forma unimodal ou multimodal de práticas de incentivos dos mecanismos de governança. 
Nossos casos ilustram que as organizações empregam diferentes práticas de incentivo de forma multimodal (nos três casos analisados). Em linha com Grandori e Furnari $(2008,2010)$, as organizações podem adotar diferentes estratégias no gerenciamento de seus processos internos, combinando diferentes configurações de práticas de incentivos mercado, burocrático, comunitário ou democrático).

Proposição 2: O processo de mudança institucional (RDC-36 - Protocolo de Higienização das Mãos) levou os gestores a utilizarem as práticas de incentivos de forma multimodal no processo adequação da mudança de comportamento em suas equipes.

Nossos resultados também oferecem uma visão complementar aos estudos sobre estrutura de governança e mudança organizacional: Grandori (2017); Grandori e Furnari $(2008,2010)$. Nos três casos, foi constatado a utilização simultânea de diferentes práticas de incentivos nas equipes de trabalho em ambos os hospitais. Nossos apresentam um passo a mais ao ilustrar como os gestores gerenciam o multimodal, indo além do aspecto descritivo (o quê), para explicar em maiores detalhes o como (em uma abordagem processual).

Nos três estudos de casos, foram observados dois principais aspectos, que nos levam a confirmação da proposição $-P 2$. Embora as práticas de incentivo ligadas às estrutura/mecanismo de governança mercado não foram usadas de maneira formal em nos casos (ou pelo menos, a nossa amostra de entrevistados não indicou tal uso), nós identificamos, conforme discutido anteriormente, práticas associadas às outras estruturas de governança. Nossos dados sugerem que práticas de incentivo monetária demandam uma maior sofisticação do sistema de gestão (com regras diferentes de orçamentação), o que pode ser mais complexo em ambientes como hospitais públicos, que dependem de verbas estatais. Como destacado, os gestores empregaram práticas de incentivos ligadas às estruturas de governança burocrática, comunitária e democrática - sendo assim constatou-se a presença da forma multimodal nas entrevistas com os gestores. $O$ segundo aspecto foi que, no processo de mudança organizacional, constatou-se que a percepção dos gestores entrevistados que houve uma intensificação na utilização de algumas práticas de incentivos. Embora os nossos dados estejam relacionados à percepção dos gestores, há uma indicação de que algumas práticas foram empregadas (com maior ênfase) após a mudança institucional analisada. Um ponto importante a ser considerado é que a diversificação da utilização das práticas de incentivos não está relacionada com a falta de 
coerência estratégica das organizações, como afirmam diversos autores (Grandori, 2017; Jardim et al., 2013; Grandori e Furnari, 2008, 2010), mas sim na heterogeneidade de percepção acerca da estrutura de governança.

\subsection{Conclusão do capítulo}

Nesse capítulo, apresentamos a discussão dos resultados obtida na pesquisa empírica, conduzida nos hospitais estudados. Inicialmente, explicamos como os resultados obtidos avançam o entendimento acerca da interação de três aspectos/dimensões: Instituições (no caso, verificamos o processo de adequação da mudança institucional da RDC n. ${ }^{\circ} 36$ ) que, estruturas de governança (formas de práticas de incentivos) e indivíduos (comportamentos e ações).

Levando em consideração esses aspectos, nossos resultados ampliam o entendimento de como as organizações podem gerir suas diferentes práticas de incentivo. Seguindo nessa perspectiva, nossos resultados contribui para a literatura de estratégia, especialmente a corrente ligada ao design organizacional e às estruturas de governança. Também destacamos que os resultados oferecem guias preliminares para praticantes de como gerir as práticas de incentivo, em busca de um determinado objetivo organizacional. 
O objetivo desse trabalho foi o de investigar como as organizações hospitalares gerenciam práticas de incentivos no processo de mudança institucional. Em atendimento a questão/problemática de pesquisa, inicialmente três objetivos específicos foram estabelecidos: (i) Construir um modelo conceitual sobre a gestão das estruturas de governança para lidar com mudança institucional; (ii) Investigar de forma exploratória casos de hospitais que passaram por uma mudança institucional; (iii) Desenvolver um framework emergente de como as organizações podem gerenciar a estruturas de governança.

Tratando dos objetivos específicos, o primeiro que foi o de propor um modelo conceitual sobre a gestão das estruturas de governança no contexto da mudança institucional investigada. Nesse sentido, apresentamos um modelo que explica como os incentivos podem ser um fator importante no processo de mudança institucional. Para isso, com base no trabalho de Grandori e Funari (2010, 2008), Grandori, (2016, 2017), dividimos as estruturas em quatro tipos de governança, classificadas em incentivos monetários e não monetários, e suas subpráticas de incentivos. O nosso modelo teórico sugere que organizações podem empregar práticas de diferentes tipos de estruturas de governança. Baseado neste modelo conceitual, estruturamos os protocolos para a fase de pesquisa empírica (segundo objetivo específico).

Na parte empírica, nossos resultados sugerem que a percepção dos gestores relacionado a algumas práticas de incentivos foram mais intensificadas e outras nem tanto. Foi constatado a intensificação na percepção das práticas de incentivos, das seguintes estruturas de governança: burocrática, como por exemplo, planejamento estratégico e processos de qualidade; a estrutura de governança comunitária, que congrega ações de comunicação, trabalho em equipe, compartilhamento de decisões obtiveram mais utilização das práticas, principalmente a práticas de incentivos, como reuniões e quadro de informação, participação em planejamentos, todos os assuntos relacionado a higienização das mãos e controle de infecção. Indo além da questão da percepção e dos vieses, nossos resultados indicam que os gestores agem para dar maior realce a algumas práticas em detrimento de outras; ou sinalizam práticas de formas distintas. 
Também, no que se refere à estrutura de governança democrática e suas práticas de incentivos, nossos resultados sugerem que a intensificação na utilização de algumas práticas de incentivos. Em uma análise geral, as práticas de incentivos que não relacionam com valores monetários, foram as mais utilizadas. Talvez, uma exploratória e preliminar explicação esteja ligada ao nível de sofisticação gerencial e flexibilidade para alocar de forma mais dinâmica os recursos, alterando, por exemplo, o orçamento. Outra explicação pode estar ligada à limitação de recursos financeiros.

Os resultados sugerem que houve uma intensificação na utilização das práticas de incentivos após a utilização a promulgação da RDC, e que os gestores utilizam a forma multimodal, ou seja a utilização de mais de uma prática de distintos tipos de governança (burocrática, mercado) para ativar diferentes comportamentos e ações dos funcionários. Baseado nas interações entre o modelo conceitual e dados empíricos, nós identificamos uma série de novos constructos, a saber: sinalização, tradução, realce, direcionalidade e consistência. Esses constructos foram a base para proposição de um framework exploratório sobre como as organizações gerenciam as práticas de incentivo.

O nosso framework dá pistas de como gerir as estruturas de governança e práticas de incentivo; o nosso framework corrobora para o uso de, forma simultânea, mais de uma prática de incentivo. O nosso framework também alerta sobre eventuais problemas que uma abordagem multimodal pode causar: tensões, ambiguidades, etc. O nosso framework alerta que os liderados podem não identificar qual estrutura de governança está(ão) sendo utilizada no momento da mudança institucional. Devido à percepção heterogênea dos atores organizacionais sobre o uso das práticas e os seus sentidos, a organização pode precisar indicar qual ou quais aspectos são os mais relevantes no processo de mudança.

Esse framework organiza os principais achados da tese e propõem uma síntese de como as organizações poderão gerenciar as estruturas da governança. Esses construtos trazem um novo entendimento sobre a utilização das práticas de governança principalmente nas organizações hospitalares. 


\subsection{Sugestão Para Estudos Futuros}

Em função dos esforços dedicados para explicar a gestão das práticas de incentivos no processo de mudança institucional, o modelo conceitual oferece uma rica agenda de pesquisa onde interessados no tema. Primeiro, pesquisadores podem desenvolver estudos que utilizem os construtos em outros contextos e setores e, não somente no setor hospitalar. Pesquisadores podem analisar o uso de tais constructos em contextos, tais como mudança tecnológica ou disrupção. Em tais contextos, pesquisas futuras poderiam explorar diferentes contingências (organizações de diferentes tamanhos, localização geográfica entre outros aspectos).

Uma sugestão de estudos futuros seria o de investigar hospitais que utilizam todas as práticas de incentivos no processo de adequação institucional e que correlacionem esses incentivos ao algum modelo de desempenho por equipe e não de forma geral. Também, pesquisas podem tentar associar diferentes estilos de gestão com o uso dos constructos. Ainda nesse cerne, pesquisas futuras podem analisar o uso do framework e controlar os diferentes tipos de comportamento/motivação. Por fim, seria interessante conduzir estudos mais confirmatórios, investigado se o uso de tais constructos impactam no desempenho.

\subsection{Limitações de Pesquisas}

O presente estudo teve diversas limitações importantes. Apesar de a pesquisa ter realizado mais um estudo de caso, é preciso realizar outros estudos de casos complementares (em outros contextos institucionais). Além disso, o nosso protocolo de pesquisa não controlou os diferentes tipos de comportamento/motivações/ações (em linha com o goal frame). Apesar de termos feito um rico levantamento de dados, a triangulação de dados, talvez, não tenha sido suficiente para reduzir os vieses de análises. Além disso, reconhecemos que os dados sobre o uso das práticas referemse às percepções dos atores nas organizações; o que também implica em vieses e limitações dos resultados. Também não conseguimos explorar em profundidade diferentes perfis de liderança e o comportamento dos times. Por fim, temos evidências muito preliminares sobre como os nossos constructos levam a um resultado superior em termos de desempenho. É preciso mais pesquisas para aumentar o entendimen- 
to sobre como o uso de tais constructos impactam nos comportamentos/ações e, consequentemente, no desempenho. 


\section{REFERÊNCIAS}

BOXENBAUM, Eva et al. From Collective Experiments to Institutional Change. Proceedings. The Academy of Management Review, vol. 2019, n. 1. https://doi.org/10.5465/AMBPP.2019.10259symposium.

BRASIL. Ministério da Saúde. Documento de referência para o Programa Nacional de Segurança do Paciente. Brasília: Ministério da Saúde, 2014. Disponível em: http://bvsms.saude.gov.br/bvs/publicacoes/documento_referencia_programa_ nacional_seguranca.pdf. Acesso em: 11 jan. 2019.

BRASIL. Resolução RDC n. ${ }^{\circ}$ 63, de 25 de julho de 2013. Institui ações para a segurança do paciente em serviços de saúde e dá outras providências. Órgão emissor: Agência Nacional de Vigilância Sanitária (Anvisa). Disponível em: http://bvsms.saude.gov.br/bvs/saudelegis/anvisa/2013/rdc0036_25_07_2013. html. Acesso em: 11 jan. 2019.

EISENHARDT, Kathleen M. Agency Theory: An Assessment and Review. The Academy of Management Review, vol. 14, n. 1, 1989, pp. 57-74. https://doi.org/10.2307/258191.

EISENHARDT, Kathleen M.; GRAEBNER, Melissa E. Theory Building From Cases: Opportunities and Challenges. The Academy of Management Review, vol. 50, n. 1. https://doi.org/10.5465/AMJ.2007.24160888.

FEHR, Ernst; FISCHBACHER, Urs. Why Social Preferences Matter - the Impact of non-Selfish Motives on Competition, Cooperation and Incentives. The Economic Journal, vol. 112, n. 478, 2002, pp. C1-C33. https://doi.org/10.1111/1468-0297.00027.

FOSGAARD, Mia Reinholt; FOSGAARD, Toke Reinholt; FOSS, Nicolai Juul. Consumer or Citizen? Prosocial Behaviors in Markets and Non-markets. Social Choice and Welfare, vol. 49, n. 2, 2017, pp. 231-253. https://doi.org/10.1007/s00355-017-1058-4.

FOSS, Nicolai; MILAGRES, Rosileia. Pro-social Motivation beyond Firm Boundaries: The Case of the Genolyptus Network. BAR - Brazilian Administration Review, v. 11, n. 4, pp. 364-384, 2014. https://doi.org/10.1590/18077692 bar2014130026.

FOSS, Nicolai; STEA, Diego. Putting a Realistic Theory of Mind into Agency Theory: Implications for Reward Design and Management in Principal-Agent Relations. European Management Review, vol. 11, n. 1, pp. 101-116, 2014. https://doi.org/10.1111/emre.12026.

FREY, Bruno S.; TORGLER, Benno. Tax morale and conditional cooperation. Journal of Comparative Economics, vol. 35, n. 1, pp. 136-159, 2007. https://doi.org/10.1016/j.jce.2006.10.006

GAGNÉ, Marylène; DECI, Edward L. Self-determination theory and work motivation. Journal of Organizational Behavior, vol. 26, pp. 331-362, 2005. 
https://doi.org/10.1002/job.322.

GRANDORI, Anna (2008). Knowledge governance. In 50th Annual Meeting of the Academy of International Business "Knowledge Development and Exchange in International Business Networks". Extraído de: http://aib.msu.edu/events/2008/AIB2008_Proceedings.pdf

GRANDORI, Anna. Corporate Governance and Firm Organization: Microfoundations and Structural Forms. Bocconi University: Milan, 2004. https://doi.org/10.1093/acprof:oso/9780199269761.001.0001.

GRANDORI, Anna. Democratic governance and the firm. Revista de Administração, vol. 52, n. $3, \quad$ pp. $353-356, \quad$ https://doi.org/10.1016/j.rausp.2017.05.008.

GRANDORI, Anna. Knowledge-Intensive Work And The (Re)emergence Of Democratic Governance. Academy of Management Perspectives, vol. 30, n. 2, pp. 167-181, 2016. https://doi.org/10.5465/amp.2015.0133.

GRANDORI, Anna; FURNARI, Santi (2008). A Chemistry of Organization: Combinatory Analysis and Design. Organization Studies, vol. 29, n. 3, pp. 459-485, 2008. https://doi.org/10.1177/0170840607088023.

GRANDORI, Anna; FURNARI, Santi. Configurational Analysis and Organization Design: Toward a Theory of Structural Heterogeneity. Configurational Theory and Methods in Organizational Research, vol. 38, pp. 77-105, 2013. https://doi.org/10.1108/S0733-558X(2013)0000038008.

GUIDELINES on Core Components Of Infection Prevention And Control Programmes at The National And Acute Health Care Facility Level. Geneva: World Health Organization; 2016. Disponível em: https://www.who.int/gpsc/core-components.pdf. Acesso em: 11 jan. 2019.

JARDIM, Gabriela Feresin; SAES, Maria Sylvia Macchione; MESQUITA, Luiz Ferraz de. Estruturas de Governança Interna e a Capacidade de Inovação em Pequenas Firmas Brasileiras de Torrefação e Moagem de Café. Revista de Administração, vol. 48, n. 2, pp. 239-253, 2013. http://dx.doi.org/10.5700/rausp1085.

KUVAAS, Bård; BUCH, Robert H.; WEIBEL, Antoinette; DYSVIK, Anders; NERSTAD, Christina G. L. Do Intrinsic And Extrinsic Motivation Relate Differently To Employee Outcomes?. Journal of Economic Psychology, vol. 61, pp. 244-258. https://doi.org/10.1016/j.joep.2017.05.004

LANGLEY, A. (1999). Strategies for Theorizing from Process DataLangley, A. (1999). Strategies for Theorizing from Process Data. The Academy of Management Review, 24(4), 691. doi:10.2307/259349. The Academy of Management Review. https://doi.org/10.2307/259349

LINDENBERG, S. (2013). Cognition and governance: why incentives have to take a back seat. Handbook of Economic Organization, 41-61.

LINDENBERG, S.; FOSS, N. J. (2011a). Managing Joint Prediction Motivation: The Role of Goal-framing and Governance Mechanisms. Academy of Management 
Review, 36(3), 500-525. https://doi.org/10.5465/AMR.2011.61031808

LINDENBERG, S.; FOSS, N. J. (2011b). Managing joint production motivation: The role of goal framing and governance mechanisms. Academy of Management Review, 36(3), 500-525. https://doi.org/10.5465/AMR.2011.61031808

OLIVEIRA, Hadelândia M.; SILVA, Cristiane P. R; LACERDA, Rúbia A. Policies for Control and Prevention of Infections Related to Healthcare Assistance in Brazil: A Conceptual Analysis. Revista da Escola de Enfermagem da USP, vol. 50, n. 3 , pp. 505-511, 2016. https://doi.org/10.1590/S0080623420160000400018.

OSTERLOH, M., e FREY, B. (2013). Motivation governance. Handbook of Economic Organization: Integrating Economic and Organization Theory. https://doi.org/10.2139/ssrn.2347549

PENNER, L. A., DOVIDIO, J. F., PILIAVIN, J. A.; SCHROEDER, D. A. (2005). Prosocial Behaviour: Multilevel Perspectives. Annual Review of Psychology, 56(1), 365-392. https://doi.org/10.1146/annurev.psych.56.091103.070141

PIRES, D.; SOULE, H.; BELLISSIMO-RODRIGUES, F.; GAYET-AGERON, A.; PITTET, D. (2017). Hand hygiene with alcohol-based hand rub: How long is long enough? Infection Control and Hospital Epidemiology, 38(5), 547-552. https://doi.org/10.1017/ice.2017.25

PORTER, M. E., e TEISBERG, E. O. (2004). HBR - Michael Porter - Redefining Competition in Healthcare - 2004.pdf. Harvard Business Review. Retrieved from http://www.ncbi.nlm.nih.gov/pubmed/15202288

RENDER, M. L.; HASSELBECK, R.; FREYBERG, R. W.; HOFER, T. P.; Sales, A. E.; ALMENOFF, P. L. (2011). Reduction of central line infections in Veterans Administration intensive care units: an observational cohort using a central infrastructure to support learning and improvement. BMJ Quality e Safety, 20(8), 725-732. https://doi.org/10.1136/bmjqs.2010.048462

RYAN, R.; DECl, E. (2000). Self-determination theory and the facilitation of intrinsic motivation, social development, and well-being. The American Psychologist, 55(1), 68-78. https://doi.org/10.1037/0003-066X.55.1.68

SINGER, S. J.; CLARK, J. R. (2011). Entrepreneurship, culture, knowledge, and learning: A multispective view of patient safety improvement. Health Care Management Review. https://doi.org/10.1097/HMR.0b013e31822599a1

SINGER, S. J.; VOGUS, T. J. (2013). Reducing Hospital Errors: Interventions that Build Safety Culture. Annual Review of Public Health, 34(1), 373-396. https://doi.org/10.1146/annurev-publhealth-031912-114439

SOUZA, E. S.; BELEI, R. A.; CARRILHO, C. M. D. de M.; MATSUO, T.; YAMADAOGATTA, S. F.; ANDRADE, G.; KERBAUY, G. (2015). Mortalidade e riscos associados a infecção relacionada à assistência à saúde. Texto e Contexto Enfermagem, 24(1), 220-228. https://doi.org/10.1590/010407072015002940013

STEG, L.; LINDENBERG, P.; KEIZER, K. (2016). Intrinsic Motivation, Norms and 
Environmental Behaviour: The Dynamics of Overarching Goals. International Review of Environmental and Resource Economics, /9(1-2), 179-207. https://doi.org/10.1561/101.00000077

TOMO, A.;TODISCO, L. (2018). Enhancing Employees ' Performance through Organizational Care Policies in the Health Care Context, 7(1), 5-19. https://doi.org/10.5539/par.v7n1p5

VAN DE VEN, A. H.; HUBER, G. P. (1990). Longitudinal Field Research Methods for Studying Processes of Organizational Change. Source: Organization Science.

WEIBEL, A.; ROST, K.; e OSTERLOH, M. (2010). Pay for performance in the public sector - Benefits and (Hidden) costs. Journal of Public Administration Research and Theory, 20(2), 387-412. https://doi.org/10.1093/jopart/mup009

WORLD HEALTH ORGANIZATION. (2009). Guide to Implementation. A Guide to the implementation of the WHO Muktimodal Hand Hygiene improvement Stratégy. World Health Association Press, 1-48. Retrieved from http://www.who.int/patientsafety/information_centre/documents/en/

YIN, R. K. (2014). Case study research: Design and methods (5th ed.). Thousand Oaks, CA: SAGE Publications.

YIN, R. K.; GRASSI, D.; Ph, D.; De, P.; CHOW, C.-J.; YANG, J.-I. (2011). Estudo de Caso Planejamento e Métodos. Journal of Food Biochemistry, 35(3), 715-734. https://doi.org/10.1111/j.1745-4514.2010.00412.x 


\section{ANEXO I \\ Protocolo de Pesquisa - 03}

Nome do entrevistado:

Cargo: Data

O objetivo dessa pesquisa foi o de analisar a relação entre higienização das mãos e a evolução das estruturas de governança interna em dois hospitais. O objetivo é entender quais foram às práticas de incentivos utilizadas por essas duas organizações no processo de mudança institucional, mas especificamente após a exigência estabelecida na RDC $n^{\circ} 36$ que publica o protocolo de higienização das mãos.

Neste contexto, utilizamos o trabalho de Grandori e Furnari (2008) que desenvolveram um instrumento denominado abordagem combinatória do design utilizado para analisar eficiência e inovação em determinadas firma. Os autores qualificam as estruturas de governança interna como elementos organizacionais que incluem uma coleção de práticas adotadas por uma determinada empresa na política de recursos humanos.

As estruturas de governança são compostas por práticas de incentivos organizacional composta por incentivos monetários e não monetários, que são divididos em quatro formas, a saber : mecanismos de governança mercado contêm incentivos monetários e de controle. Os elementos burocráticos incluem regras e planos formais de divisão do trabalho e os elementos comunitários apresentam divisão de conhecimento, valores e cultura comum. Já os elementos democráticos são (difusão de direitos de propriedade e direitos de representação em órgãos dirigentes direitos de autodeterminação de tarefas). A tabela abaixo descreve melhor as estruturas de governança e suas práticas de incentivos.

Os resultados obtidos com base nas entrevistas realizadas em 2017 demonstraram que a um novo entendimento acerca das estruturas de governança: a heterogeneidade de percepção acerca da estrutura de governança. Os resultados sugerem que os colaboradores nessas duas organizações possuem dificuldades em perceber qual é a estrutura de governança atual utilizada pelos gestores. Abaixo estão elencadas as estruturas de governança e suas práticas de incentivos. 


\begin{tabular}{|c|c|c|}
\hline $\begin{array}{l}\text { Mecanismos } \\
\text { de } \\
\text { Governança }\end{array}$ & \multicolumn{2}{|c|}{ Práticas em Cada Tipo de Estrutura } \\
\hline $\begin{array}{l}\text { Mercado: } \\
\text { incentivos } \\
\text { Monetários }\end{array}$ & \multicolumn{2}{|c|}{$\begin{array}{l}\text { - Pagamento pelo desempenho individual } \\
\text { - Pagamento pelo desempenho da equipe } \\
\text { - Pagamento pelo desempenho da firma } \\
\text { - Terceirização }\end{array}$} \\
\hline Burocrática & \multicolumn{2}{|c|}{$\begin{array}{l}\text { - Plano de carreira } \\
\text { - } \text { Alinhamento ao Planejamento Estratégico } \\
\text { - Programa e processo de controle da qualidade das atividades e } \\
\text { - } \text { Sarefas } \\
\text { - Sistema de avaliação de desempenho - feedback }\end{array}$} \\
\hline \multirow{4}{*}{ Comunitária } & $\begin{array}{l}\text { - Compartilhamento de } \\
\text { informações e valores }\end{array}$ & $\begin{array}{l}\text { - Salas compartilhadas } \\
\text { - Área de socialização } \\
\text { - Frequência de confraternização }\end{array}$ \\
\hline & - Canal de comunicação & 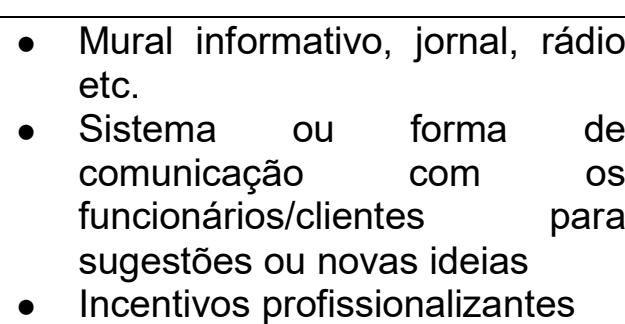 \\
\hline & - Trabalho em equipe & $\begin{array}{l}\text { - Frequência de reuniões da } \\
\text { diretoria } \\
\text { - Frequência de reuniões da } \\
\text { gerência ou da supervisão } \\
\text { - Frequência de reuniões da área } \\
\text { de produção } \\
\text { - Treinamento e dinâmica de } \\
\text { grupos }\end{array}$ \\
\hline & $\begin{array}{l}\text { - Compartilhamento } \\
\text { decisão }\end{array}$ & $\begin{array}{l}\text { - Quem faz o planejamento para } \\
\text { o ano seguinte } \\
\text { - Quem participa da } \\
\text { escolha/desenvolvimento de } \\
\text { produtos, ações para as } \\
\text { melhorias. } \\
\text { - Acordos ou parcerias com } \\
\text { stakeholders para o } \\
\text { desenvolvimento de produtos } \\
\text { ou processo }\end{array}$ \\
\hline Democrática & \multicolumn{2}{|c|}{$\begin{array}{l}\text { - Difusão de Direitos de representação } \\
\text { - Difusão de decisão e Direitos de recompensa para unidades } \\
\text { - Difusão de Propriedade } \\
\text { - Enriquecimento de trabalho e capacitação }\end{array}$} \\
\hline
\end{tabular}

Fonte: Adaptado de (Grandori, 2017; Grandori \& Furnari, 2008). 


\section{Protocolo de Entrevistas 03:}

1. Qual é a sua função atual e no momento da RDC $n^{\circ} 36$ (protocolo de higienização)?

2. Trabalhava no hospital no momento antes da RDC n 36 (protocolo de higienização)? Durante?

\section{Realce:}

3. Para atingir os resultados esperados, quais destas práticas foram mais empregadas? Por quê? Você poderia ilustrar?

4. Se novas práticas foram implantadas, como você destacou a importância dessas novas práticas em relação ao que existia?

Tradução (por que pode existir lacuna de entendimento entre novas práticas e os objetivos a serem atingidos).

5. Ao introduzir novas práticas ou um empregar práticas existentes (ex: reuniões), o gestor deixou claro que o objetivo era incentivar a higienização das mãos?

6. Como você explicou que tais práticas (novas ou não) estavam associadas aos novos procedimentos de higienização das mãos? Poderia ilustrar.

\section{Sinalização}

7. Antes de realizar as mudanças nas práticas ou criar uma nova, houve momentos nos quais você explicou a necessidade de tais mudanças? A relevância e o que seria mudado (em relação às práticas)? 


\section{Direcionalidade}

8. Como você avalia quais dos mecanismos de governança eram predominantes antes da RDC 36? Depois da RDC 36? Se houve mudança (ex: de mercado para burocrática), como foi comunicado esse processo? Em quais momentos? Quem foi envolvido?

\section{Coerência}

9. Como você avaliava se existia conflito entre as práticas antes da RDC no 36 (protocolo de higienização)? Depois da RDC $n^{\circ} 36$ (protocolo de higienização)? Se sim, poderia ilustrar?

10. Como o gestor explicou o que esperava? Havia o auxílio de alguma outra área do Hospital envolvida nesse processo? Ex: (RH, Qualidade, $\mathrm{CCIH})$.

11. Quais eram as contradições ou tensões entre as práticas antes da mudança? Como isso afetava o comportamento das equipes?

\section{Pergunta com os funcionários}

12. Como você percebeu as práticas de incentivos utilizadas pelo líder no processo de motivação para higienização das mãos? Tem alguma que você julga mais importante que outras? No caso, teve alguma que ele reforçou ou fez questão de mostrar que era mais importante?

13. O objetivo da utilização das práticas eram o de moldar comportamentos para ampliar a utilização do protocolo de higienização das mãos. Como você percebia que seu gestor utilizava uma determinada prática? Ele segue alguma forma de ordem lógica? 


\section{Finalizar a entrevista}

14. Como está hoje? Quais as práticas continuam valendo? O que deu certo? O que poderia ser diferente? 
ANEXO II

Questionário médico líder de equipe

1. Os processos de controle de infecção sofreram mudanças depois da RDC? (Ex: tecnológicas, compram de novos equipamentos, novos postos de higienização etc.). ( ) Sim ( ) Não. Se sim, quais foram?

2. Quais são os profissionais que estão sob sua liderança hoje? (Colocar o número de profissionais entre parênteses).

( ) Enfermeiros, ( ) Técnicos de Enfermagens, ( ) farmacêuticos, ( )

Nutrição ( ) Outros

2.1. O número dos profissionais sob sua liderança antes da implantação da RDC 36/2013 era igual ao atual?

( ) $\operatorname{sim}($ )não. Se não qual era?

( ) Enfermeiros, ( ) Técnicos de Enfermagens, ( ) farmacêuticos ( ) Nutri-

ção ( ) Outros

3. O Sr. (a) poderia me apontar quais as práticas de RH utilizadas na equipe que você lidera, antes da RDC 36 e depois. Marcar com X somente. Anotar informações gerais.

\begin{tabular}{|c|c|c|c|}
\hline & Práticas & Antes & Depois \\
\hline \multirow{2}{*}{ 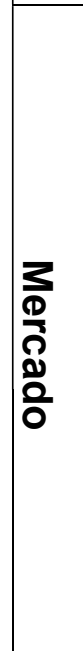 } & $\begin{array}{l}\text { 3.1 O hospital paga bônus } \\
\text { por desempenho individual? } \\
\text { Se sim, em quais funções? } \\
\text { Atual: }\end{array}$ & $\begin{array}{l}\text { ( ) Sim } \\
\text { ()Não }\end{array}$ & $\begin{array}{l}\text { ( )Sim } \\
\text { ()Não }\end{array}$ \\
\hline & $\begin{array}{l}\text { 3.2 O hospital paga bônus pelo } \\
\text { desempenho da equipe? Se } \\
\text { sim, explicar como é dado? } \\
\text { Atual: }\end{array}$ & $\begin{array}{l}\text { ( )Sim } \\
\text { ( )Não }\end{array}$ & $\begin{array}{l}\text { ( )Sim } \\
\text { ( )Não }\end{array}$ \\
\hline
\end{tabular}




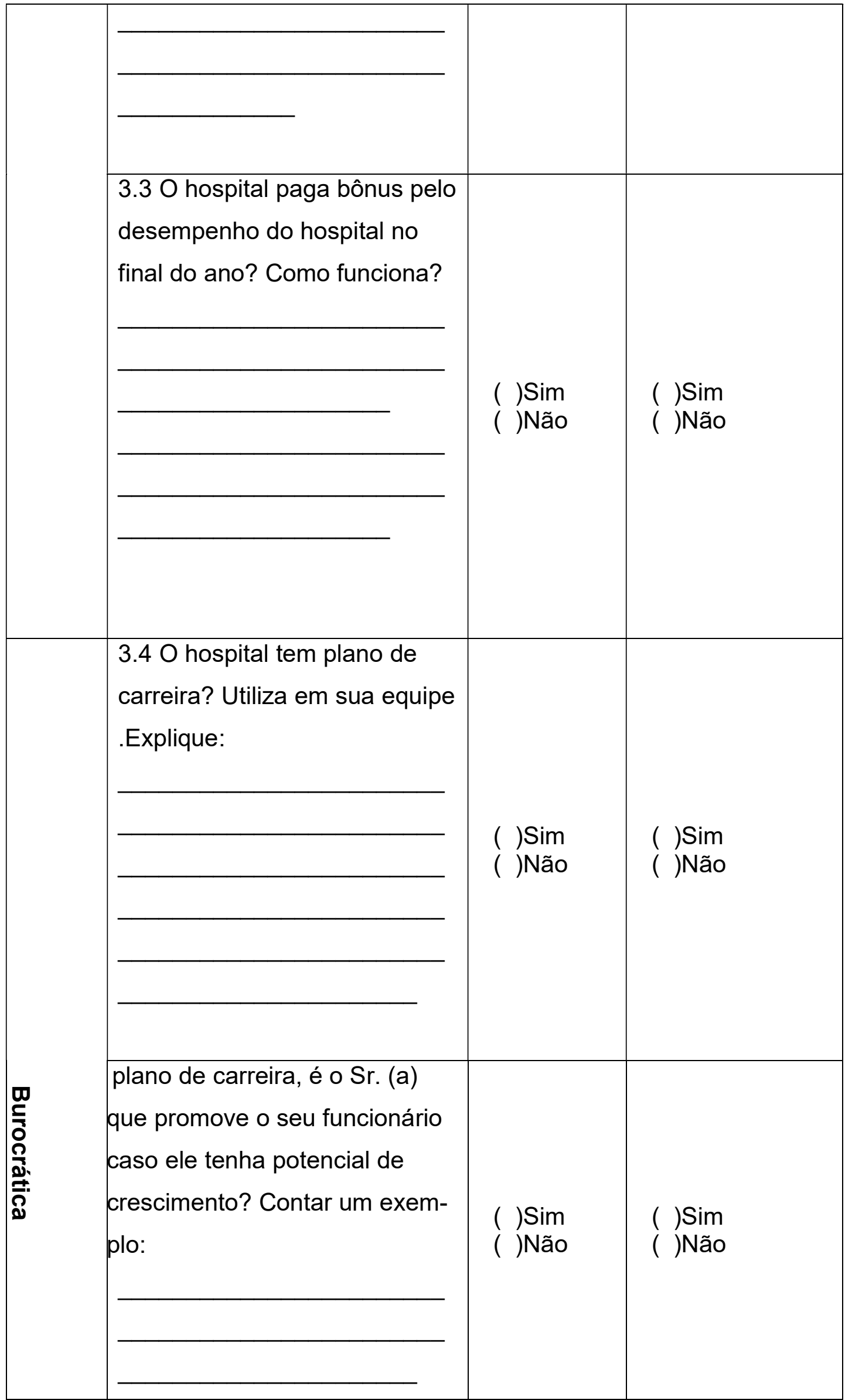




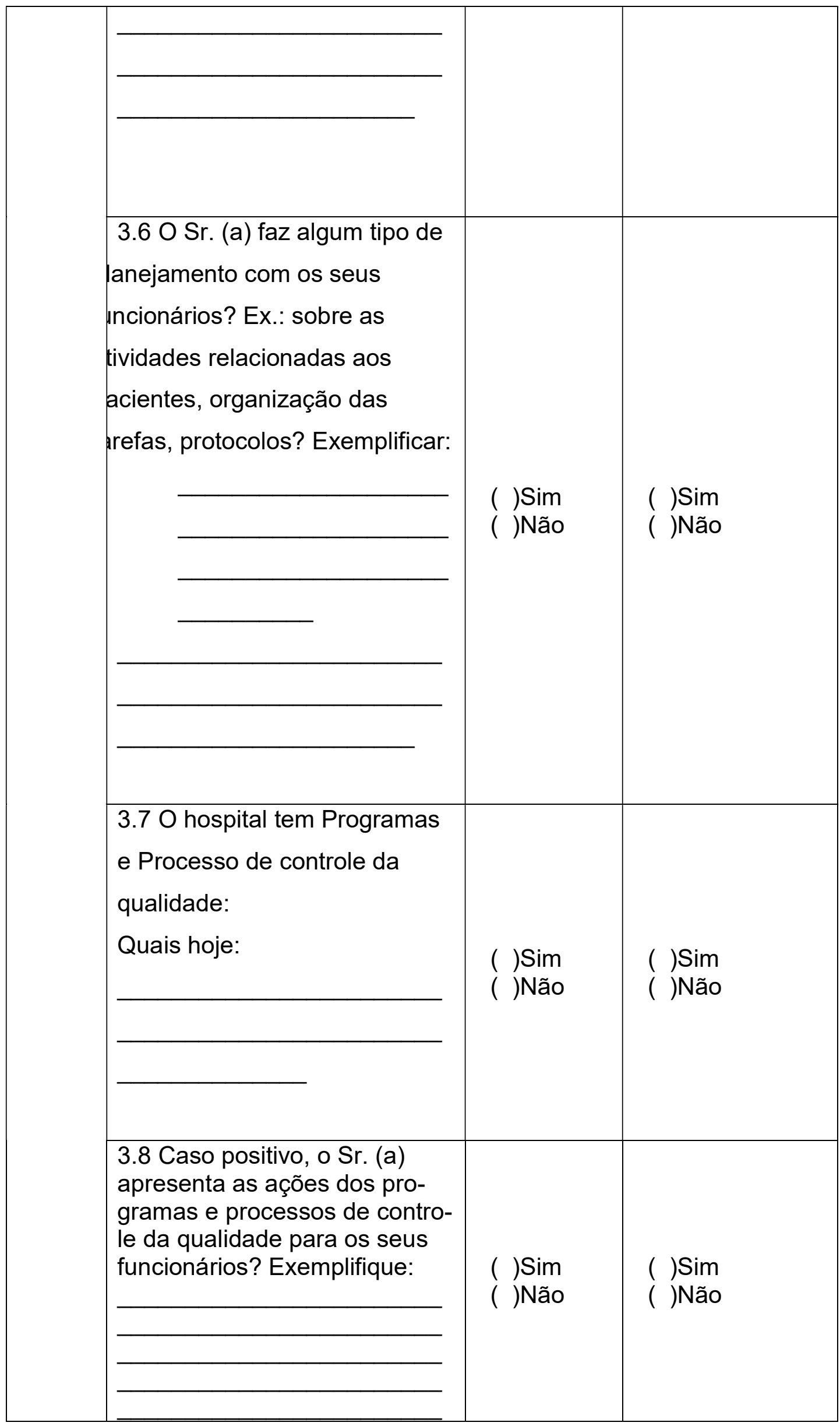




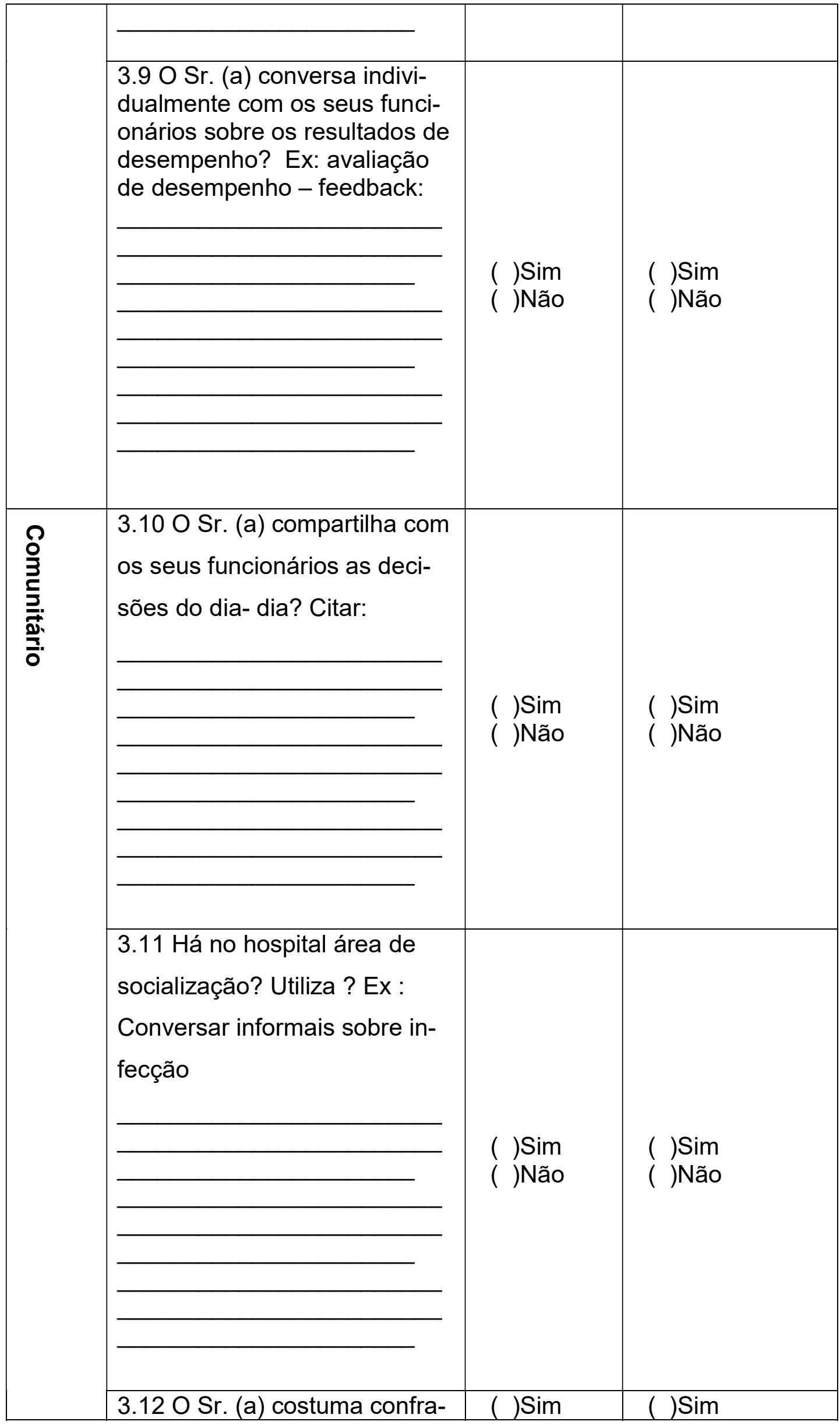




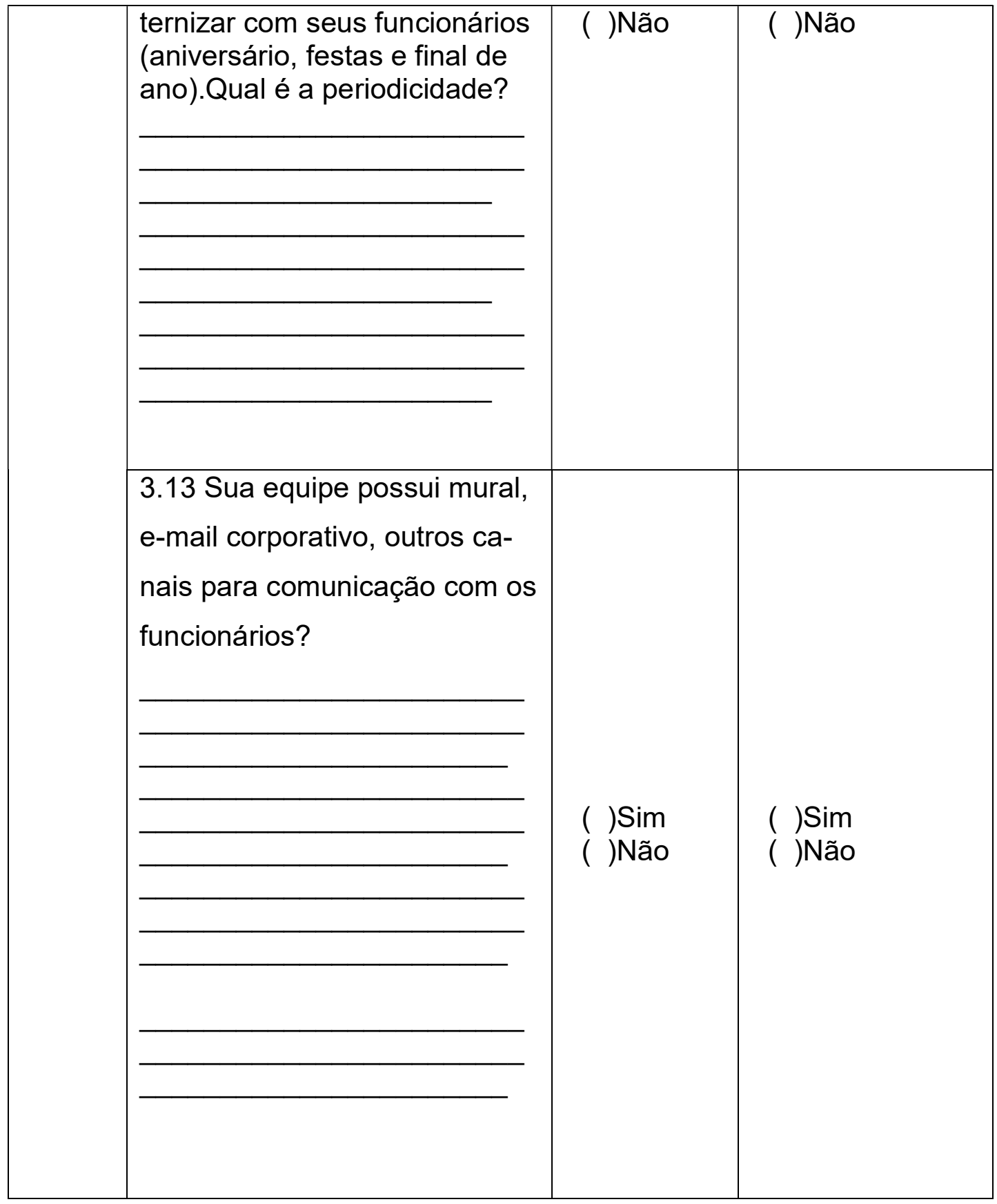




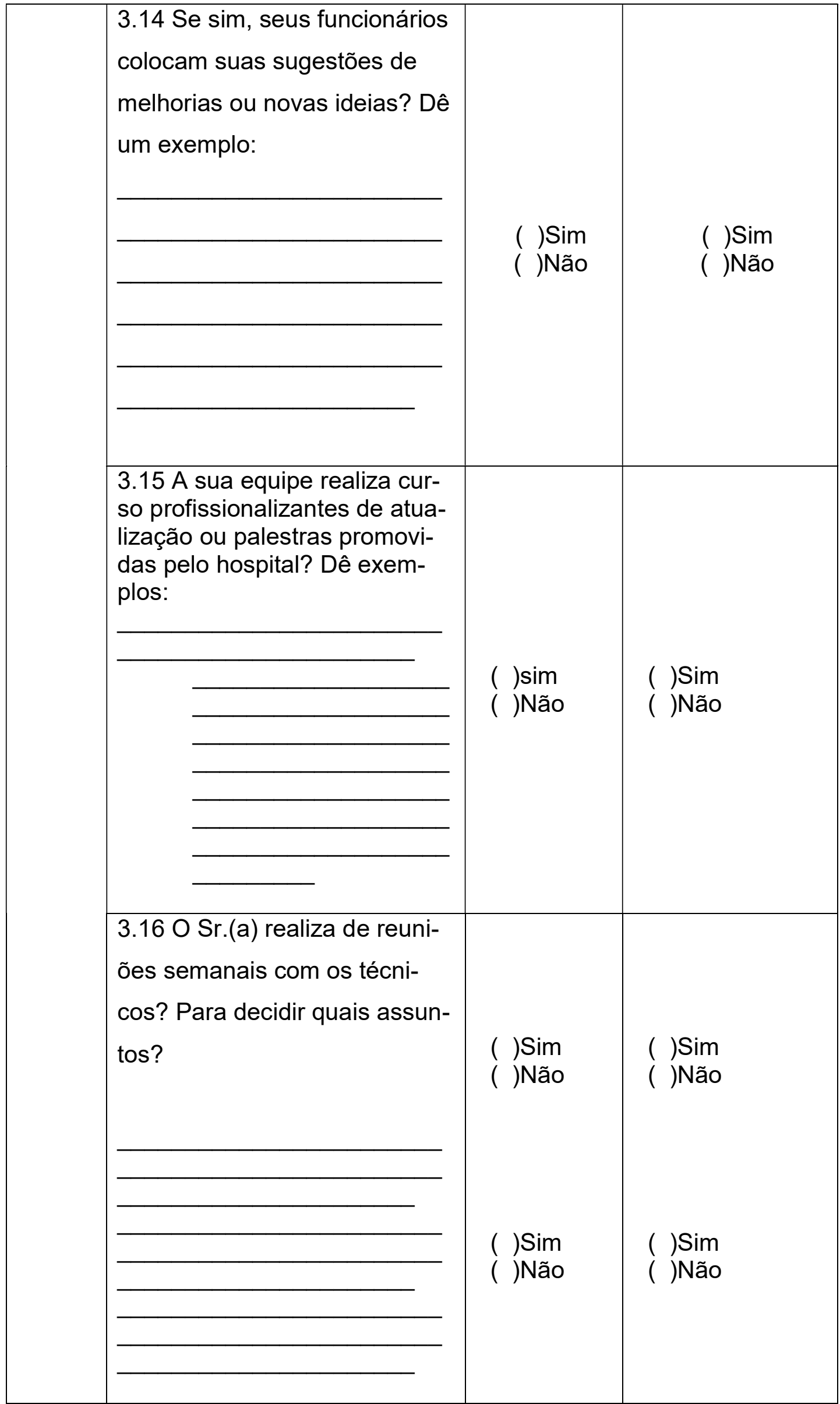




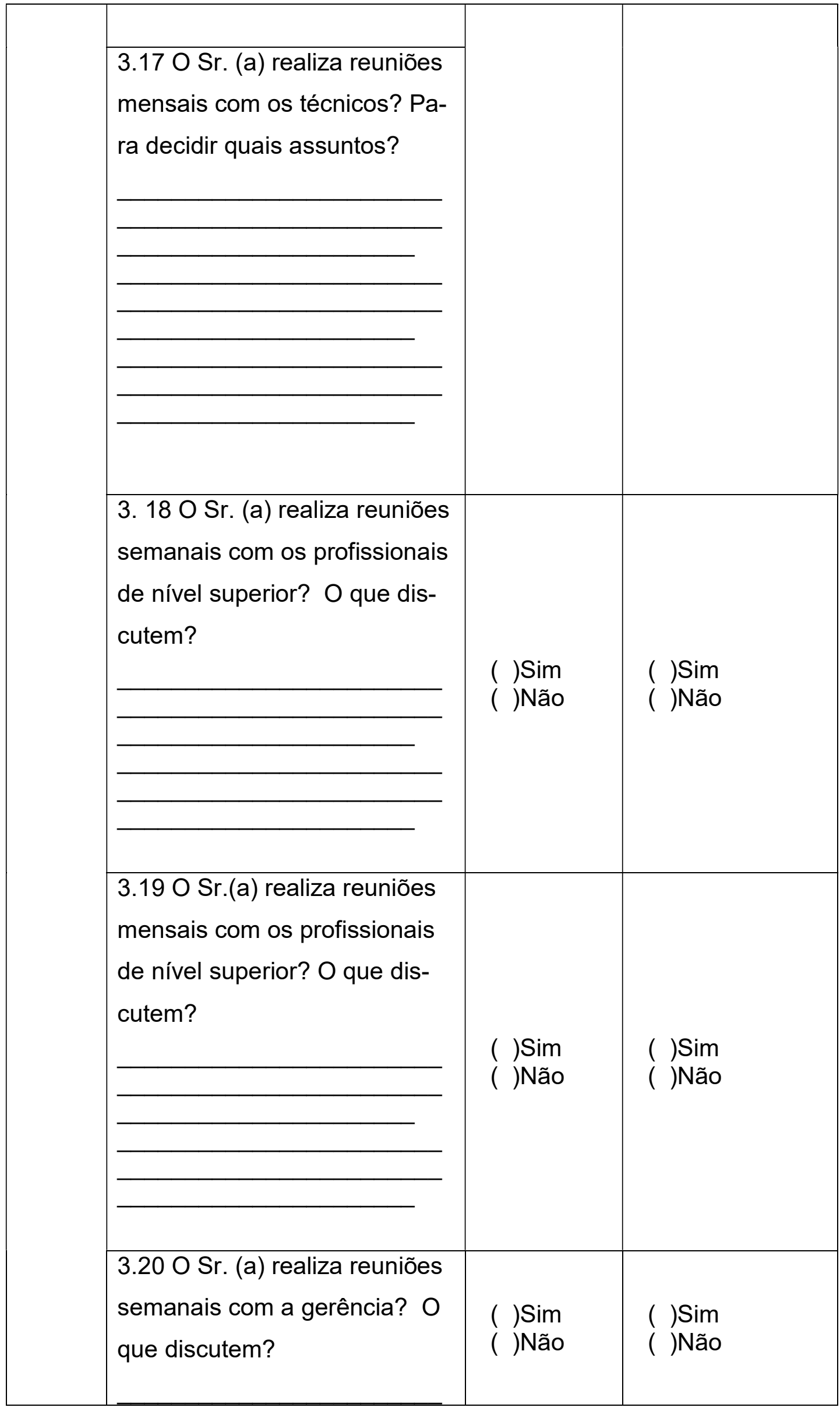




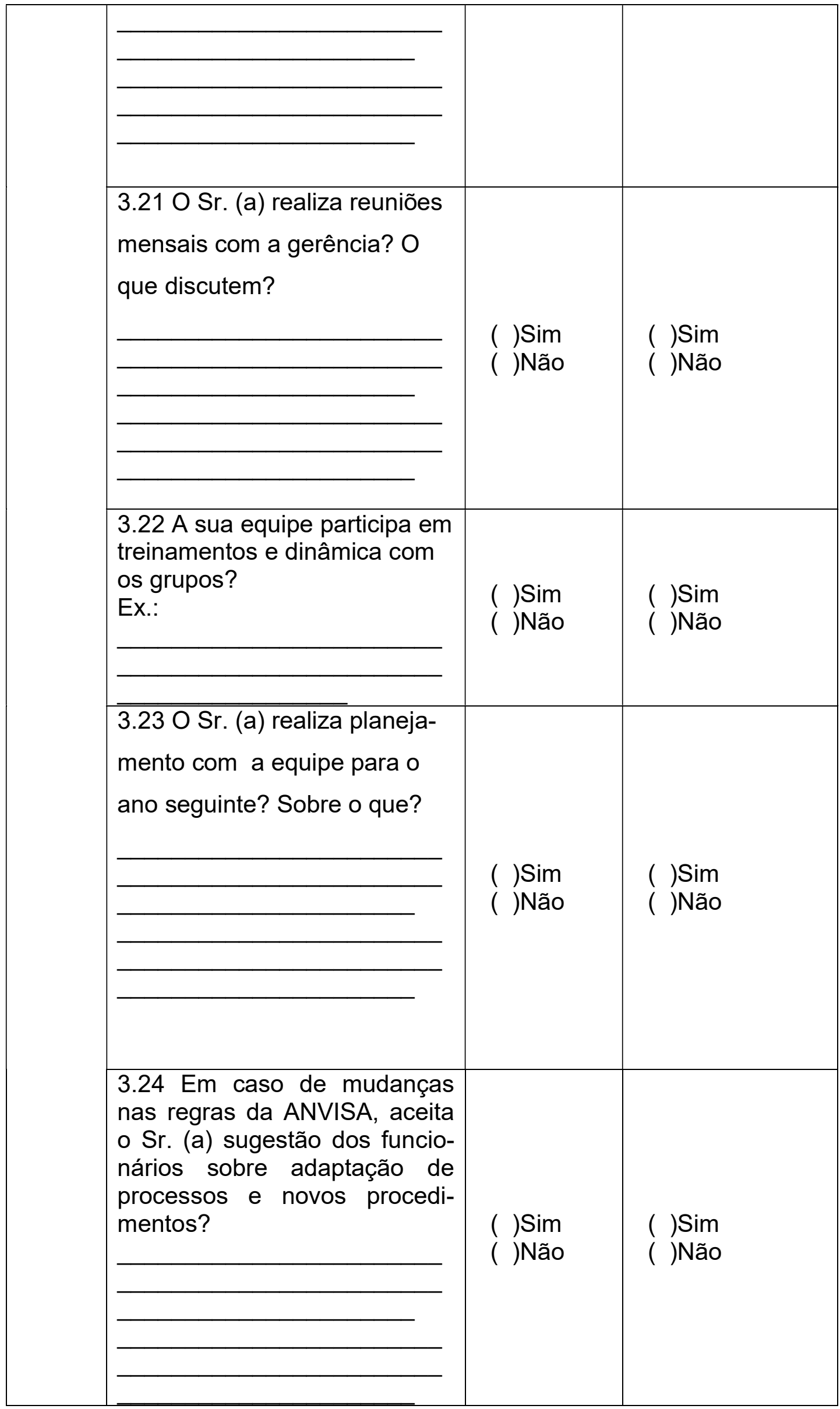




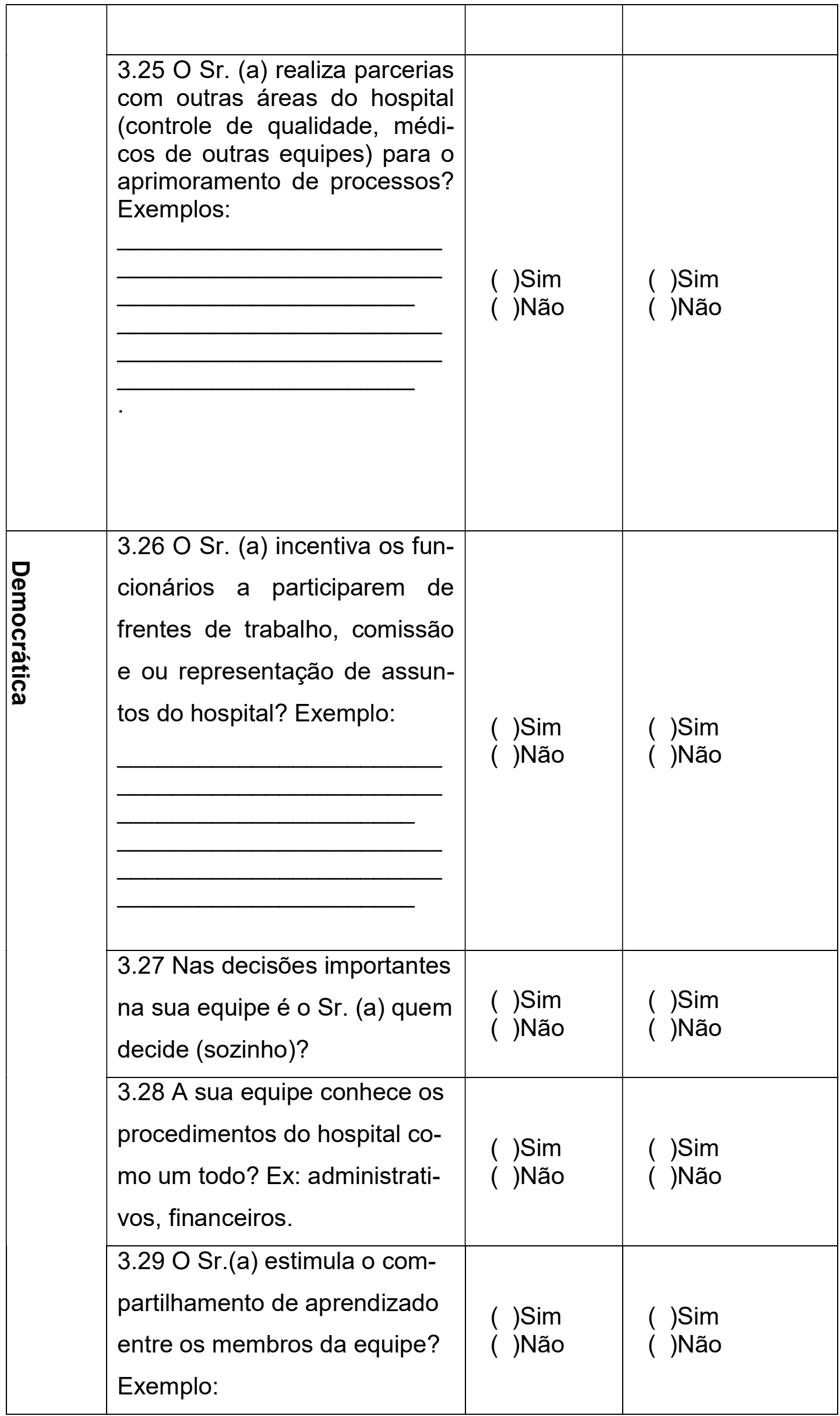




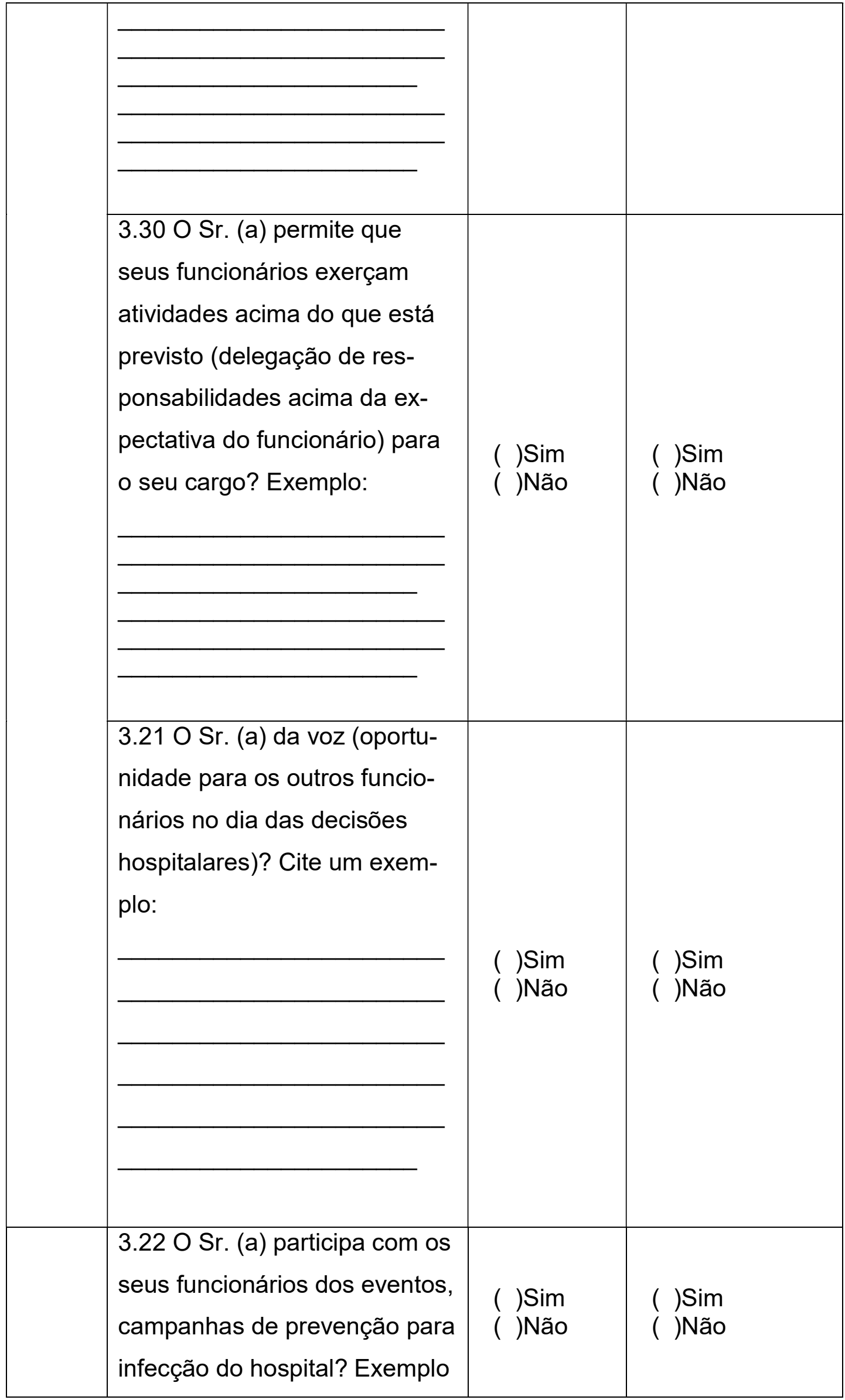




\begin{tabular}{|l|l|l|l|}
\hline de ações: & & \\
\hline & & & \\
\hline & & & \\
\hline
\end{tabular}

4. Quais são os protocolos que mais impactam a sua rotina no hospital?

\begin{tabular}{|c|}
\hline $\begin{array}{l}\text { Protocolos relacionados à RDC. (Você deverá marcar qual protocolo é mais im- } \\
\text { portante para a equipe). Perguntar para o médico como era antes e depois. Colo- } \\
\text { car entre parênteses se 1_ALTA CONFORMIDADE - 2_ MÉDIA CONFORMIDA- } \\
\text { DE - 3_BAIXA CONFORMIDADE }\end{array}$ \\
\hline $\begin{array}{l}\text { 4.1 Identificação do Paciente, Comunicação entre profissionais. } \\
\text { antes da RDC } 36 \text { ( ) depois da RDC } 36 \text { ( ) }\end{array}$ \\
\hline $\begin{array}{l}\text { 4.2 Segurança, Prescrição e Administração do Paciente. } \\
\text { antes da RDC } 36 \text { () depois da RDC } 36 \text { ( ) }\end{array}$ \\
\hline $\begin{array}{l}\text { 4.3 Assegurar cirurgia em local de intervenção, procedimentos, e paciente cor- } \\
\text { reto. } \\
\quad \text { antes da RDC } 36(\text { ) depois da RDC } 36(\text { ) }\end{array}$ \\
\hline $\begin{array}{l}\text { 4.4 Higienizar as mãos para evitar infecções } \\
\text { antes da RDC } 36 \text { ( ) depois da RDC } 36 \text { ( ) }\end{array}$ \\
\hline $\begin{array}{l}\text { 4.5 Redução e quedas e úlceras por pressão } \\
\text { antes da RDC } 36(\text { ) depois da RDC } 36 \text { ( ) }\end{array}$ \\
\hline $\begin{array}{l}\text { 4.6 Comunicação entre Profissionais de Saúde } \\
\text { antes da RDC } 36(\quad) \text { depois da RDC } 36 \text { ( ) }\end{array}$ \\
\hline
\end{tabular}

5. Na sua opinião o que mais mudou com a RDC36? 


\section{Questionário Demográfico}

a) ( ) Hospital Gavazza ( ) Hospital de Nossa Senhora das Dores

b) Sexo: ( ) $\mathrm{F}(\mathrm{)} \mathrm{M}$ Idade: Posição: Especialidade:

c) Ano de Formado Instituição:

d) Cursou alguma especialização

e) Realizou curso de gestão: ( ) $\operatorname{sim}(\quad)$ não. Se sim, qual?

f) Trabalha em outro hospital? Qual?

g) Tempo que trabalha neste hospital (anos):

h) Área (s) de atuação no hospital: ( ) cirurgia ( ) diagnóstico ( ) consulta ( ) outra:

i) Quanto tempo ocupa cargo de liderança? anos meses 


\begin{abstract}
ANEXO III
Faculdade de Economia, Administração e Contabilidade da Universidade de São Paulo.
\end{abstract}

Nome do entrevistado

Cargo data

\title{
Protocolo para entrevistas
}

O objetivo desse questionário é entender quais práticas de incentivos foram utilizados no processo de mudança institucional no controle de infecção nosocomial em dois hospitais, sendo um público e o outro privado.

Como era o controle de infecção antes da RDC 36?

\section{Mercado}

\section{Antes}

1. Antes da RDC 36, Como era o sistema de bonificação por desempenho para os profissionais envolvidos no controle de infecção? Havia um sistema de remuneração por desempenho? Como ele era desenvolvido? Individual, coletivo ou pelo resultado da firma? Existiu algum tipo de incentivo extra para equipes com baixo índice de infecção?

\section{Depois}

2. Atualmente, quais tipos de incentivos são utilizados para bonificar equipes medicas com baixo índice de infecção, existe algum? Como são remuneradas as equipes? Individual, coletivo ou pelo resultado da firma?

\section{Burocrático}

\section{Antes}

3 Havia planejamento estratégico para o controle de infecção antes da RDC 36 ? Quem participava? Quantas vezes eram realizadas ao ano?

$4 \quad$ Como era antes da RDC 36, existia algum programa de desenvolvimento de carreira que leve em consideração o controle de infecção? Como ele funciona? Cite um exemplo de metas a ser atingida para desenvolvimento na carreira? 
5 Como era antes da RDC 36, existia planejamento estratégico que priorizasse

o controle de infecção? Como são desdobradas as ações destes planejamentos? Quem participa? São realizados quantas vezes ao ano?

\section{Depois}

6 Atualmente é realizado planejamento estratégico? Como que o controle de infecção é abordado nesse planejamento? Quem são os profissionais que participam? Como são estabelecidas as metas?

7 Como era antes da RDC 36, existia sistema de avaliação de desempenho que englobe o controle de infecção? Como são relacionados desempenho e controle de infecção? Essa avaliação é pelo desempenho individual ou por equipes?

8 Atualmente o hospital conta com avaliação com sistema de avaliação que avalie o controle de infecção? Como ele funciona?

\section{Comunitário}

9 Como era comunicados e repassados os resultados dos índices de infecção? Antes

10 Havia Mural informativo com informações sobre os casos de infecção? Onde ficam fixados esses murais? Todos profissionais tinham acesso fácil?

11 Existiu algum sistema de informação dos resultados dos índices de infecção coletivo? Como ele funcionava?

12 Tinha algum tipo de Incentivos profissionalizantes para o controle de infecção? Quem recebia esse tipo de incentivo? Qual era o incentivo?

13 Atualmente como são as formas de comunicação e repasses dos resultados dos índices de infecção?

Depois

13.2 Atualmente a $\mathrm{CCIH}$ tem Mural informativo com informações sobre os casos de infecção? Onde ficam fixados esses murais? Qual é a periodicidade de atualização desses murais?

13.3 Quais outros sistemas de informação são utilizados na divulgação dos resultados dos índices de infecção?

13.4 Atualmente o hospital fornece algum tipo de incentivos para cursos (interno ou externo) de prevenção e controle de infecção?

\section{Antes}

14 Trabalho em equipe - Como era realizado o acompanhamento dos resultados?

14.1 Havia reuniões com a diretoria de infecção? Qual era a periodicidade? O que era tratado nessas reuniões? 
14.2 Havia reuniões com a gerência ou da supervisão de infecção (quinzenal, mensal, etc)?

14.3 Como era frequência de reuniões com os médicos - para informar os índices de infecção?

14.4 Havia algum tipo de treinamento ou dinâmica de grupos relacionado a higienização das mãos. Tinha alguma data especifica? Quem participava?

\section{Depois}

14.5 Atualmente são realizadas reuniões com a diretoria de infecção? Qual a periodicidade? Quais são os assuntos tratados com a diretoria?

14.6 Atualmente, Como são realizadas as reuniões com a gerência ou da supervisão de infecção (quinzenal, mensal, etc) ?

14.7 Com que frequência são as reuniões com os médicos? Para informar os índices de infecção?

14.8 Havia algum tipo de treinamento ou dinâmica de grupos relacionados à higienização das mãos. Tinha alguma data especifica? Quem participava?

15 Como são o Compartilhamento as decisões?

\section{Antes}

15.1 Como era realizado o planejamento para o ano seguinte? Quem participa? Como são definidas as metas?

15.2 Como eram realizadas as escolhas e desenvolvimento de ações para melhorias? Quais eram? Quais áreas são responsáveis?

15.3 A CClH já obteve algum acordo ou parceria para o desenvolvimento de processo de controle de infecção? Ex: Consultoria, parceria com outras áreas?

\section{Depois}

15.4 Vocês realizam planejamento para o ano seguinte Ex: metas de casos de infecção. Antes de 2013 era assim?

15.5 Como são realizadas as escolha e desenvolvimento de ações para as melhorias para o controle de infecção? Quais foram as principais ações nos últimos anos?

15.6 Atualmente tem algum acordo ou parcerias para o desenvolvimento de processo de controle de infecção? Ex: Consultoria ou parceria com outras áreas?

\section{Democrático}

\section{Antes}


16 A CCIH tinha voz nas decisões sobre a conduta médica (relacionado ao controle de infecção)?

17 Algum membro do $\mathrm{CClH}$ participava das decisões médicas relacionadas à infecção hospitalar?

\section{Depois}

18 A CCIH atualmente tem voz nas decisões sobre a conduta médica (relacionado ao controle de infecção)? Como funciona a relação do médico com o controle de infecção?

19 Algum membro do $\mathrm{CClH}$ participa das decisões médicas relacionadas à infecção hospitalar? 